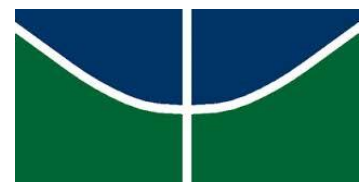

Universidade de Brasília

Instituto de Psicologia

Programa de Pós-Graduação

Departamento de Psicologia Clínica e Cultura

\title{
Análise de trabalhos em Psicologia da Saúde produzidos pela Universidade de Brasília de 2011 a 2015
}

Andréa Lino e Silva Cunha

Brasília, AGOSTO de 2016. 


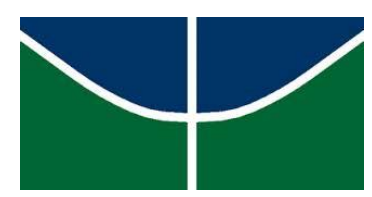

Universidade de Brasília Instituto de Psicologia Programa de Pós-Graduação

Departamento de Psicologia Clínica e Cultura

\title{
Análise de trabalhos em Psicologia da Saúde produzidos pela Universidade de Brasília de 2011 a 2015
}

\author{
Andréa Lino e Silva Cunha
}

Dissertação apresentada ao Instituto de Psicologia da Universidade de Brasília, como requisito parcial à obtenção do título de Mestre em Psicologia Clínica e Cultura, área de concentração Psicologia da Saúde.

Orientador: Professor Doutor Áderson Luiz Costa Júnior

Brasília, AGOSTO de 2016. 


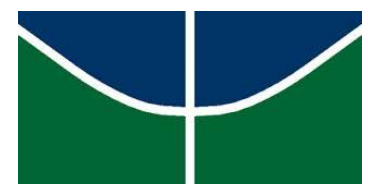

Universidade de Brasília Instituto de Psicologia Programa de Pós-Graduação

Departamento de Psicologia Clínica e Cultura

\title{
DISSERTAÇÃO DE MESTRADO APROVADA PELA SEGUINTE BANCA EXAMINADORA:
}

\author{
Prof. Dr. Áderson Luiz Costa Júnior - Presidente \\ Universidade de Brasília (UnB)
}
Prof $^{a}$. Dr ${ }^{\mathrm{a}}$. Tereza Cristina Cavalcanti Ferreira de Araújo - Membro Universidade de Brasília (UnB)

Prof $^{a}$. Dr ${ }^{\mathrm{a}}$. Marina Kohlsdorf - Membro

Centro Universitário de Brasília (CEUB)

Prof $^{a}$. Dr ${ }^{\mathrm{a}}$. Sílvia Maria Gonçalves Coutinho - Suplente

Secretaria de Estado da Saúde do Distrito Federal (SES/DF)

Brasília, AGOSTO de 2016. 
Ao meu gato de estimação, Sartre, que me acompanhou durante a redação da dissertação (inclusive tentando digitar algumas vezes), ouviu pacientemente os ensaios da defesa e com seu olhar 'blasé' de gato persa, me olhava e dizia: "pára de mimimi e acaba logo esse mestrado".

Obrigada, parceiro.

Às instituições pelas quais passei nos últimos doze anos e onde tanto aprendi: Hospital Araújo Jorge em Goiânia e Rede SARAH de Hospitais de Reabilitação em Brasília, que me oportunizaram riquezas de aprendizado, experiências e humanidade, reforçando minha paixão pela Psicologia da Saúde. 


\section{Agradecimentos}

Ao pensar na conclusão do meu mestrado, com tantos percalços enfrentados durante a caminhada, diversos sentimentos me ocorrem. Primeiro, o de alívio por conseguir cumpri-lo a despeito de todos os empecilhos e dificuldades do caminho. Em seguida, sou inundada por uma imensa GRATIDÃO.

Começo agradecendo àquelas pessoas que são as mais importantes da minha vida. Aquelas que de um modo ou de outro, fazem parte tão intrinsecamente da minha existência, que tenho um pouco delas em cada decisão, pensamento ou atitude perante a vida. São elas que estão sempre sentadas na primeira fila das minhas conquistas, as primeiras que me ligam quando alguma turbulência acontece, aquelas que eu largo tudo e pego o primeiro voo quando precisam de mim. Obrigada, vovó Belinha, meu pai Reinaldo, minha mãe Edméa, minha irmã Mirela, meu sobrinho-afilhado Guilherme, minha tia-madrinha Maria Adélia, minhas tias gêmeas Ana Rita e Ana Amélia, minhas primas-irmãs Danielle e Bruna, e minhas irmãs de vida Elisa Meirelles, Camila Fussi, Isadora Caixeta, Fernanda Nóbrega e Michelle Morlin.

Já com o mestrado em andamento, a vida me trouxe um presente tão maravilhoso em forma de amor, cuidado, carinho e companheirismo, que foi difícil manter a disciplina de estudos ao invés de preferir estar com ele. Erick Kill, por toda compreensão e apoio, eu quero te agradecer diariamente daqui até a eternidade.

Eu seria injusta de não citar amigos muito caros também, que invariavelmente ouviram minhas lamúrias sobre o mestrado e tentaram de uma forma ou de outra me apoiar ao longo dessa jornada, me incentivando a prosseguir. Obrigada Bia Daibert, Rodrigo Hollanda, Paulinha Muniz, Fill Braga, Silvinha Borges, Pat Yurie, Gabriel Moraes, Jônatan Augusto, Marina "Brazil”, Lica Viana, Alê Dias, Carol Borges, Soraia Lima e Beta Mariotto.

Áderson, eu não sei de onde você tirou tanta paciência comigo! Minha história 
na UnB começou em 2006 graças à sua aposta em mim. Recém saída de uma cidade provinciana e recém chegada à Brasília, fui abençoada com seu voto de crédito. De lá pra cá, tanta coisa aconteceu, que muitas vezes me perguntei quando é que você desistiria dessa aluna que parecia nunca conseguir terminar esse bendito mestrado! E, por isso, vou sintetizar minha gratidão por você com essa frase de Isaac Newton: "Se enxerguei mais longe, foi porque estava apoiada sobre ombros de gigantes”.

Não posso deixar de agradecer imensamente a você, caríssima Professora Tereza Cristina, que também acompanhou essa "montanha russa" de acontecimentos na minha trajetória acadêmica e sempre apoiou com sua experiência. Beber dessa fonte rica de conhecimentos que é você e seu trabalho, me fazem me sentir uma profissional privilegiada. Não haveria outra presença tão significativa e importante na minha banca e, por isso, agradeço também o aceite do convite à participação.

Marina Kohlsdorf... Vulgo NinaK! Você foi uma amizade que a vida me presenteou logo no início dessa trajetória e que agora, depois de tantos anos, está mais próxima novamente. Obrigada por aceitar fazer parte da banca. Te admiro demais, como profissional, como professora, como Marina! Através de você, quero agradecer às outras amigas Babacas (uma doce piada interna), herança rica da UnB: Camila Guerra, Camila Tokarski, Jucileia Resende, Marcela Abreu, Flávia Brasil e Catarina Machado.

Obrigada ainda, Dr ${ }^{a}$ Sílvia Coutinho, que primeiramente conheci através de sua nobre produção literária e grande contribuição para a Psicologia da Saúde e, depois, pelo privilégio de tê-la como suplente na minha banca.

Obrigada Larissa Frioli, minha guru, minha "MasterMind", que ao longo desse processo foi minha terapeuta, supervisora e hoje, minha sócia.

Gratidão a Deus! Sem Sua presença, constante e profunda nos melhores e piores momentos de vida, nada disso seria possível. 


\section{Sumário}

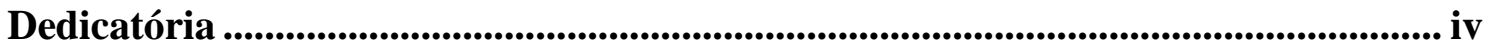

Agradecimentos .................................................................................................................................. V

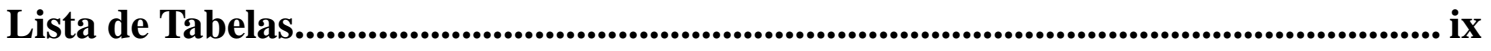

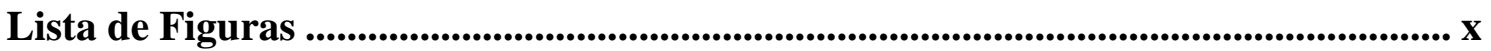

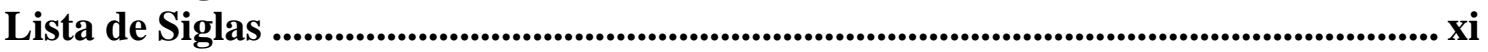

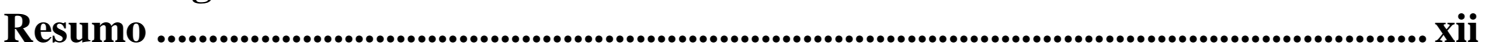

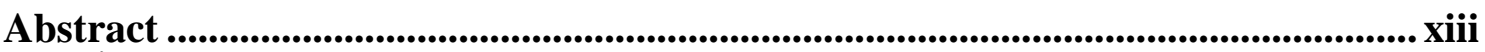

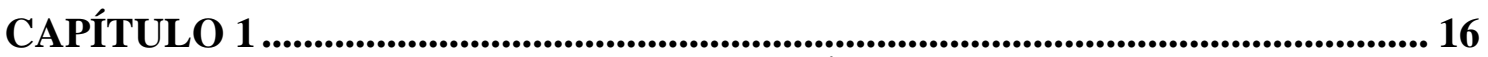

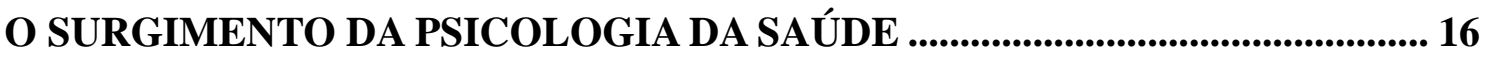

1.1. Caracterizando a Psicologia da Saúde ............................................................ 16

1.2. Diferentes Campos e áreas afins à Psicologia da Saúde...................................... 21

1.3 A criação formal da Divisão 38 da APA ............................................................ 25

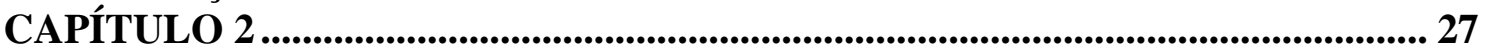

O PERFIL DA PRODUÇÃO BIBLIOGRÁFICA EM PSICOLOGIA DA SAÚDE

NO BRASIL E NO MUNDO ................................................................................. 27

2.1. O crescente aumento do número de publicações ................................................. 27

2.2. Principais perspectivas teórico-filosóficas em Psicologia da Saúde .................... 32

2.2.1. Modelo de crenças em saúde ..................................................................... 34

2.2.2. Teoria da Ação Racional e Teoria da Ação Planejada .................................. 36

2.2.3. Modelo Transteórico de Estágios da Mudança .............................................. 37

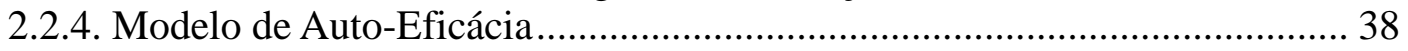

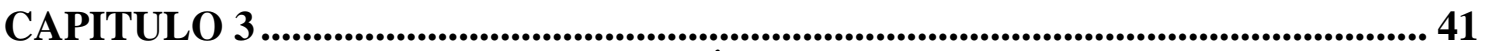

O FUTURO DA PSICOLOGIA DA SAÚDE ............................................................. 41

3.1. A publicação do Volume Especial do Journal of Health Psychology (JHP) .. 41

3.1.1) A Evolução do Modelo Biopsicossocial de Saúde ...................................... 42

3.1.2) Metodologias de estudo empregadas em Psicologia da Saúde ............... 43

3.1.3) Formação curricular em Psicologia da Saúde e Perspectivas de mercado

3.1.4) Uso de tecnologia em intervenções na área de saúde

3.1.4.1. Telesaúde comportamental e informática para a saúde............................. 47

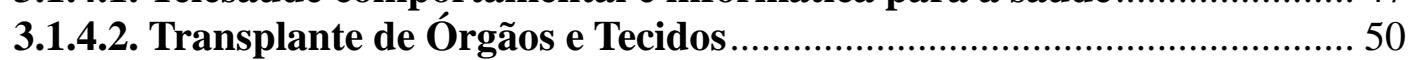

3.1.4.3. Estudos em Genética Humana .............................................................. 52

3.2) $\mathrm{O}$ (novo) futuro das intervenções em Psicologia da Saúde ........................... 54

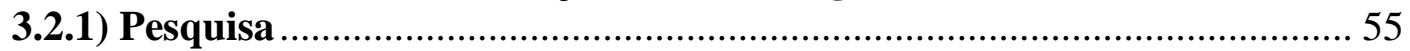

3.2.2) Aplicações clínicas e nas políticas públicas .......................................... 56

3.2.3) Formação educacional e treinamento profissional................................ 57

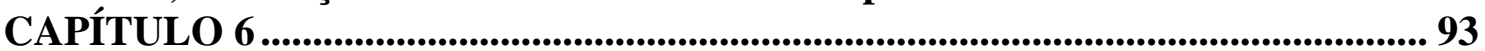

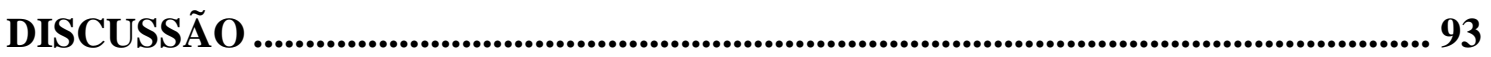

6.1. Evolução do modelo biopsicossocial de saúde................................................. 93

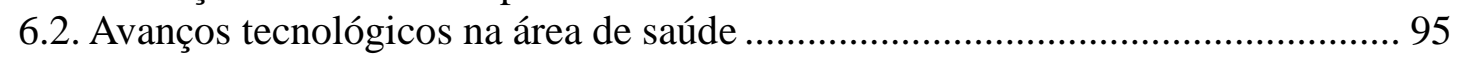

6.3. Mudanças nos indicadores demográficos das populações (e a adoção de

instrumentos sensíveis à essa diversidade) ................................................................ 97

6.4. Fatores econômicos na saúde e perspectivas de mercado para o Psicólogo da

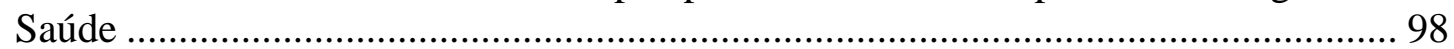

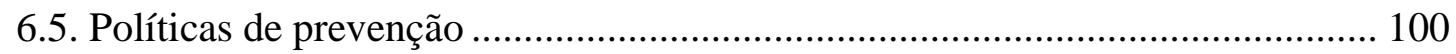

6.6. Aumento das Intervenções Clínicas em Psicologia da Saúde (com ênfase em

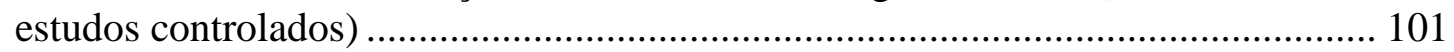

6.7. Outras contribuições apontadas pelos estudos ....................................... 104 
6.8. Limitações apontadas pelos estudos da amostra ...................................... 104

6.9. Sugestões de novos estudos em Psicologia da Saúde no Brasil ..................... 105

6.10. Contribuições e limitações desta análise descritivo-crítica........................ 107

CONSIDERAÇÕES FINAIS.................................................................................... 108

REFERÊNCIAS BIBLIOGRÁFICAS ..............................................................112

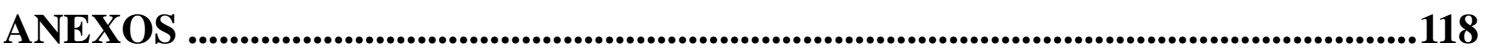

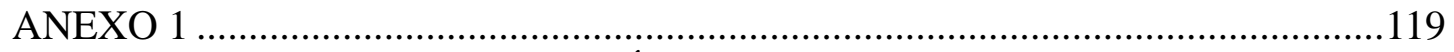

MODELO DE FICHA CATALOGRÁFICA PARA ….............................................119

ANÁLISE DE CADA TRABALHO .................................................................119 


\section{Lista de Tabelas}

Tabela 1. Distribuição de trabalhos produzidos pela área de Psicologia da Saúde, do IP/UnB (dez/2011 a ago/2015). 47

Tabela 2. Relação de trabalhos analisados publicados de 2011 a 2015 pelo IP/UnB registrados no Repositório Institucional da $\mathrm{BCE} / \mathrm{UnB}$.

Tabela 3. Distribuição de trabalhos por temas, conforme a ocorrência de palavras-

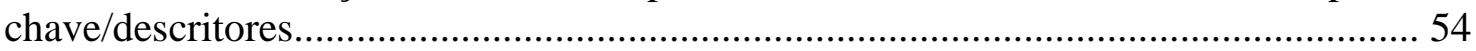

Tabela 4. Distribuição dos trabalhos por métodos de pesquisa empregados.................. 58 Tabela 5. Modalidades de participantes, ou base de dados de pesquisa, nos trabalhos selecionados, conforme listados nas palavras-chave. 60 


\section{Lista de Figuras}

Figura 1. Distribuição de trabalhos orientados no período de Dez/2011 a Ago/2015 por cada docente da área de Psicologia da Saúde 


\section{Lista de Siglas}

APA - American Psychological Association

DSM-IV - Manual Diagnóstico de Transtornos Mentais - $4^{\mathrm{a}}$ Edição

EUA - Estados Unidos da América

FUB - Fundação Universidade de Brasília

HBM - Health Belief Model

HC-FM/USP - Hospital das Clínicas da Faculdade de Medicina da Universidade de São

Paulo

HIV/Aids - Human Immunodeficency Virus / Acquired Immunodeficiency Syndrome

(Vírus da Imunodeficiência Humana/ Síndrome da Imunodeficência Adquirida)

IBGE - Instituto Brasileiro de Geografia e Estatística

JHP - Journal of Health Psychology

NRAD - Núcleo Regional de Atenção Domiciliar

OMS - Organização Mundial de Saúde

PIB - Produto Interno Bruto

PID - Programa de Internação Domiciliar

TARV - Terapia Antirretroviral

TI - Tecnologia da Informação

WHO - World Health Organization 


\section{Resumo}

Com o aumento do reconhecimento da interface entre estilos e repertórios de comportamento humano e indicadores de saúde-doença a partir da segunda metade do século XX, os psicólogos da época se viram diante de desafios que forçaram estudiosos da American Psychological Association (APA) a lançarem uma força-tarefa buscando definir quais seriam as áreas responsáveis por estudar os fenômenos psicológicos, emocionais e comportamentais no âmbito da saúde. Esse movimento culminou com a criação, em 1978, da divisão 38 da APA, chamada Health Psychology e, quatro anos mais tarde, do periódico oficial da área, o Journal of Health Psychology (JHP). A partir de então, observou-se um período bastante prolífico na produção de trabalhos nacionais e internacionais com temáticas que contribuíram para consolidar a área da Psicologia da Saúde como um campo único e independente. Passados vinte e cinco anos da fundação oficial da área, os estudiosos voltaram a se reunir para debater os avanços alcançados ao longo do tempo e antever desafios futuros. $\mathrm{O}$ saldo resultou na publicação de um volume especial, em 2004, pelo JHP, que definiu seis tópicos de discussão, que também serviram de diretrizes aos psicólogos da saúde para estudo, pesquisa e atuação profissional nos anos consecutivos: (a) a evolução do modelo biopsicossocial de saúde, (b) os avanços tecnológicos na área da saúde, (c) as mudanças no indicadores demográficos das populações, (d) os fatores econômicos na saúde e as perspectivas de mercado para o psicólogo da saúde, (e) as políticas de prevenção e (f) o aumento das intervenções clínicas em psicologia da saúde. O presente trabalho teve o objetivo de analisar o perfil da produção bibliográfica, em nível de pósgraduação strictu sensu, do Instituto de Psicologia (IP), da Universidade de Brasília (UnB) e compará-lo com as mesmas diretrizes de criação da divisão de Psicologia da Saúde, pela APA, e diretrizes de revisão, publicadas na edição comemorativa do JHP. Para tanto, foram identificados quarenta dissertações de mestrado e teses de doutorado, registradas no Repositório Institucional da UnB, defendidas de dezembro de 2011 a agosto de 2015, orientadas por quatro docentes da área. Esses trabalhos foram analisados descritivamente por meio de categorias temáticas e metodológicas e comparados criticamente com as diretrizes da APA. Os resultados mostraram que a produção bibliográfica do IP/UnB, primou pela realização de trabalhos principalmente relacionados à evolução do modelo biopsicossocial; deixou importantes contribuições voltadas a intervenções clínicas, principalmente em nível secundário e terciário de atenção à saúde, merecendo destaque por trabalhos pioneiros e inovadores. Esse panorama define o IP/UnB como um dos grandes expoentes atuais no cenário das universidades brasileiras que desenvolvem pesquisas em Psicologia da Saúde. A produção bibliográfica, no entanto, não abordou temáticas relacionadas a avanços tecnológicos, genética comportamental e atenção primária em saúde, que mereciam destaque, conforme sugerido pelo JHP, em 2004. A análise realizada contribuiu com sugestões para estudos futuros com os seguintes eixos temáticos: (a) impacto do uso de recursos de tecnologia da informação e internet como ferramentas para obtenção de informações sobre doenças, tratamentos e assuntos correlacionados; (b) fatores psicossociais relacionados a transplante de órgãos e tecidos, em doadores vivos; (c) genética comportamental, analisando impacto cognitivo, emocional e comportamental de testes genéticos sobre os indivíduos; (d) variáveis de gênero em processos saúde-doença; (e) novas frentes de atuação ao psicólogo da saúde, principalmente na atenção básica; (f) resolução de questões metodológicas como tamanho da amostra, otimização do tempo de condução da pesquisa, além da atenção ao uso de instrumentos adequados à população estudada; $(\mathrm{g})$ investimento na adequação de instrumentos de pesquisa para a cultura brasileira, que sejam viáveis em contextos de saúde. Alguns desafios permanecem em aberto e novos desafios são lançados, na direção de fazer com que psicológos da saúde brasileiros se mantenham bem preparados para lidar com uma realidade em constante transformação e, assim, continuar a fazer importantes contribuições futuras.

Palavras-chave: Psicologia da saúde, análise descritiva, American Psychological Association; produção bibliográfica. 


\begin{abstract}
With the increasing recognition of the interface between human behavior and health indicators from the second half of the twentieth century, psychologists at the time were faced with challenges that have forced scholars of the American Psychological Association (APA) to launch a task force seeking to define what are the areas responsible for studying the psychological, emotional and behavioral phenomena in the field of health. This movement culminated in the creation in 1978 of Division 38 of the APA, called Health Psychology, and four years later, the official journal of the area, the Journal of Health Psychology (JHP). From then on, there was a very prolific period in the production of national and international works with themes that contributed to consolidate the area of Health Psychology as a specific and independent field. Twentyfifth anniversary of the official founding of the area, scholars reconvened to discuss the progress made over time and anticipate future challenges. The balance resulted in the publication of a special issue in 2004 by JHP, which defined six discussion topics, which also served as guidelines to health psychologists to act in study, research and professional practice in consecutive years: (a) the evolution of the biopsychosocial health model, (b) technological advances in health, (c) changes in demographic indicators of populations, (d) economic factors on health and the market prospects for health psychologist, (e) policies in prevention and (f) the increase in clinical interventions in health psychology. This study aimed to analyze the profile of the scientific production in the strict sense graduate level, of the Institute of Psychology (IP), of the University of Brasilia (UNB) and compare it with the same guidelines of the division of Health Psychology, by APA and guidelines of review, published in the commemorative edition of the JHP. Therefore, we identified forty dissertations and doctoral thesis, registered in the Institutional Repository of UnB, defended in December 2011 to August 2015, directed by four professors from the area. These works were analyzed descriptively through thematic and methodological categories and critically compared with the guidelines of the APA. The results showed that the bibliographic production of IP/UnB, were excelled by performing mainly related to the evolution of the biopsychosocial model works; made important contributions focused on clinical interventions, especially in secondary and tertiary health care, deserving prominence by pioneering and innovative works. This scenario sets the IP/UnB as one of the current exponents in the prospect of Brazilian universities that develop research in Health Psychology. However, the choice of topics related to technological advances in health, behavioral genetics and primary health care is still underused. The analysis contributed bringing suggestions for future studies with the following themes: (a) the impact of the use of information and internet technology resources as tools to obtain information about diseases, treatments and related issues; (b) psychosocial factors related to transplantation of organs and tissues in living donators; (c) behavioral genetics, analyzing cognitive, emotional and behavioral impact of genetic testing on individuals; (d) gender variables in health-disease processes; (e) new fronts to health psychologist, particularly in primary care; (f) resolution of methodological issues such as sample size, optimization of search time driving, as well as attention to the use of instruments appropriate to the population studied; (g) the adequacy of investment research tools for Brazilian culture, that are viable in health contexts. Some challenges remain open and new challenges are thrown in the direction to make brazilian health psychologists keep well prepared to deal with a constantly changing reality and thus continue to make important future contributions.
\end{abstract}

Key-words: Health Psychology, descriptive analysis, American Psychological Association; bibliographical research. 


\section{INTRODUÇÃO}

O termo Psicologia da Saúde pode soar um tanto redundante para um leigo que o ouve pela primeira vez, já que parece óbvia a associação entre a psicologia e os cuidados com a saúde. No entanto, ao longo do tempo, a relação entre a(s) psicologia(s) e a compreensão do processo saúde-doença passou por muitas mudanças filosóficas e conceituais, que caracterizavam o contexto histórico e cultural de cada época, influenciando as tendências da pesquisa científica e da produção de conhecimento.

Uma vez que a interface entre os comportamentos das pessoas e os indicadores de saúde tenha ganhado maior reconhecimento nos últimos cinquenta a sessenta anos, os psicólogos do século XX se viram diante de desafios de saúde pública, de gestão, intervenção e avaliação, que contribuíram para moldar científica e profissionalmente aquela que viria a ser uma das áreas mais promissoras das ciências do comportamento: a Psicologia da Saúde.

O presente trabalho analisa algumas demandas que impulsionaram o surgimento da Psicologia da Saúde e a alçaram o patamar de uma das áreas mais reconhecidas da psicologia moderna. Além disso, busca-se integrar esses fundamentos históricos às demandas recentes, de pesquisa e conhecimento, na área, considerando um pequeno conjunto de produção científica, no contexto de pós-graduação strictu sensu.

Assim, os objetivos gerais desse estudo foram descrever o perfil da produção bibliográfica, restrita a dissertações de mestrado e teses de doutorado, defendidas entre janeiro de 2011 e agosto de 2015, orientadas por docentes da área de Psicologia da Saúde, do Instituto de Psicologia (IP), da Universidade de Brasília (UnB), e compará-lo, criticamente, com as diretrizes de criação da divisão de Psicologia da Saúde, pela American Psychological Association (APA), e diretrizes (do, então, futuro) da área de Psicologia da Saúde, publicadas em 2004, em um número especial do Journal of Health 
Psychology (JHP - Print ISSN 1359-1053), um periódico reconhecido como uma das principais revistas da área de Psicologia da Saúde. Além disso, a pesquisa realizada objetiva fornecer subsídios à construção de um perfil de objetos e temas de estudo a serem investigados pela área de Psicologia da Saúde na UnB.

Para tanto, a dissertação está dividida em seis capítulos: o primeiro remonta a algumas bases da criação da área da Psicologia da Saúde e ao cenário histórico-social no qual surgiu; o segundo traça um breve perfil da produção bibliográfica, em Psicologia da Saúde, nos Estados Unidos da América (EUA), berço da área, no restante do mundo e, por último, no Brasil; o terceiro faz um apanhado do que a APA vislumbrou para os anos que se seguiriam ao lançamento do Volume Especial do JHP, em 2004, que discutia o, então, futuro da psicologia da saúde; o quarto capítulo apresenta os objetivos gerais do presente estudo e explicita a metodologia adotada para realização de uma análise descritiva e crítica dos trabalhos produzidos, no período mencionado. No quinto capítulo, são apresentados os resultados obtidos, a partir da leitura, classificação e categorização de vinte e cinco dissertações de mestrado e quinze teses de doutorado, orientadas por quatro docentes da área de Psicologia da Saúde, do IP/UnB.

O sexto capítulo, discute as contribuições dos estudos analisados, identificando suas limitações e comparando esses achados com o que foi presumido pelo JHP ao longo da história do crescimento da Psicologia da Saúde.

Por fim, fazem-se algumas considerações finais, identificando contribuições e limitações dessa proposta de análise descritiva e crítica, seguidas pelas referências bibliográficas. 


\section{CAPÍTULO 1}

\section{O SURGIMENTO DA PSICOLOGIA DA SAÚDE}

O primeiro capítulo contextualiza o berço sócio-histórico no qual a Psicologia da Saúde foi lançada, bem como os conceitos de onde se derivou e os desafios que foram atribuídos aos profissionais e pesquisadores que lidavam com as questões a ela relacionadas, à época de sua criação oficial.

\subsection{Caracterizando a Psicologia da Saúde}

Compreender como variáveis psicológicas interferem para maior ou menor susceptibilidade individual ao desenvolvimento de certas doenças não é um escopo inteiramente novo e exclusivo da psicologia da saúde moderna. Essa preocupação já rondava estudiosos desde a Grécia Antiga (Reis, 1998).

Alguns fatos, mais recentes, ajudam a explicar o surgimento da psicologia da saúde. A partir da segunda metade do século $\mathrm{XX}$, o mundo começou a assistir ao aumento da expectativa de vida das populações, ao passo que diversos transtornos relacionados ao estilo de vida moderno começaram a chamar a atenção nas estatísticas de morbidade e mortalidade. Além disso, o paradigma de saúde vigente até então (modelo biomédico), já vinha dando indícios de seu declínio, necessitando ser repensado, especialmente no que se referia a explicações mais consistentes para doenças e transtornos associados a padrões de comportamento e a estilos de vida, além dos custos dos atendimentos em saúde que aumentavam de forma expressiva (Straub, 2014).

Em 1970, os princípios fundamentais da saúde, formulados pela Organização Mundial de Saúde (OMS), pareceram se alinhar com a busca que os gregos já haviam referido, de um estado de bem estar integral. Preocupações como considerar o contexto sociocultural da pessoa, investigar a exposição individual a vulnerabilidades e a fatores 
de risco, avaliar os fatores de proteção ao processo de desenvolvimento da pessoa, promover ações em todos os níveis de atenção à saúde e priorizar a educação para a saúde, nunca haviam adquirido tamanho enfoque até então (Cerqueira-Silva, Dessen \& Costa Junior, 2011).

Nessa mesma época, os debates em torno do tema da atenção integral à saúde, de indivíduos e grupos, passaram a fervilhar ainda mais quando os primeiros trabalhos publicados apontaram possíveis relações funcionais entre variáveis de natureza psicológica e manifestação de doenças e, ao mesmo tempo, observou-se uma crescente e significativa inserção de psicólogos em campos de especialidade médica, inicialmente de maneira mais predominante nos Estados Unidos da América (Ogden,1999).

Datam dessa mesma época, no Brasil, a estruturação dos primeiros serviços de psicologia em hospitais, a exemplo do Hospital das Clínicas da Faculdade de Medicina da Universidade de São Paulo (Gorayeb, 2010).

A evolução temporal da expectativa de vida e dos indicadores de morbidade e mortalidade também ajudam a explicar o surgimento da Psicologia da Saúde. No início do século XX, cerca de 15\% dos nascituros, nos Estados Unidos da América (EUA), morriam no primeiro ano de vida, segundo dados da OMS (2000), e a expectativa de vida média dos sobreviventes não ultrapassava os 50 anos de idade. Atualmente, esses índices se modificaram e menos de $10 \%$ dos recém-nascidos não sobrevivem ao primeiro ano de vida, enquanto a expectativa de vida média do norte-americano já ultrapassou os 75 anos de idade. Segundo o último censo realizado nos EUA (United States Census Bureau, 2012), a expectativa média atual de vida do norte-americano já está estimada em 78,74 anos.

No restante do mundo, a tendência tem sido a mesma, ainda que as desigualdades persistam, de acordo com o padrão médio de qualidade dos cuidados e 
serviços de saúde vigentes nos diferentes países (WHO, 2000).

Nesse quesito, destacam-se os mais recentes dados do Instituto Brasileiro de Geografia e Estatística (IBGE), apontando que a esperança de vida ao nascer de um brasileiro - 73,62 anos para ambos os sexos - aumentou mais de dez anos entre 1980 e 2012 (IBGE, 2012). Estimativas indicam um crescimento consistente da população acima de 60 anos, o que deve ocasionar uma alteração significativa na estrutura da pirâmide populacional brasileira: a quantidade de pessoas acima dessa faixa etária deve dobrar nos próximos 20 anos, até atingir, aproximadamente, 30\% da população total em 2050.

No entanto, o fato de as pessoas viverem mais, não significa que, necessariamente, vivam melhor. Com as mudanças de hábitos de vida do mundo moderno, as principais causas de morte passaram a ser decorrentes das "doenças do estilo de vida", que, em grande parte, são evitáveis e associadas a comportamentos que comprometem a saúde, tais como tabagismo, má alimentação, sedentarismo e consumo de substâncias psicoativas. Cada um desses comportamentos, em diferentes graus de influência e comprometimento, é controlado ou está associado funcionalmente, por fatores psicológicos e sociais (Straub, 2014). Se, de fato, podemos apontar relações funcionais entre padrões de comportamento e padrões de adoecimento, uma área de conhecimento que privilegie os princípios da promoção e manutenção da saúde seria muito bem-vinda à comunidade científica.

Nos séculos anteriores ao século XX, as principais causas de morte estavam mais relacionadas a más condições sanitárias básicas, como falta de tratamento adequado para a água, contaminação de alimentos ou infecção cruzada (Straub, 2014). As grandes epidemias também foram responsáveis pelo abatimento de milhares de pessoas, já que muitas das doenças epidêmicas, como varíola, febre amarela, gripe, 
haviam sido trazidas para as Américas por colonizadores europeus. A partir do melhoramento de algumas condições básicas de higiene pessoal, higienização da alimentação, implementação de redes de esgoto e água tratada e programas de imunização e cobertura vacinal, o número de mortes por doenças infecciosas caiu consideravelmente, inserindo grande parte das doenças infecto-contagiosas como de natureza evitável.

A melhoria das condições básicas de saúde veio acompanhada de um expressivo crescimento da tecnologia médica e de uma série de avanços científicos, especialmente farmacológicos. No entanto, a medicina tradicional já não era capaz de responder a todos os desafios que se interpunham, como por exemplo, explicar porque um mesmo conjunto de fatores de risco biológico poderia desencadear doença em uns indivíduos e não em outros. Esta dificuldade revelou algumas limitações próprias do modelo biomédico de saúde, até então vigente, e a necessidade de ser repensado, rediscutido e ampliado para um modelo de saúde que priorizasse a educação e a atenção integral ao indivíduo, cujo enfoque fosse biopsicossocial e que, além de reconhecer variáveis individuais, considerasse, também, o sistema de crenças das pessoas e as relações profissionais-pacientes, por exemplo, aspectos até então bastante negligenciados (Straub, 2014). Nesta perspectiva, crenças de saúde, estilos de vida e comportamentos poderiam ser modificados e submetidos a sistemas de aprendizagem, formal e informal.

Desta forma, a psicologia da saúde, por estar fundamentada num paradigma de saúde biopsicossocial, representa um rompimento com o modelo de racional linear de saúde, de causa e efeito, centrado na identificação de doenças, métodos diagnósticos e tratamentos farmacológicos (Cerqueira-Silva, Dessen \& Costa Jr., 2011). Os principais indicadores individuais e de grupos sobre enfrentamento de processos saúde-doença e adesão a tratamentos, passam a ser os fatores biológicos, psicológicos e sociais, 
considerados, na medida do possível, de maneira integrada e inter-relacionada ao processo de desenvolvimento humano.

Outro fator que contribuiu para o crescimento da Psicologia da Saúde foi o rápido aumento dos custos de serviços de saúde, tendo impacto significativo sobre o produto interno bruto (PIB) dos países. Com esses índices em alta, as ações de promoção e manutenção da saúde e prevenção de doenças, antes de suas manifestações clínicas, por demandarem menor custo financeiro e potencial eficiência (preventiva), tomaram o foco dos debates em torno do assunto, dando ênfase à psicologia da saúde como uma área promissora para modificar comportamentos que apresentassem risco à saúde das pessoas, antes que elas ficassem doentes e, assim, reduzir expressivamente os custos com tratamentos médicos, odontológicos e demais campos da saúde.

De acordo com projeções estatísticas, os custos de saúde tendem a aumentar com o tempo. Na década de 1980, o custo anual dos serviços de saúde, nos EUA, por exemplo, consumiu mais de $13 \%$ do PIB norte-americano, o que correspondia a mais de 3.900 dólares para cada homem, mulher ou criança (Straub, 2014). Segundo estatísticas mais recentes (OMS, 2011), tais despesas já correspondiam a 15,7\% do PIB norteamericano e algumas projeções indicam que os gastos podem atingir $20 \%$ do PIB, nos próximos 10 anos, o que tem provocado importantes discussões sobre a sustentabilidade do sistema de saúde norte-americano (Pedroso \& Malik, 2015; WHO, 2011). No Brasil, o segmento também é bastante significativo, representando o equivalente a $8,4 \%$ de seu produto interno bruto (OMS, 2011).

Em nível mundial, os gastos, no setor dos cuidados com a saúde, foram de 9,7\% do PIB do planeta em 2007 (últimos dados disponíveis), um valor estimado em US\$ 5,3 trilhões (Pedroso \& Malik, 2015). Projeta-se que as necessidades crescentes de cuidados, bem como os investimentos e gastos com saúde, tendem a aumentar 
gradativamente, tanto em função de maior conscientização, por parte dos indivíduos, de que devem se cuidar melhor, quanto pela maior disponibilidade de recursos tecnológicos e pelo aumento da expectativa de vida das populações (OMS, 2011).

\subsection{Diferentes Campos e áreas afins à Psicologia da Saúde}

Todas essas perspectivas dos custos da saúde pública, somadas ao aumento do número de trabalhos publicados que apontavam a promoção de saúde como uma estratégia potencialmente eficiente para o controle parcial de gastos com alta tecnologia (Bennett \& Murphy, 1997), e a inserção de psicólogos, como membros de equipes de especialidade médica, em diferentes instituições de saúde, acompanharam alguns debates que já ocorriam em torno de quais áreas teriam como desafios comuns os mesmos que viriam a se tornar alvo da Psicologia da Saúde, como a Medicina Psicossomática, a Medicina Comportamental e a Saúde Comportamental. Contudo, esses termos, muitas vezes, eram utilizados como sinônimos (Matarazzo, 1980).

A Medicina Psicossomática, cujo termo vem das raízes psico, que significa mente e soma, que significa corpo, surgiu como um ramo da medicina que se concentrava sobre o diagnóstico e o tratamento de doenças físicas sem correlato orgânico, causadas por processos psicológicos que não funcionavam adequadamente, tendo sua trajetória associada, inicialmente, aos estudos de Sigmund Freud.

$\mathrm{Na}$ época em que surgiu, também referida como Psicologia Médica, foi considerada revolucionária dentro da medicina tradicional, mas com o tempo também revelou suas limitações (Kerbauy, 2002; Straub, 2014). Um modelo psicossomático de saúde leva em consideração que as doenças são resultantes de conflitos emocionais específicos e não resolvidos adequadamente pelo indivíduo. Trata-se de um modelo teórico de orientação psicodinâmica, no qual a ênfase está na relação mente-corpo. No 
entanto, na medida em que a ênfase tenha sido dada tão somente às causas inconscientes e irracionais e sua vertente de pesquisa privilegiava apenas estudos de caso individuais, suas fraquezas metodológicas vieram à tona e esse conceito foi perdendo reconhecimento entre os pesquisadores que analisavam relações funcionais entre fatores ambientais e repertórios de comportamentos adquiridos.

Com o declínio desse movimento, a área científica de estudo do comportamento observável e as teorias de aprendizagem ganharam força, contribuindo para que os pesquisadores concebessem um campo que explorava o papel do condicionamento clássico e operante, originário da filosofia behaviorista de Burrhus F. Skinner, dentro da medicina, que foi cunhado de Medicina Comportamental, reconhecido como:

(...) um campo interdisciplinar preocupado com o
desenvolvimento e integração dos conhecimentos e técnicas das
ciências comportamentais e biomédicas, relevantes para a
compreensão da saúde e doença e a aplicação desse conhecimento e
dessas técnicas para a prevenção, diagnóstico, tratamento e
reabilitação (Schwartz \& Weiss, 1978 apud Kerbauy, 2002).

Outro termo bastante empregado na época era o de Saúde Comportamental, que mais tarde passou a ser referido como uma subespecialidade interdisciplinar, dentro da Medicina Comportamental, lidando com a habilidade de pessoas e grupos saudáveis de manterem a saúde e prevenirem doenças e disfunções (Matarazzo, 1980).

Estes dois últimos termos são, ainda hoje, por definição, atividades interdisciplinares que atraem cientistas, professores e profissionais de diversas áreas, como medicina, fisiologia, psicologia, epidemiologia, sociologia médica, enfermagem, odontologia, dentre outras.

Concomitantemente à confusão conceitual em torno dos termos mais adequados 
a cada campo, a American Psychological Association (APA) lançou, em 1973, uma força-tarefa para explorar o papel específico da Psicologia no campo da saúde, com o objetivo de determinar se deveria permanecer como uma subcategoria da Medicina Comportamental ou se teria seu campo próprio, com objetivos e focos específicos.

Com isso, o termo Psicologia da Saúde passou a se referir, de maneira mais específica, ao papel da Psicologia como ciência e profissão no domínio dos cuidados com a saúde. A psicologia da saúde, dessa forma, segundo Matarazzo (1980), se diferenciaria como o conjunto de contribuições educacionais, científicas e profissionais, específicas da disciplina de psicologia, para a promoção e manutenção da saúde, a prevenção e o tratamento de doenças e a identificação de correlatos etiológicos e diagnósticos para saúde, doença e disfunções relacionadas.

Ainda é possível que a distinção entre esses termos se mostre confusa ou que esses conceitos se sobreponham, pois, mesmo no âmbito restrito da Psicologia, com todo o avanço que já se alcançou, a denominação é ainda problemática e baseada em referenciais teóricos e discussões sobre como distinguir, por exemplo, psicologia da saúde e psicologia hospitalar (Kerbauy, 2002). Especialmente no Brasil, vários autores e profissionais da área ainda empregam erroneamente os dois conceitos.

Psicologia Hospitalar pode ser compreendida como um campo, dentro da Psicologia da Saúde, com necessidade de uma intervenção precisa e adequada em um ambiente acostumado a raciocinar com base em evidências (Gorayeb, 2010). Já a Psicologia da Saúde é um campo mais amplo, incluindo a Psicologia que se pratica em hospitais e talvez, justamente pelo fato de uma grande parcela dos psicólogos que começaram a trabalhar em Psicologia da Saúde tê-lo feito em ambientes hospitalares, a celeuma ainda persista (Castro \& Bornholdt, 2004). 
De acordo com Yamamoto, Trindade e Oliveira (2002) a denominação Psicologia Hospitalar poderia ser descartada, uma vez que se mostra inadequado usar um local de trabalho para designar uma área de atuação, o que gera o efeito de pulverização e fragmentação desse campo profissional e torna ainda mais difícil para o psicólogo que atua em contexto hospitalar, construir uma identidade de profissional da saúde.

Castro e Bornholdt (2004) incluem a psicologia hospitalar na área ampla da Psicologia da Saúde, uma vez que essa última utiliza conhecimentos das ciências biomédicas, da Psicologia Clínica e da Psicologia Comunitária para intervir em diversos contextos sanitários, incluindo o hospital.

A área se distingue da Psicologia Clínica por analisar e compreender os comportamentos que ocorrem nos contextos dos cuidados com a saúde e o tratamento de doenças, diferenciando-os daqueles que estão relacionados a outros contextos de vida dos indivíduos, tais como as configurações familiares, conjugais e profissionais. Dessa forma, os modelos teóricos empregados em saúde mental nem sempre se mostram como referenciais adequados à Psicologia da Saúde, que busca focalizar a integralidade e a dinamicidade de fatores biológicos, psicológicos e sociais sobre o processo saúdedoença, mas sempre reconhecendo a importância de se distinguir indicadores de saúde mental e de saúde física (Kerbauy, 2002).

Enquanto um campo de contribuição específica da psicologia, científica e profissional, a psicologia da saúde prioriza a promoção e a manutenção da saúde, bem como a prevenção e o tratamento das doenças (Cerqueira-Silva et al, 2011). Assim, seu foco está no estudo das relações funcionais que se estabelecem entre fatores psicossociais, tais como idade, gênero, status socioeconômico, hábitos de vida, crenças, 
rede de suporte social e comportamentos em geral e a etiologia, o diagnóstico, o tratamento e o prognóstico de doenças e disfunções.

Vale ressaltar que todo o conjunto de conhecimentos que fazem parte da psicologia da saúde pode ser aplicado não somente a usuários de saúde, mas também aos recursos humanos envolvidos, às instituições e políticas de saúde (Cerqueira-Silva et al, 2011). Princípios de promoção de saúde se aplicam a pacientes em tratamento médico, a familiares e acompanhantes, a profissionais de saúde e ao próprio sistema de saúde.

\subsection{A criação formal da Divisão 38 da APA}

Os debates em torno da definição das áreas responsáveis por estudar os fenômenos psicológicos, emocionais e comportamentais no âmbito da saúde, culminaram, então, com a criação, em 1978, da divisão número 38, denominada Health Psychology, pela American Psychological Association (APA) e, quatro anos mais tarde, do periódico específico e representante oficial da área, até o presente momento, o Journal of Health Psychology (JHP).

Com o reconhecimento da nova Divisão de psicologia e o esclarecimento do escopo da Psicologia da Saúde, algumas diretrizes foram traçadas pela APA (Matarazzo, 1982) como objetivos do novo campo de estudo, pesquisa e prática profissional: (a) estudar de forma científica a etiologia de determinadas doenças, principalmente suas origens psicológicas, comportamentais e sociais, investigando, por exemplo, por que as pessoas se envolvem em comportamentos que comprometem a saúde, tais como a prática de sexo inseguro e o hábito de fumar; (b) promover a saúde, buscando compreender como fazer as pessoas se engajarem em comportamentos que privilegiem a saúde, como, por exemplo, a prática regular de exercícios físicos e/ou a ingestão regular de alimentos 
nutritivos; (c) prevenir e tratar doenças, projetando programas para ajudar as pessoas a reduzirem hábitos nocivos, tais como melhor administração do estresse, parar de fumar, perder peso, ou ainda, auxiliar pessoas que já estão doentes a se adaptarem melhor às condições e restrições impostas pela doença e a aderirem melhor aos planos de tratamento; e, por último, (d) promover políticas públicas de saúde e aprimoramento do sistema de saúde vigente, reunindo-se com líderes governamentais e subsidiando pesquisas na tentativa de melhorar a eficiência dos serviços de saúde a todos os indivíduos e grupos populacionais. 


\section{CAPÍTULO 2}

\section{O PERFIL DA PRODUÇÃO BIBLIOGRÁFICA EM PSICOLOGIA DA SAÚDE NO BRASIL E NO MUNDO}

O segundo capítulo traça um breve panorama histórico da produção de trabalhos científicos, na área de Psicologia da Saúde, desde a década de criação formal da área, pela American Psychological Association, e décadas seguintes, apontando os principais temas estudados, além de mencionar os modelos teóricos mais referidos em pesquisas.

\subsection{O crescente aumento do número de publicações}

Desde que Joseph Matarazzo $(1980,1982)$ publicou seus comunicados, nos primeiros anos da década de 1980, reforçando a importância da implementação de um modelo filosófico, de natureza biopsicossocial, para a Medicina e demais campos da saúde, suas premissas passaram a se tornar referência, associados ao trabalho de George Engel (1977), considerado o grande iniciador da Psicologia da Saúde (SantiagoDelfosse \& Chamberlain, 2008; Carvalho, 2013). Caracteristicamente, esses autores rejeitaram o pensamento reducionista e dualista na abordagem dos processos de saúde e doença e fizeram referência a um modelo integral de atenção à saúde, resultante da intervenção de fatores tanto biomédicos, quanto psicológicos, sociais, culturais e históricos, que deveriam ser levados em consideração quando da análise dos mecanismos de manutenção da saúde e dos determinantes etiológicos de uma doença e seus respectivo(s) tratamento(s) (Dias, Duque, Silva \& Durá, 2004).

Já a partir do início da década de 1970, observou-se um período de grande produção de pesquisas nacionais e internacionais, com temáticas que levariam ao crescimento e reconhecimento da área da Psicologia da Saúde. Esse período, tão prolífico em produção bibliográfica, veio acompanhado de igual crescimento, também, 
de práticas profissionais voltadas à promoção de comportamentos que mantivessem a saúde de indivíduos e grupos, chegando a ser considerado um marco teórico conhecido como a Segunda Revolução da Saúde. Tal período histórico foi caracterizado, especialmente, por estudos que conceituavam o comportamento como "a grande epidemia" do século XX, e centravam-se nos indicadores de saúde, ao invés da doença, tendo a promoção da saúde e a análise do estilo de vida como dois conceitos centrais e que poderiam nortear o manejo comportamental e/ou psicossocial ao longo do curso de vida (Ogden, 1998; Carvalho, 2013).

Uma vez que os benefícios da chamada Primeira Revolução da Saúde já eram percebidos com a disseminação de práticas de prevenção de doenças, os estudiosos dessa área começaram a se preocupar com intervenções que aumentassem a probabilidade da adoção de estilos de vida mais saudáveis, sistemas de manejo/controle comportamental, implementação de ações de proteção contra acidentes, bem como a compreender como os comportamentos de saúde podem ser influenciados por atitudes, crenças, valores, hábitos e sentimentos (Dias et al., 2004)

O aumento do número de publicações de pesquisas com temática relacionadas às relações entre saúde e comportamentos, iniciado na década de 1970, também ocorreu tanto quantitativa quanto qualitativamente, em formato de livros e de artigos científicos, gerando material importante para a divulgação do conhecimento e para a formação de novos profissionais que ingressavam na área. E esse movimento continua ocorrendo. Segundo Gorayeb (2010), a realização de congressos científicos e eventos de área também vêm crescendo de forma expressiva, bem como a criação de grupos de trabalho, organizações e sociedades. Outra ação crescente tem sido a abertura de espaços para tratar de temáticas relacionadas à Psicologia da Saúde em congressos de especialidades médicas. 
O crescimento do número de trabalhos em Psicologia da Saúde, publicados no Brasil, acompanhou a tendência vigente no restante do mundo, no entanto, ainda não pode ser considerado suficiente para afirmarmos que haja uma diversidade de temas e uma quantidade de artigos significativamente relevantes para a formação de mais psicólogos da saúde, em número adequado às necessidades brasileiras (Gorayeb, 2010).

As primeiras publicações, no Brasil, identificadas nas bases de dados MEDLINE e LILACS, usando os descritores "Psicologia", "Saúde" e "Brasil", datam de 1971 e 1982, respectivamente. Nos anos que se seguiram a estas primeiras publicações, a partir de 1990, observou-se um crescimento que variou de 140 a $250 \%$ no número de publicações e, na primeira década do século XXI, o crescimento foi de 180 a $300 \%$ em relação aos dez anos anteriores (Gorayeb, 2010).

Um estudo realizado por Dela Coleta, em 1998, a partir da análise de comunicações livres apresentadas nas Reuniões Anuais da Sociedade Brasileira de Psicologia (SBP), apontou que o número de trabalhos na área de psicologia da saúde, entre 1986 e 1996, cresceu de zero a 40, correspondendo a 11,6\% de aumento (Dela Coleta, 1999).

Com o notável crescimento do número de publicações, em periódicos nacionais e internacionais, o futuro passou a apontar para a necessidade de uma adequada inserção do conceito de psicologia da saúde, bem como de seus objetivos e mecanismos de intervenção, no conteúdo básico de ensino de graduação e com a oferta de novas oportunidades de formação em pós-graduação, permitindo que a área de psicologia da saúde venha a se desenvolver, ainda mais no Brasil, coerente com premissas e perspectivas dos grandes centros de pesquisa dos Estados Unidos da América e Canadá, por exemplo. 
Espera-se que as pesquisas nacionais, em Psicologia da Saúde, continuem contribuindo para a crescente inserção de psicólogos qualificados, tanto em contextos de atenção básica à saúde, quanto em equipes de especialidades médicas, da rede pública e privada de saúde, com reflexos positivos sobre o estado de bem-estar de indivíduos e grupos.

Dos temas atuais, mais investigados, merecem destaque os trabalhos sobre adesão ao tratamento, sobre estratégias de enfrentamento ou coping, indicadores de qualidade de vida, aspectos comportamentais e contextuais das doenças e educação para a saúde. Contudo, os delineamentos de pesquisa carecem de maior sistematização (Cerqueira-Silva et al., 2011).

Cerqueira-Silva et al. (2011) chamam a atenção para a forte tendência ao uso de métodos quantitativos dos estudos que investigam variáveis do processo saúde-doença. Citando um estudo que considerou publicações de janeiro de 2001 a outubro de 2007, por exemplo, identificou-se que $91 \%$ dos trabalhos empregaram alguma metodologia quantitativa, sobretudo usando estatística inferencial. Uma justificativa para esse resultado pode fundamentar-se na tradição do paradigma positivista, incluindo uma preocupação com a generalização dos resultados, o que, inevitavelmente, remete a testes estatísticos, protocolos de validação e à necessidade de um maior número de participantes de pesquisa.

A predominância de trabalhos quantitativos e com enfoque comportamental também pode ser atribuída à influência do já referido autor clássico, Joseph Matarazzo, que contribuiu para nortear a atual concepção de psicologia da saúde, e cuja referência se faz presente em seus textos por meio da alusão à terceira edição do Manual Diagnóstico e Estatístico de Desordens Mentais (DSM-III), publicado pela American Psychiatric Association, em 1980 (Wilson, 1983). 
Outro aspecto importante diz respeito ao fato de que a metodologia quantitativa, por seu caráter descritivo no estabelecimento de relações funcionais entre variáveis, pressupondo descrição, predição e controle, favorece a investigação de indicadores e preditores do processo saúde-doença. Além disso, por se tratar de uma área de abrangência multiprofissional, espera-se que os estudos sejam acessíveis a profissionais e pesquisadores de diferentes áreas da saúde, que, por formação acadêmica e tradição positivista, reconhecem a credibilidade de metodologias quantitativas e o refinamento de análises estatísticas adequadas.

Acrescentamos, ainda, que o impacto de um trabalho de pesquisa que adota um número representativo de participantes e que busca indicadores, de saúde-doença, de evidência empírica, associados a conceitos de verificabilidade mais objetiva, e potencialmente generalizáveis, facilita o processo de divulgação e comunicação científica, permitindo que protocolos de pesquisa sejam testáveis e adaptáveis a diferentes contextos e serviços de atenção à saúde. Pesquisas multicêntricas, nacionais e internacionais, por exemplo, se beneficiam destas metodologias e os resultados são aplicáveis a um crescente número de usuários dos sistemas de saúde.

Paralelamente, as primeiras discussões sobre estratégias qualitativas de pesquisa na área de psicologia da saúde começam a despontar nos trabalhos de Giorgi (1970, 1978) e, posteriormente, debatidos por Schneider (1998, 1999). Segundo os defensores dessa perspectiva metodológica, os estudos quantitativos negligenciariam a singularidade do sujeito e de seu contexto, devido à ênfase na generalização e na análise estatística.

No final da década de 1990, alguns periódicos de psicologia da saúde passaram a publicar pesquisas com análises qualitativas, com destaque para o Journal of Health 
Psychology e o Psychology and Health (Carvalho, 2013), reconhecidas como duas das principais revistas mundiais da área.

Com o desenvolvimento e a legitimidade percebidas, tanto da pesquisa qualitativa quanto da pesquisa quantitativa, não somente no campo específico da psicologia da saúde, mas nas ciências sociais e humanas, de maneira geral, uma versão combinada de abordagens de ambas as vertentes, passa a ganhar popularidade. Em 2003, foi publicado o Handbook of Mixed Methods in the Social and Behavior Sciences (Tashakkori \& Teddlie, 2003 apud Creswell, 2010), apresentando a primeira visão geral abrangente de uma estratégia mista de investigação. Atualmente, várias revistas acadêmicas enfatizam, ou apoiam ativamente, a pesquisa de métodos mistos, como é o caso dos periódicos Journal of Mixed Methods Research, Quality and Quantity, Field Methods, International Journal of Social Research Methodology, Qualitative Health Research e Annals of Family Medicine (Creswell, 2010).

\subsection{Principais perspectivas teórico-filosóficas em Psicologia da Saúde}

Diversas foram as perspectivas sociais e históricas que contribuíram para o crescimento da Psicologia da Saúde. Do ponto de vista teórico e filosófico, diferentes modelos foram propostos, por pesquisadores sociais, para explicar as relações entre comportamentos e o processo saúde-doença. Inicialmente, teorias e métodos de outras áreas foram tomados de empréstimo pela Psicologia da Saúde, bem como as avaliações e intervenções propostas (Smith \& Suls, 2004). Os mais referidos e que merecem destaque são os modelos cujas perspectivas socioculturais e/ou biopsicossociais estão ligadas ao curso de vida e de gênero (Straub, 2014).

A perspectiva sociocultural estuda a maneira como os fatores sociais e culturais contribuem para o delineamento do processo saúde-doença. Dentro desse modelo, 
incluem-se estudos ligados a minorias étnicas, grupos religiosos e comunidades expostas a vulnerabilidades sociais, por exemplo (Ogden, 1999).

A perspectiva biopsicossocial reconhece variáveis biológicas, psicológicas, sociais e espirituais agindo conjuntamente para condicionar o grau de vulnerabilidade de um indivíduo, ou grupo, a determinados riscos e doenças. Nesse contexto, destacamse os estudos que correlacionam, por exemplo, taxas metabólicas com determinadas reações emocionais, estudos que identificam crenças que contribuem para manutenção de comportamentos nocivos à saúde, e ainda, pesquisas que ressaltam a importância da existência de uma rede de suporte social para uma pessoa doente ou em tratamento médico, por exemplo (Straub, 2014).

Já a perspectiva do curso de vida, se concentra em estudar indicadores de saúde e doença relacionados funcionalmente a etapas do ciclo vital em que o indivíduo se encontra, e investigar as principais causas de mortalidade, morbidade e de incapacidades que acometem diferentes grupos etários. Nesse modelo, se destacam pesquisas que investigam relações entre puberdade e comportamentos de risco à saúde e entre envelhecimento e manutenção/redução de dimensões de qualidade de vida, por exemplo (Straub, 2014).

Por último, a perspectiva de gênero tem apontado preocupações com problemas de saúde, específicos de homens e mulheres (Straub, 2014). Apesar de as diferenças em saúde entre homens e mulheres serem objeto de grande interesse, as interpretações tendem a ser naturalizadas e essencialistas. Os estudos de perspectivas de gênero têm criticado essa literatura, oferecendo alternativas de análise mais promissoras para explicar as diferenças nas condições de predisposição a riscos de saúde (Aquino, 2006).

Entre os modelos teóricos, propostos a explicar a ocorrência de determinados repertórios de comportamentos, e de grande influência sobre o estudo das relações entre 
comportamento(s) e saúde, estão as abordagens adotadas pelos psicólogos sociais de orientação cognitivista, que desenvolveram modelos teóricos aplicáveis à compreensão da aquisição e mudanças de comportamentos (Dela Coleta, 1999) e que privilegiam ações individuais voltadas a mudança de estilos de vida e adoção de comportamentos saudáveis. Tratam-se de modelos teóricos, com foco nos usuários de serviços de saúde, partindo do pressuposto de que, direcionando-os a assumirem a responsabilidade por sua própria saúde, seria possível reduzir o peso financeiro da assistência de saúde (Staliano, 2012).

Os modelos teóricos com foco no indivíduo, de modo geral, buscam explicar por que as pessoas praticam, ou não, determinado(s) comportamento(s) de saúde, descrevendo e analisando as etapas de mudança comportamental por elas vivenciadas (Travassos \& Martins, 2008) e tentando explicar como a percepção individual, acerca do próprio processo saúde-doença, pode influenciar a adoção de certos comportamentos associados a determinado(s) estilo de vida (Dias, Duque, Silva \& Durá, 2004).

Os principais representantes deste grupo de modelos teóricos são: (a) o modelo de crenças em saúde (Rosentock, 1974); (b) o modelo da ação racional e da ação planejada (Ajzen \& Fishbein, 1977); (c) o modelo transteórico de mudança comportamental (Prochaska, 1994); e (d) o modelo de auto-eficácia (Bandura, 1989), descritos, sumariamente, a seguir.

\subsubsection{Modelo de crenças em saúde}

Referido como o modelo mais pesquisado em Psicologia da Saúde, o Health Belief Model (HBM), ou Modelo de Crenças em Saúde, foi proposto, nos EUA, como uma tentativa de explicar por que as pessoas não se preveniam adequadamente contra 
certas doenças para as quais já haviam teste, vacinas, ou outros procedimentos de eficácia reconhecida, tais como a tuberculose ou a poliomielite (Dela Coleta, 1999).

Este modelo teórico, proposto por Rosentock (1974), contempla quatro dimensões que interagem entre si e influenciam as percepções de uma pessoa acerca de determinada doença ou condição adversa: (a) suscetibilidade percebida: refere-se à percepção subjetiva do risco pessoal de contrair uma doença; (b) gravidade percebida: avaliada tanto pelo grau de perturbação emocional, gerada ao pensar na doença, quanto pelos tipos de consequências que ela pode acarretar; (c) benefícios percebidos: crença na efetividade da ação e na percepção de suas consequências positivas; e (d) barreiras percebidas: avaliação dos aspectos negativos da ação associados a uma lógica de custobenefício.

De acordo com esse modelo, as crenças de um indivíduo são fruto de suas ideias, convicções e atitudes sobre saúde e doença, podendo, portanto, terem força tanto para promover a saúde como para influenciá-la negativamente. Mais do que os fatos objetivos em si, acerca dos benefícios ou barreiras percebidas por uma pessoa, suas crenças sobre o quanto determinada ação é viável ou efetiva é que determina sua iniciativa ou posição para assumir alguma ação em torno de sua saúde ou doença (Rosentock, 1974).

Podemos citar alguns exemplos de estudos brasileiros, referidos pela literatura especializada, que aplicaram o Modelo de Crenças em Saúde em sua metodologia: o trabalho de Seidl e Gimenes (1997), por exemplo, sobre comportamentos de prevenção do câncer feminino; o estudo conduzido por Brun (1992) sobre tabagismo; e dois trabalhos realizados por Dela Coleta, em anos diferentes, sendo um publicado em 1993 sobre o uso do preservativo como prevenção à AIDS e outro, publicado em 1995, sobre adesão a comportamentos de prevenção e controle de doenças cardiovasculares (Dela 
Coleta, 1999). Há, também, estudos mais recentes como o que discute relações funcionais entre espiritualidade e promoção da saúde, usando o modelo de Crenças em Saúde (Isaac, Hay \& Lubetkin, 2016) ou sobre a percepção e práticas do psicólogo no contexto da atenção básica à saúde (Freire \& Pichelli, 2013).

\subsubsection{Teoria da Ação Racional e Teoria da Ação Planejada}

A Teoria da Ação Racional foi inicialmente proposta por Ajzen e Fishbein (1977), admitindo que seres humanos são racionais e usam as informações que estão disponíveis, avaliando as implicações de seus comportamentos, para, então, decidirem se devem ser realizadas, ou não. São objetivos dessa teoria predizer e entender o comportamento e precisar a intenção de realizá-lo.

Um dos elementos que diferencia a Teoria da Ação Racional do Modelo de Crenças em Saúde é a presença do construto da intenção comportamental, ou seja, o que determina o comportamento saudável é o controle volitivo, exercido pelo próprio indivíduo, por meio de aspectos pessoais que dirigem suas atitudes e por meio de normas subjetivas, que se referem à influência social (Moutinho \& Roazzi, 2010) ou normas de convenção.

Apesar do sucesso da Teoria da Ação Racional, esse modelo tem sofrido questionamentos, uma vez que intenções e comportamentos podem ser influenciados por outros fatores, tais como os hábitos. A crítica que se faz a esse modelo teórico é de que as intenções comportamentais refletem apenas uma motivação para agir, enquanto a execução de uma ação não depende só da intenção, mas, também, do maior ou menor controle sobre o comportamento.

Sendo assim, esses mesmos autores, com a ajuda de novos colaboradores, vêm modificando e expandindo o modelo teórico, inserindo outro elemento preditor da ação: 
as crenças sobre o controle. Além das crenças comportamentais (atitudes favoráveis ou desfavoráveis em relação ao comportamento) e das crenças normativas (expressão da pressão social percebida pelo indivíduo), deve-se levar em conta as crenças de controle, ou seja, a presença de fatores que podem impedir ou facilitar o desempenho do comportamento (Moutinho \& Roazzi, 2010). Dessa maneira, a ação humana seria influenciada por três tipos de crenças: comportamentais, normativas e as crenças de controle. Essas três dimensões, combinadas, conduzem à formação de uma intenção comportamental.

Alguns exemplos de trabalhos usando esse modelo teórico são os desenvolvidos por Cavalcanti, Dias, Rodrigues, Gouveia, Ramos e Serrano (2007), sobre a teoria da ação racional e obesidade, e o de Gonçalves e Dias (1999) sobre a prática do autoexame da mama em mulheres de baixa renda.

\subsubsection{Modelo Transteórico de Estágios da Mudança}

Prochaska et al. (1994) propuseram o modelo transteórico, também conhecido como teoria dos estágios da mudança, como um modelo para explicar, originalmente, o comportamento relacionado ao ato de fumar. Mas, desde então, o modelo vem sendo aplicado a uma grande variedade de comportamentos em saúde.

O modelo transteórico postula cinco etapas pelas quais um indivíduo, ou grupo, vivencia um processo de mudança comportamental. As etapas ou fases são: (a) précontemplação: na qual o indivíduo não tem qualquer intenção de mudar seu comportamento pelos próximos seis meses; (b) contemplação: o indivíduo manifesta séria intenção de mudar seu comportamento dentro dos próximos seis meses, reconhecendo a existência e a severidade de um problema; (c) preparação: o indivíduo pretende agir num futuro equivalente a, aproximadamente, um mês e envolve 
pensamentos e ações que favorecem a mudança; (d) ação: quando o comportamento já foi incorporado, por menos de seis meses; e (e) manutenção: a ação já acontece há mais de seis meses e são reduzidas as chances de recaída ou retorno ao antigo comportamento.

Este modelo teórico reconhece que o avanço e o retrocesso ao longo dessas fases ou etapas ocorrem de maneira não-linear e que diferentes processos comportamentais, cognitivos e sociais, podem ser preponderantes ao longo do percurso vivenciado para atingimento dos objetivos de mudança, como conscientização (busca de mais informações sobre o comportamento prejudicial à saúde), contracodicionamento (substituição do comportamento que está sendo alvo de mudança por outro alternativo) e administração com reforço (instituição de recompensas a si mesmo ou de outras pessoas pelo sucesso obtido) (Staliano, 2012).

Diversos trabalhos relacionando esse modelo teórico com mudanças de comportamento, em diferentes campos, podem ser referidos, como, por exemplo, o estudo sobre os estágios da mudança aplicados a exercícios físicos tanto a pessoas aparentemente sem alguma doença (Horiuchi, Tsuda, Watanabe, Fukamachi \& Samejima, 2013), quanto em pacientes com alguma condição adversa (Kirk, MacMillan \& Webster, 2010), bem como em trabalhos sobre o uso de preservativos por jovens vivendo com HIV/AIDS (Naar-King, Wright, Frey, Templin, Ondersma \& Kaplan, 2006) ou, ainda, o estudo com participantes de grupos de tabagismo e a intenção para a cessação desse comportamento (Martins, 2009).

\subsubsection{Modelo de Auto-Eficácia}

O conceito de auto-eficácia foi proposto por Albert Bandura, em 1977, no contexto da teoria da aprendizagem social (Salvetti \& Pimenta, 2005). Trata-se da 
crença que o próprio indivíduo considera possuir acerca de suas habilidades para desempenhar, com sucesso, atitudes que produzam resultados desejáveis.

A crença de auto-eficácia tem implicações para várias questões crônicas de saúde, podendo afetar a resposta do doente à doença e ao tratamento, sendo inclusive, considerada como mediadora de mudanças terapêuticas (Salvetti \& Pimenta, 2005).

A crença de auto-eficácia é composta pela expectativa desta e expectativa de resultados. Expectativa de auto-eficácia é a crença ou convicção de que se pode executar o comportamento necessário para se atingir determinados resultados, e expectativa de resultados é a crença, ou convicção pessoal, de que dado comportamento levará a determinados resultados.

A expectativa de auto-eficácia é alimentada por quatro fontes de informação: (a) realizações pessoais, ou seja, o quanto as próprias experiências do indivíduo corroboram suas ideias sobre suas capacidades; (b) observação de experiências, ou como afirma Bandura sobre o conceito de reforçamento vicário, o quanto a observação da experiência alheia, sem produzir consequências adversas, pode contribuir para aumentar sua expectativa de ele próprio também realizá-las; (c) persuasão verbal, ou seja, receber estímulos de outrem acerca de suas capacidades para realizar determinadas tarefas; e (d) respostas emocionais, ou seja, o nível de respostas afetivas desencadeadas por situações estressantes.

Algumas pesquisas sobre auto-eficácia em saúde mostraram que auto-eficácia elevada está relacionada a estilos de vida saudáveis. Auto-eficácia elevada foi capaz de predizer a intenção de deixar de fumar, a participação em programas de rastreamento e ajustamento ao câncer, a adesão ao tratamento, comportamentos de autocuidado, melhor funcionalidade e diminuição de sintomas físicos e psicológicos (Beck \& Lund, 1981; Anderson et al., 1995; Lev, 1997 apud Salvetti \& Pimenta, 2005). O conceito também 
está relacionado com a percepção da dor e com a funcionalidade física e psíquica dos doentes com dor crônica. Os estudos mostraram que pacientes com auto-eficácia elevada apresentaram melhor funcionalidade, humor mais positivo, menos comportamentos indicadores de dor e sofrimento, menos sintomas depressivos, menos desesperança e menos angústia emocional (Buescher et al., 1991; Jensen et al., 1994; Anderson et al., 1995; Lefebvre et al., 1999 apud Salvetti \& Pimenta, 2005).

Outros exemplos relevantes incluem pesquisas sobre a expectativa de autoeficácia e a adesão ao tratamento anti-retroviral, em pessoas vivendo com HIV/AIDS (Faustino, 2006), sobre estratégias de promoção da adesão a diabetes tipo 1 (Fleury, 2006) e sobre a experiência dolorosa entre pacientes cirúrgicos e sua correlação com a percepção de auto-eficácia (Almeida, 2011).

Tendo em vista a descrição da evolução da Psicologia da Saúde, ora mencionada, o próximo capítulo nos remete a uma análise de conteúdo do volume especial do Journal of Health Psychology, publicado em 2004, que teve o propósito de discutir os avanços científicos e profissionais alcançados pela área de Psicologia da Saúde ao longo de quase 26 anos (1978-2004), que antecederam seu lançamento e, ainda, debater os principais desafios vindouros, que poderiam caracterizar o futuro da área. 


\section{CAPITULO 3}

\section{O FUTURO DA PSICOLOGIA DA SAÚDE}

O terceiro capítulo disserta a respeito do lançamento do Volume Especial do periódico Journal of Health Psychology (JHP), que fez um apanhado do "estado da arte", da área de Psicologia da Saúde, desde a década de 1980 até 2004, ano de sua publicação. E ainda, lança desafios para os anos seguintes em relação à continuidade da evolução científica da área.

\subsection{A publicação do Volume Especial do Journal of Health Psychology (JHP)}

A partir da criação da divisão de Psicologia da Saúde, pela APA, e da publicação de suas diretrizes no início da década de 1980, muito se caminhou. Esse crescimento contribuiu para que mais tarde, no ano de 2004, essa mesma entidade analisasse, criticamente, quais haviam sido os avanços da área nos vinte e cinco anos que sucederam a sua criação.

Para tanto, o JHP lançou um volume especial, identificando os avanços alcançados desde 1980, e discutindo as perspectivas vindouras de desenvolvimento e desafios para os psicólogos da saúde (Smith \& Suls, 2004), tendo como ponto intermediário a Conferência sobre o Futuro da Psicologia da Saúde, ocorrida em março do ano 2.000 em Pittsburgh, no estado da Pennsylvania, nos EUA. A conferência definiu seis grupos de trabalho para discutir os seguintes temas: (a) a evolução do modelo biopsicossocial de saúde; (b) os avanços da medicina e da tecnologia médica e suas repercussões em outras áreas de conhecimento; (c) as mudanças em indicadores demográficos das populações; (d) os gastos e fatores econômicos em torno dos cuidados 
em saúde e as perspectivas de mercado para a psicologia da saúde; (e) prioridades de políticas de prevenção; e (f) intervenções clínicas em psicologia da saúde.

O saldo, referido pelos estudiosos, até então, foi que a maior parte das perspectivas projetadas pelos fundadores da Divisão 38 vinha se cumprindo, visto que os 20 anos que antecederam a Conferência, forneceram uma atraente e crescente evidência da importância da aplicação da ciência e da prática psicológica para questões relacionadas à saúde física, incluindo o aumento das pesquisas em ciências do comportamento, com financiamento público e privado no contexto da saúde (Smith \& Suls, 2004). No entanto, alguns desafios ainda mereciam atenção, e os principais deles, encontram-se brevemente comentados nos tópicos a seguir.

\subsection{1) A Evolução do Modelo Biopsicossocial de Saúde}

A fim de medir a difusão e aceitação do modelo biopsicossocial, Suls e Rothman (2004) realizaram uma pesquisa na base de dados Medline - uma das maiores referências que atraem revistas médicas do mundo todo - para o termo “biopsicossocial”, abrangendo títulos e resumos de artigos datados de 1974 até 2001, reconhecendo que, embora o uso do termo biopsicossocial nos descritores não revelassem necessariamente a adoção efetiva do modelo, essa referência explícita ao termo refletiria, no mínimo, o reconhecimento das influências da perspectiva. Os autores verificaram que - a despeito da imprecisão desses indicadores - os termos "biopsicossocial" e "comportamento" vinham sendo mencionados com mais frequência na literatura médica do que haviam sido nos 30 anos anteriores.

Muito embora haja esse e muitos outros sinais de que já houve um expressivo aumento da consciência de que fatores comportamentais e sociais merecem tanta atenção quanto os fatores biológicos para a compreensão e direcionamento dos problemas de saúde do mundo, o grau em que o modelo biopsicossocial foi 
efetivamente incoporado pelo establishment médico permanece nebuloso. Por exemplo, uma pesquisa realizada em universidades de medicina dos EUA mostrou que quase $50 \%$ das escolas destinavam carga horária inferior a 40 horas da grade curricular total para disciplinas relacionadas a medicina psicossomática e/ou psicologia da saúde para estudantes de medicina (Waldstein, Neumann, Drossman, \& Novack, 2001 apud Suls \& Rothman, 2004).

$\mathrm{Na}$ medida em que se avança na compreensão das relações funcionais entre variáveis biológicas, psicológicas e sociais, torna-se essencial que não só psicólogos mas também outros profissionais de saúde recebam treinamentos que abordem essa importância para todas as etapas do processo-doença dos pacientes.

\subsection{2) Metodologias de estudo empregadas em Psicologia da Saúde}

Num campo onde os primeiros estudos se baseavam em pesquisas tão somente observacionais, Smith e Suls (2004) chamaram a atenção para a necessidade de estudos experimentais que levassem em conta intervenções metodologicamente mais complexas, como, por exemplo, estudos de controle com pré e pós-tratamento.

Embora ensaios clínicos randomizados, controlados, e pesquisas baseadas em evidência empírica demonstrem que os benefícios das intervenções em Psicologia da Saúde são essenciais neste contexto atual, a crescente ênfase em pesquisa aplicada sobre a eficácia e a efetividade de tratamentos também fornece novas oportunidades para a pesquisa básica (Smith \& Suls, 2004).

Apesar de um corpo considerável de pesquisas ter sido acumulado ao longo desse período e de o crescimento dos serviços em Psicologia da Saúde ter sido bastante expressivo, o foco de trabalho dos psicólogos da saúde precisou ser mudado, face às mudanças demográficas das populações e alterações em seus padrões de saúde (Smith \& 
Suls, 2004; Yali \& Revenson, 2004). Nos EUA, por exemplo, a população vem se tornando cada vez mais idosa e etnicamente diversificada. Dessa maneira, a Psicologia da Saúde precisou refinar modelos teóricos, métodos de investigação e recursos que fossem sensíveis a estas variações.

Para cumprir com esse desafio identificado há cerca de quinze anos, na Conferência de Pittsburgh, as sugestões dos grupos de trabalho remetiam à adequação do perfil dos psicólogos buscando cursos de extensão em desenvolvimento humano, formação de especialistas em métodos de pesquisa, étnica e culturalmente adaptados, bem como uma ênfase na formação de profissionais e pesquisadores que Yali e Revenson (2004) chamaram de "contextualmente competentes". Com esse termo, os autores buscaram se referir ao preparo necessário dos profissionais para lidarem com um maior número de pessoas envelhecendo - sabendo distinguir o envelhecimento saudável ou normal do envelhecimento disfuncional - e, portanto, com o aumento do número de pessoas vivendo com doenças crônicas e/ou incapacidades. Além disso, ser contextualmente competente também inclui saber lidar com mais pessoas que se autoidentificam como gays, lésbicas, bissexuais e/ou transgêneros, e ainda, com um maior número e diversidade de configurações familiares e arranjos parentais, por exemplo.

Anos depois, fazendo uma análise dessa evolução no cenário brasileiro, Gorayeb (2010) destacou o quão carente a área ainda se mantinha no que se referia a instrumentos adequados para mensuração dos diversos aspectos de comportamentos, sentimentos e cognições dos indivíduos, para analisar a eficácia das intervenções, ressaltando que boa parte dos instrumentos utilizados em Psicologia da Saúde ainda é de origem estrangeira, alguns com adequada tradução, adaptação, validação e normatização, como as Escalas de Beck para Depressão e Ansiedade (Cunha, 2001) ou mesmo a Escala Modos de Enfrentar Problemas, adaptada por Gimenes e Queiroz 
(1997). Esse mesmo autor cita exemplos de produção nacional de instrumentos que são úteis na área de Psicologia da Saúde, como a adaptação feita por Fleck e cols. (2000 apud Gorayeb, 2010) de um instrumento criado pela OMS para avaliar qualidade de vida, o WHOQOL-Brief (World Heatlh Organization Quality of Life-Brief Tool) e bastante adotado em pesquisas. Entretanto, essa produção, no país, ainda é tímida e o leque de instrumentos disponíveis para pesquisa na área de Psicologia da Saúde ainda se mostra incompleto e insuficiente.

\subsection{3) Formação curricular em Psicologia da Saúde e Perspectivas de mercado}

Os Psicólogos da Saúde também tiveram que rever sua formação curricular, que embora já fosse considerada extensa, necessitava de contínua atualização e aprimoramento, dada sua natureza em constante mudança e de sua interface com áreas/campos como a medicina, a saúde pública e a economia de cuidados em saúde.

De acordo com Yali e Revenson (2004), para atenderem à necessidade de serem contextualmente competentes, os psicólogos da saúde devem ter larga orientação interdisciplinar, sendo versados tanto em outras subdisciplinas dentro da própria Psicologia, como psicologia sociocultural e psicologia comunitária, como em outras ciências sociais afins com a área da saúde, como saúde pública, epidemiologia ou mesmo sociologia médica, por exemplo. Nesse sentido, em tese, o psicólogo da saúde seria responsável, inclusive, pela concepção, implementação e avaliação de programas de treinamento relacionados a outras áreas da saúde que integram uma equipe interdisciplinar, como enfermagem, medicina, odontologia, nutrição, fonoaudiologia, fisioterapia. 
A importância do enfoque interdisciplinar na formação do psicólogo da saúde e também na contribuição para a formação de outros profissionais da saúde, deve contemplar não somente os cursos em nível de graduação, com ênfase nas possibilidades de pesquisa em diversos níveis de atenção à saúde, como também haveria que se estimular a existência de programas de formação em nível de pós-graduação, seja em especializações (por exemplo, programas de residência hospitalar), seja em programas de pós-graduação stricto sensu e em outros programas que visem educação continuada, inclusive contribuindo, também, para o aprimoramento do próprio Modelo Biopsicossocial de Saúde (Suls \& Rothman, 2004; Gorayeb, 2010), na medida em que permite a todos refletirem sobre suas práticas e reconhecerem a natureza multisistêmica, multivariada e multinivelada dos processos saúde-doença.

Outra forma de oxigenação do conhecimento seria a oferta de programas de mentoria, nos quais estudantes recém-formados, de diversas áreas de formação, servissem de modelos para estudantes e entidades-juniores (Yali \& Revenson, 2004).

Ainda nessa análise de condições necessárias para o desenvolvimento da área, há que se destacar o papel das sociedades científicas. Em países como o Canadá, as entidades de classe e comunidades científicas são interligadas, havendo um favorecimento maior do desenvolvimento da profissão, com o conhecimento científico servindo como suporte e apoio para as decisões de ordem profissional. No Brasil, os esforços de integração por parte das sociedades científicas, entidades de classe e comunidade acadêmica ainda são discretos e não há articulação política significativa que favoreça esse diálogo.

\subsection{4) Uso de tecnologia em intervenções na área de saúde}


Avanços tecnológicos e médicos vêm desafiando os modelos de treinamento até então vigentes para preparar psicólogos da saúde a responder às novas demandas em pesquisa, prática clínica e políticas públicas.

Segundo Saab e cols. (2004), com os avanços científicos da medicina e aplicação de tecnologias inovadoras de saúde, existem novas fronteiras e oportunidades de estudo contidos numa vasta gama de tópicos de pesquisa que iriam desde o Projeto Genoma Humano até o transplante de órgãos e tecidos, passando pelo estudo cada vez mais refinado de imagens biomédicas. Nesse sentido, esses mesmos autores fizeram menção às potenciais contribuições dos psicólogos da saúde à investigação e à prática clínica, em esferas que mereceram destaque por esse estudo, quais sejam: telesaúde comportamental e informática para a saúde, obtenção de consentimento para transplante de órgãos e tecidos e manejo comportamental em genética.

\subsubsection{Telesaúde comportamental e informática para a saúde}

Telesaúde comportamental e informática para a saúde se refere a todo o tipo de informação em saúde veiculada por meio de recursos de engenharia, tecnologia de informação (TI), serviços de multimídia e telecomunicações de banda larga. Todos esses recursos possibilitam a transferência, cada vez mais rápida de dados, imagens e informações, com a promessa de alcançar pessoas em localidades remotas onde os serviços de saúde fiquem a desejar (Saab et al., 2004) ou que sejam viabilizados mais facilmente por essas plataformas.

Os procedimentos, atualmente em uso, envolvendo cuidados com a saúde de indíviduos e/ou grupos, incluindo ações educativas e de compartilhamento de informações, primariamente nos EUA, incluem programas online (por exemplo, programas de controle de peso, manejo de dor, apoio psicoeducacional para cuidadores 
e cessação do tabagismo), de autoajuda (por exemplo, salas de bate-papo on-line (chats) com pacientes oncológicos), ou mesmo avaliações neuropsicológicas, por exemplo, aumentando a adesão a estratégias metacognitivas como uso de lembretes de compromissos, emails e páginas da web, além de serviços de consultoria para várias pessoas, incluindo crianças em idade escolar, idosos, militares e prisioneiros (neste último caso, apenas nos EUA) (Saab et al, 2004).

Aplicativos para smartphones que dão acesso a profissionais de saúde, no domicílio, para consultas médicas (por ex. Dokter; Doutor já; Docway) ou mesmo a programas sistematizados para controle de peso, controle de hábitos alimentares e orientação de prática regular de exercícios físicos (como MyFitnessPal; Sworkit; InstantHeartRate; VirtuaGym; NutraBem, dentre outros) ou contratação de cuidadores de crianças e/ou idosos (GetNinjas, HomeAngels), que auxiliam nos cuidados aos idosos (Cuidar de Idosos, Elderly Care), já se encontram disponíveis ou em fase de construção no Brasil e em diversos outros países, para uso em aparelhos com sistema operacional Android, iOS ou Windows Phone.

Nessa mesma perspectiva, já existem iniciativas como o Ambulance Drone, ou drone-ambulância, desenvolvido na Delft University of Technology, na Holanda, pelo estudante Alex Monton (Hypeness, 2016). Feito com fibra de carbono, o pequeno avião não-tripulado é equipado com ferramentas básicas de primeiros socorros, como um desfibrilador, materiais para reanimação cardiorrespiratória e medicamentos, que podem ser enviadas, em um minuto, até a equipe de profissionais alcançar o paciente. Por viajar a até $100 \mathrm{~km} / \mathrm{h}$ e em linha reta, o drone consegue chegar em poucos minutos e, enquanto os socorristas estão a caminho, a central pode auxiliar a pessoa solicitante por meio de um sistema de comunicação embutido, orientando o que precisa ser feito e como usar as ferramentas de apoio presentes no equipamento. 
No entanto, no que diz respeito à informatização do conhecimento vinculado aos cuidados em saúde, Smith, Orleans e Jenkins (2004) ressaltam uma série de implicações de ordem prática que devem ser levantadas no que concerne à formação em pesquisa, políticas públicas e educação: as intervenções tradicionais, a exemplo de grupos presenciais com pacientes para melhora da adesão a tratamentos médicos ou mesmo palestras informativas sobre programas de prevenção a contaminação por algum agente biológico, precisam ter sua linguagem traduzida para o formato de intervenções teleguiadas. Uma mesma abordagem técnica, realizada presencialmente, quer seja de cunho psicoeducativo, quer seja de cunho intervencionista, requer adequação de sua linguagem e metodologia para um formato que seja assimilado, remotamente, por meio de plataformas virtuais cujo acesso possa alcançar um público o mais abrangente possível.

Além da busca por essa adequação, o psicólogo da saúde tem ainda o desafio de conduzir estudos que determinem a eficácia de intervenções em telesaúde, em comparação com as referidas intervenções presenciais tradicionais (Saab, et al., 2004).

Outro aspecto que chama a atenção, no que diz respeito à informatização do conhecimento na área de saúde, é que - muito embora a criatividade e a inovação sejam característicos ao universo da TI, possibilitando o surgimento cada vez mais rápido de novos aplicativos muito eficazes - o desafio maior, ainda será o da inclusão digital, uma vez que o intuito primeiro da telesaúde é justamente fazer os conhecimentos em saúde chegarem até as pessoas cujo acesso aos serviços tradicionais seja restrito. Esta parece uma necessidade potencial para países como o Brasil.

No tocante aos conteúdos de saúde disponíveis em plataformas virtuais, também deve ser levada em consideração a preocupação com critérios para a submissão de conteúdo relacionado ao assunto. Dados apontados por Saab et al. (2004) revelam 
que só nos EUA, há mais de 15.000 sites sobre o tema da saúde. Isso propricia que pessoas não capacitadas disponibilizem informações inapropriadas, o que pode gerar demora na busca adequada por tratamento ou equívocos na interpretação de um exame médico, por exemplo. Programas de psicologia da saúde poderiam orientar o usuário de internet a identificar indicadores de sites mais vantajosos ou comportamentos a serem adotados para buscar, analisar e identificar sites de informações relevantes.

No entanto, se bem empregados, são esses mesmos recursos de informática que também poderão organizar e monitorar registros de informações sobre pacientes em prontuários de saúde, para subsidiar pesquisas futuras ou mesmo direcionar pacientes que buscam informações específicas de saúde, a buscarem guias on-line ou comunidades de pacientes, inclusive sendo útil para tomadas de decisão de tratamento, por exemplo (Saab et al., 2004).

\subsubsection{Transplante de Órgãos e Tecidos}

No tocante ao tema do transplante de órgãos e tecidos, os autores destacaram o inegável progresso das técnicas cirúrgicas, estratégias de preservação de órgãos, e métodos melhorados para diminuição de rejeição de enxerto, incluindo avanços em testes de histocompatibilidade e tolerância imunológica. No entanto, embora se reconheça a larga aplicabilidade desse tipo de intervenção para um crescente número de doenças bastante devastadoras, ainda há uma grande disparidade entre a gama de doadores compatíveis disponíveis e a demanda pela substituição de órgãos ou tecidos (Saab e cols., 2004).

Em que pese essa escassez de doadores disponíveis, a literatura clínica nessa área sugere que sejam abordados aspectos psicossociais em torno dos indivíduos envolvidos, tanto no sentido de delinear estratégias que maximizem a sobrevida do 
paciente que aguarda um novo órgão ou tecido, quanto no desenvolvimento e refinamento de métodos de avaliação, triagem, e tomada de decisão em torno da doação.

Quando identificaram esse panorama, em 2004, Saab e colaboradores, destacaram que pouco se sabia sobre os fatores que influenciavam as decisões ou os efeitos em torno da doação na saúde e no bem-estar do doador. A vulnerabilidade a riscos médicos em torno dos doadores vivos, desde aquela época, parecia ser mais reconhecida no seio científico, do que em relação aos riscos psicossociais.

Nesse sentido, um objetivo central da pesquisa em psicologia da saúde deveria ser a criação de uma base de conhecimento sobre os efeitos da doação de órgãos e tecidos sobre o bem-estar físico e emocional dos doadores, tais como investigação de características e motivações dos doadores bem como potenciais influências e efeitos sobre os receptores.

Embora já existam alguns dados normativos disponíveis relacionados a medidas psicossociais para candidatos a transplante (Streisand et al., 1999 apud Saab et al., 2004), existe uma variabilidade considerável entre os programas de transplante no que diz respeito às medidas utilizadas e aos domínios avaliados. Além disso, faz-se necessário discutir a confiabilidade e a validade dos fatores psicossociais específicos na determinação de quem deve ou não deve receber um órgão. Nesse quesito, os estudiosos apontam que os psicólogos da saúde estão bem adaptados para abordar esses aspectos. Contudo, o desafio adicional seria desenvolver e implementar protocolos de avaliação psicossocial empiricamente validados que subsidiassem diretrizes para a criação de recomendações clínicas que alcançassem as equipes multidisciplinares de tratamento.

Em face a esse cenário, programas de educação e formação adequados devem ser delineados com o objetivo de aumentar a presença de psicólogos da saúde em programas de transplante. Uma estratégia para isso, seria, mais uma vez, o investimento 
em treinamento de colegas da equipe, sobretudo médicos, sobre o papel dos psicólogos da saúde, demonstrando os resultados objetivos da atuação desse profissional em todas as etapas do processo de doação.

\subsubsection{Estudos em Genética Humana}

À medida que o trabalho do Projeto Genoma Humano progride e testes genéticos vão se expandindo, mais indivíduos serão cada vez mais expostos a informações sobre a sua suscetibilidade a várias doenças que têm componente genético. Embora os testes preditivos disponíveis à época da publicação do volume especial do JHP fossem destinados a indivíduos com alto risco para certas doenças (por exemplo, indivíduos com história familiar de câncer de mama e doença de Huntington), estimava-se que, dentro de 10 anos, cerca de 12 testes estariam disponíveis para condições médicas comuns, sugerindo que a genética se tornaria uma parte da medicina geral num futuro próximo.

Até o início do século XXI, pouca pesquisa havia sido feita em relação ao efeito psicossocial destes resultados sobre os indivíduos, suas famílias e na sociedade em geral. Ainda menos se sabia sobre os efeitos desses resultados sobre comportamentos de saúde, estratégias de prevenção e delinamento de políticas públicas. Além disso, os avanços associados a mapeamentos genéticos levantavam preocupações sobre o uso potencialmente indevido de informações genéticas (como, por exemplo, para a adoção de critérios na aquisição de seguros, como seguro de vida ou plano de saúde).

É essencial que os indivíduos que optem pela submissão a testes genéticos sejam adequadamente informados quanto ao entendimento acerca das consequências desses testes, que sejam assistidos na tomada de decisões, recebam apoio ao enfrentamento e suporte à compreensão do significado de resultados positivos e negativos (Lerman, 
Croyle, Tercyak, \& Hamann, 2002 apud Saab e cols., 2004). Nesse sentido, o psicólogo da saúde detém as habilidades e competências que serviriam de instrumental clínico para o adequado cumprimento desses objetivos. Desse modo, são necessárias estratégias de colaboração entre os psicólogos da saúde, médicos e demais profissionais envolvidos e todas as etapas do processo de aconselhamento genético.

Estudos ainda citados por Saab e cols. (2004), sugeriram que pessoas que recebem um resultado negativo de um teste genético são menos propensas a se envolverem em comportamentos de prevenção em saúde, contribuindo para aumento do risco de vida, ao passo que aqueles que recebem um resultado positivo, podem se sentir como se não houvesse nenhuma necessidade de se engajar em comportamentos preventivos ou se esforçarem por manter um estilo de vida saudável.

Outras pesquisas citadas por estes mesmos autores, sugerem que terapias com abordagens cognitivo-comportamental se mostram eficazes em aliviar o sofrimento associado com os resultados de testes genéticos e contribuem para a modificação de pensamentos distorcidos sobre a testagem (Salkovskis \& Rimes, 1997 apud Saab e cols., 2004). Além disso, é importante ressaltar que muitas doenças não são causadas por um único gene (a exemplo das doenças coronarianas), mas sim, resultam da interação entre um componente genético e múltiplos fatores de estilo de vida. Dessa maneira, os psicólogos da saúde estariam aptos a ajudar as pessoas na adoção de hábitos de vida saudáveis, na redução de comportamentos de risco, apoiando mudanças comportamentais e favorecendo, inclusive, a deteção precoce de certas doenças.

Para tanto, os psicólogos da saúde precisariam ser incluídos como membros das equipes multidisciplinares que estudam indivíduos em risco genético. Fazem-se necessários estudos que correlacionem a compreensão das informações de risco genético dos pacientes e seu impacto psicológico, comportamental e social sobre a 
tomada de decisão para mudanças comportamentais. Também é vital avaliar como a tomada de decisão é afetada por variáveis sociodemográficas e fatores culturais.

\section{2) O (novo) futuro das intervenções em Psicologia da Saúde}

Ao se discutir para onde o futuro das intervenções em psicologia da saúde vinha apontando, há doze anos, Nicassio, Meyerowitz e Kerns (2004) acrescentaram o destaque à necessidade de novas intervenções em nível de atenção secundária e terciária, tais como: (a) propostas para o manejo de doenças crônicas ou que ameaçam a vida (como diabetes, atrite reumatóide ou câncer); (b) intervenções voltadas ao tratamento de desordens psicofisiológicas, como hipertensão, síndrome do intestino irritável, cefaléia tensional e insônia; (c) intervenções que forneçam cuidados complementares ou tratamentos adjuvantes a pacientes com sintomas médicos refratários (como dor, por exemplo) e comorbidades psicológicas como ansiedade e depressão; e, por último, (d) intervenções em pacientes em preparo pré-cirúrgico e outros procedimentos médicos potencialmente estressantes. Essas intervenções, discutidas pelos autores, contemplaram uma série de objetivos, que variavam desde a redução do estresse e melhora da qualidade de vida, até o fornecimento de suporte (social, emocional, operacional) e reforço do sistema imunológico, passando por estratégias sobre como fomentar a adesão a recomendações da equipe médica, redução de incapacidades e aumento da educação e conscientização para a saúde (Nicassio \& cols, 2004).

Já Smith, Orleans e Jenkins (2004) destacaram a necessidade de maior inserção do psicólogo da saúde na atenção básica. Segundo esses autores, atualmente, grande parte da atuação do psicológo da saúde é direcionada para a remediação dos impactos negativos de doenças, condições adversas em saúde e seus respectivos tratamentos. No 
entanto, forçosa é a presença do psicólogo também no nível primário de atenção à saúde, endossando esforços para impedir que estes impactos predominantes e dispendiosos venham a ocorrer. Neste e em outros exemplos de prevenção e promoção da saúde comportamental, a inserção do psicológo subsidiaria inclusive atendimentos coletivos ou em grandes grupos, em substituição às abordagens individuais tradicionais e em serviços clínicos de pequenos grupos.

Essa perspectiva exige também o desenvolvimento e a expansão de parcerias com outras profissões na área da saúde, cabendo aos psicólogos da saúde o desafio de estarem envolvidos no desenvolvimento de intervenções e coordenando sua execução, ao invés de ocupar o tradicional papel de prestador direto de serviços. O desenvolvimento e implementação de intervenções para dimensões essenciais de risco psicossocial e resiliência também poderia levar a avanços importantes em direção a práticas mais globais e integradas no âmbito da prevenção.

Analisando os avanços nessa área e buscando antever o novo futuro para pesquisa, aplicações clínicas e políticas públicas, além de subsidiar a formação educacional e o treinamento de novos profissionais, alguns princípios e temas são destacados, a seguir, em diferentes campos de aplicação.

\subsection{1) Pesquisa}

Ao longo dos 25 anos anteriores à publicação do volume especial do JHP, os estudiosos da área de psicologia da saúde fizeram grandes descobertas identificando os primeiras preocupações e necessidades associadas com doenças crônicas e com sintomas médicos refratários a intervenções médicas e, também, desenvolvendo intrumentos de avaliação padronizados válidos e confiáveis para mensuração de resultados clínicos em indivíduos, incluindo diferentes culturas. 
Os psicólogos da saúde também foram bem sucedidos na tarefa de adaptarem tratamentos psicológicos a serem aplicados no domínio dos cuidados em saúde, incluindo intervenções psicoeducativas, em suporte social, mudanças comportamentais, redução de estresse, expressão e auto-regulação emocional. Grande parte dessas intervenções envolveram abordagens comportamentais, cognitivo-comportamentais ou de biofeedback, para tratamento de sintomas e incapacidades associadas a condições adversas, tais como cefaléias, doença reumática, dor lombar e outras condições dolorosas.

$\mathrm{Na}$ maior parte dessas investigações, as pesquisas examinam como os indivíduos respondem aos tratamentos de acordo com gênero, idade e diversidade etnico-racial. Nesse último aspecto, atenção especial tem sido dada a estudos de diversidade sociodemográfica e cultural.

Como desdobramento dessa evolução, na investigação de diferenças individuais relevantes, Nicassio e cols. (2004) sugerem abordagens que transcendam as variáveis genéricas já mencionadas e abranjam tempo de duração da doença, arcabouço cultural, e variáveis disposicionais como depressão e otimismo, por exemplo. Para esses autores, essas variáveis são, provavelmente, mais relevantes para serem consideradas como preditoras de resultados no desenvolvimento e implementação de intervenções, bem como no refinamento e aprimoramento de ferramentas de avaliação.

Métodos estatísticos e delineamentos de pesquisa sofisticados, que reconheçam toda essa complexidade dos contextos do mundo real, também devem ser considerados.

\subsection{2) Aplicações clínicas e nas políticas públicas}

Intervenções em psicologia da saúde devem, também, alcançar as populações 
clínicas afetadas para as quais foram designadas a atingir. No entanto, nem sempre há uma efetiva aplicação dessas intervenções de saúde em situações clínicas. De acordo com Nicassio e colaboradores (2004), essa limitação sofre a influência dos seguintes fatores: (a) falta de entendimento, por parte dos pesquisadores, no que diz respeito à aplicabilidade clínica e a relevância das intervenções por eles delineadas; (b) falta de vontade ou relutância, principalmente de médicos, em aceitar o valor efetivo das intervenções, ou ainda, falta de treinamento profissional, e (c) várias barreiras institucionais, como restrições de tempo, falta de pessoal apropriado, para conduzir as intervenções ou limitações de fomento e reembolso financeiro.

Ainda de acordo com Nicassio e cols. (2004), como parte do desafio de se implementar, efetivamente, as intervenções em psicologia da saúde em situações clínicas, os autores advogam por uma visão na qual a prática clínica e o desenvolvimento de políticas públicas relacionadas a essas intervenções sejam considerados conjuntamente, por toda a equipe de saúde, uma vez que as associações entre essas mesmas práticas são indissociáveis de questões de cunho político, como acesso a serviços, direitos humanos, gestão em saúde, reembolsos, dentre outros.

\subsection{3) Formação educacional e treinamento profissional}

Grande parte das iniciativas em formação educacional e em treinamento profissional deve promover uma consciência da natureza, disponibilidade e efetividade das intervenções psicológicas direcionadas a equipes profissionais e ao público em geral. Equipes de saúde, primariamente, incluem psicólogos, médicos, epidemiologistas, professores, assistentes sociais, enfermeiros e outros, além dos próprios usuários de saúde e seus cuidadores. Nesse contexto, a própria identidade profissional do psicólogo da saúde, passa a ser reformulada, deixando de ser vista como uma profissão de saúde 
mental para uma profissão de cuidados em saúde, podendo, inclusive o psicólogo da saúde servir como cuidador primário da saúde, atendendo primeiramente na "porta de entrada" de qualquer sistema de saúde, e referenciando o paciente, em seguida, aos demais profissionais, quando indicado, inclusive aos médicos (Tovian, 2004).

Esse fluxograma, que subverteria completamente a lógica atualmente vigente, atenderia adequadamente aos desafios impostos pelo novo sistema de saúde, por fornecimento efetivo de serviços de cuidados em saúde a um custo financeiro e operacional mais barato possível, respondendo às demandas de prestação responsável de contas, ênfase na prevenção, educação para a saúde e auto-responsabilidade do indíviduo para com a própria saúde.

Sendo assim, com o advento cada vez mais disseminado da internet e de recursos tecnológicos de informática, a interface entre os já mencionados avanços no sistema de saúde, com o desenvolvimento de novas formas de aquisição de informação, formação educacional e aprimoramento profissional, torna-se indispensável a disponibilização de plataformas educacionais voltadas para os cuidados em saúde, tanto para refinamento das habilidades de todos os profissionais de saúde como para o empoderamento de pacientes, familiares e cuidadores. 


\section{CAPÍTULO 4 \\ DELINEAMENTO DE PESQUISA}

Neste capítulo, são explicitados os objetivos gerais da presente pesquisa, bem como os procedimentos de coleta e análise de dados. Trata-se de um estudo de caráter descritivo-crítico e exploratório.

\subsection{Objetivos gerais}

(1) Descrever o perfil da produção bibliográfica, de dissertações de mestrado e teses de doutorado, defendidas entre janeiro de 2011 e agosto de 2015, orientadas por docentes da área de Psicologia da Saúde, do Instituto de Psicologia, da Universidade de Brasília, e compará-lo, criticamente, com as diretrizes de criação da divisão de Psicologia da Saúde, pela American Psychological Association (APA), e diretrizes (então futuras, publicadas no ano de 2004) da área de Psicologia da Saúde, em número especial do Journal of Health Psychology (JHP).

(2) Fornecer subsídios à construção de um perfil de objetos e temas de estudo a serem investigados pela área de Psicologia da Saúde da UnB e de outros centros de ensino e pesquisa brasileiros.

\subsection{Método}

\subsubsection{Material}

Com vistas a identificar um volume significativo de trabalhos a serem analisados, foi realizada busca por produções bibliográficas, no formato de dissertações de mestrado e teses de doutorado, relacionadas à área de Psicologia da Saúde, da UnB. Para tanto, o critério de busca incluiu trabalhos concluídos e orientados por docentes do quadro permanente de pessoal da Fundação Universidade de Brasília (FUB) e vinculados ao Instituto de Psicologia (IP). 
As buscas se referiram ao período cronológico de janeiro de 2011 a dezembro de 2015, disponível no Repositório Institucional (RIUnB) de teses e dissertações da Biblioteca Central (BCE), da UnB.

O Repositório Institucional da UnB é um conjunto de serviços oferecidos pela BCE, para a gestão e disseminação da produção científica e acadêmica da própria Instituição. Todos os seus conteúdos estão disponíveis publicamente e na íntegra, e, por estarem amplamente acessíveis, em formato digital, proporcionam maior visibilidade e impacto da produção científica da Universidade.

Foram identificados quarenta trabalhos, dos quais vinte e cinco dissertações de mestrado e quinze teses de doutoramento. A distribuição, por data e tipo de trabalho, está ilustrada na Tabela 1.

Tabela 1. Distribuição de trabalhos produzidos pela área de Psicologia da Saúde, do IP/UnB (dez/2011 a ago/2015).

\begin{tabular}{cccccc}
\hline Trabalho/Ano & $\mathbf{2 0 1 1}$ & $\mathbf{2 0 1 2}$ & $\mathbf{2 0 1 3}$ & $\mathbf{2 0 1 4}$ & $\mathbf{2 0 1 5}$ \\
\hline Dissertações de Mestrado & 5 & 6 & 11 & 3 & 0 \\
Teses de Doutorado & 2 & 4 & 3 & 5 & 1 \\
Total de trabalhos por ano & $\mathbf{7}$ & $\mathbf{1 0}$ & $\mathbf{1 4}$ & $\mathbf{8}$ & $\mathbf{1}$ \\
\hline Total & & $\mathbf{4 0}$ & \\
\hline
\end{tabular}

As teses e dissertações foram orientadas por quatro docentes da UnB, os quais são graduados em Psicologia e portadores do título de Doutor, com ampla experiência profissional e em docência universitária na área de Psicologia da Saúde. Cada docente é identificado, neste trabalho, a partir de seus nomes de publicação acadêmica. A Figura 01 identifica o percentual de teses e dissertações orientadas por cada um dos docentes. 
Figura 1. Distribuição de trabalhos orientados no período de Jan/2011 a Ago/2015 por cada docente da área de Psicologia da Saúde

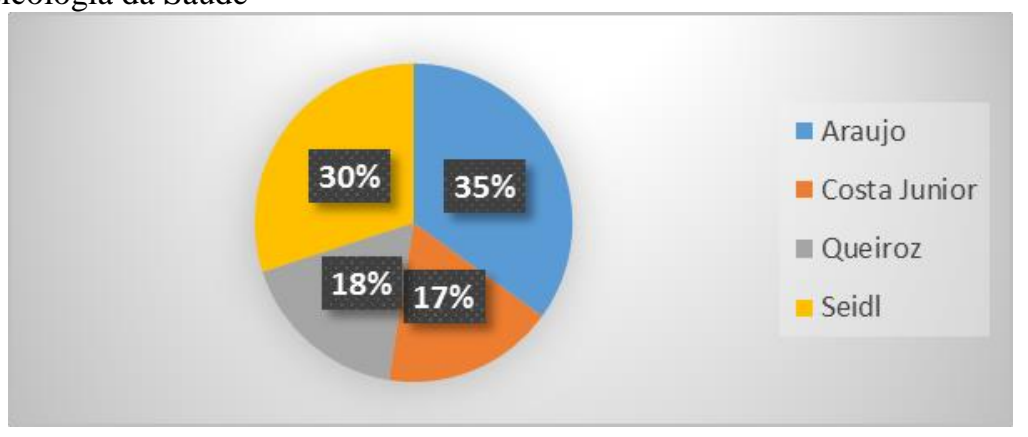

A tabela 2 relaciona a amostra analisada de trabalhos publicados no período

selecionado.

Tabela 2. Relação de trabalhos analisados publicados de 2011 a 2015 pelo IP/UnB registrados no Repositório Institucional da BCE/UnB

\begin{tabular}{|c|c|c|c|c|c|}
\hline $\mathbf{N}$ & Autor (a) & Trabalhos analisados & Ano & Orientador (a) & Nível \\
\hline 1 & Abreu-Rodrigues, $\mathrm{M}$. & $\begin{array}{l}\text { Apoio social e reganho de peso pós cirurgia bariátrica: } \\
\text { efeitos de intervenção comportamental com cuidadores }\end{array}$ & 2014 & Seidl, E.M.F. & $\mathrm{D}$ \\
\hline 2 & Andrade, T.L. & $\begin{array}{l}\text { Internação domiciliar: perfil de pacientes com acidente } \\
\text { vascular cerebral e seus cuidadores }\end{array}$ & 2014 & Queiroz, E. & $\mathrm{M}$ \\
\hline 3 & Assunção, G.S. & $\begin{array}{l}\text { Relação profissional de saúde-paciente: avaliação de uma } \\
\text { intervenção com estudantes da área de saúde }\end{array}$ & 2013 & Queiroz, E. & $\mathrm{M}$ \\
\hline 4 & Bergerot, C.D. & $\begin{array}{l}\text { Avaliação de Distress para identificação de fatores de risco } \\
\text { e proteçãona experiência oncológica: contribuições para } \\
\text { estruturação de rotinas e programas em Psico-Oncologia }\end{array}$ & 2013 & Araujo, T.C.C.F. & $\mathrm{D}$ \\
\hline 5 & Bernardes, L.C.G. & $\begin{array}{l}\text { Bioética, deficiência e políticas públicas: percepção de } \\
\text { gestores públicos e defensores de direitos }\end{array}$ & 2011 & Araujo, T.C.C.F. & $\mathrm{M}$ \\
\hline 6 & Birck, M.D. & $\begin{array}{l}\text { Crianças e adolescentes sobreviventes de câncer: análise de } \\
\text { estressores }\end{array}$ & 2013 & Costa Junior, A. L. & $\mathrm{M}$ \\
\hline 7 & Braga, F.C. & $\begin{array}{l}\text { Cuidados Paliativos em Unidade de Terapia Intensiva } \\
\text { Neonatal: práticas e percepções dos profissionais de saúde }\end{array}$ & 2013 & Queiroz, E. & $\mathrm{M}$ \\
\hline 8 & Coelho, M.G. & $\begin{array}{l}\text { A relação criança queimada e cuidador e a vivência da } \\
\text { queimadura }\end{array}$ & 2013 & Queiroz, E. & $\mathrm{M}$ \\
\hline 9 & Coutinho, S.M.G. & $\begin{array}{l}\text { Comunicação médico-paciente em onco-hematologia } \\
\text { pediátrica: efeitos de um procedimento de intervenção } \\
\text { psicológica }\end{array}$ & 2013 & Costa Junior, A.L. & $\mathrm{D}$ \\
\hline 10 & Cristo, L.M.O. & $\begin{array}{l}\text { Comunicação em Saúde da criança: desenvolvimento e } \\
\text { avaliação de um sistema de análise interacional para } \\
\text { consultas pediátricas }\end{array}$ & 2014 & Araujo, T.C.C.F. & $\mathrm{D}$ \\
\hline 11 & Dias, C.V. & $\begin{array}{l}\text { Percepções de estudantes sobre comunicação em saúde: } \\
\text { implicações para a atuação profissional }\end{array}$ & 2011 & Queiroz, E. & $\mathrm{M}$ \\
\hline 12 & Doca, F.N.P. & $\begin{array}{l}\text { A dor pediátrica no contexto de internação em hospitais } \\
\text { públicos do DF }\end{array}$ & 2014 & Costa Junior, A.L. & $\mathrm{D}$ \\
\hline 13 & Duarte, A.N. & $\begin{array}{l}\text { Avaliação de grupo de educação nutricional pra mulheres } \\
\text { com excesso de peso }\end{array}$ & 2012 & Queiroz, E. & $\mathrm{M}$ \\
\hline 14 & Estavela, A.J. & $\begin{array}{l}\text { Vulnerabilidade de gênero e infecção pelo HIV: percepção } \\
\text { de pessoas vivendo com HIV/Aids e profissionais de saúde } \\
\text { da cidade de Maputo, Moçambique }\end{array}$ & 2014 & Seidl, E.M.F. & $\mathrm{D}$ \\
\hline 15 & Flesch, L.D. & $\begin{array}{l}\text { Pacientes Idosos e seus cuidadores: um estudo específico } \\
\text { sobre a alta hospitalar }\end{array}$ & 2013 & Araujo, T.C.C.F. & $\mathrm{M}$ \\
\hline 16 & Franco, T.N.R. & $\begin{array}{l}\text { Análise bioética do processo de autorização de doação } \\
\text { intervivos não relacionados no Brasil }\end{array}$ & 2015 & Araujo, T.C.C.F. & $\mathrm{D}$ \\
\hline
\end{tabular}




\begin{tabular}{|c|c|c|c|c|c|}
\hline 17 & Gobatto, C.A. & $\begin{array}{l}\text { Religiosidade e Espiritualidade em oncologia: um estudo } \\
\text { sobre as concepções de profissionais de saúde }\end{array}$ & 2012 & Araujo, T.C.C.F. & $\mathrm{M}$ \\
\hline 18 & Gonzalez, L.M.B. & $\begin{array}{l}\text { Efeitos de intervenção psicoeducativa voltada para o } \\
\text { autocuidado de homens idosos }\end{array}$ & 2011 & Seidl, E.M.F. & $\mathrm{D}$ \\
\hline 19 & Guimarães, T.B. & $\begin{array}{l}\text { Intervenção psicoeducativa em oncologia: um estudo sobre } \\
\text { uso de site com jogos eletrônicos }\end{array}$ & 2012 & Araujo, T.C.C.F. & $\mathrm{M}$ \\
\hline 20 & Jácome, M.Q.D. & $\begin{array}{l}\text { Análise dos comitês de ética em pesquisa do Brasil: } \\
\text { percepção de seus coordenadores e membros }\end{array}$ & 2013 & Araujo, T.C.C.F. & $\mathrm{D}$ \\
\hline 21 & Kohlsdorf, M. & $\begin{array}{l}\text { Proposta de pré-consulta comportamental: análise da } \\
\text { comunicação médico-cuidador-paciente em onco- } \\
\text { hematologia pediátrica }\end{array}$ & 2012 & Costa Junior, A.L. & $\mathrm{D}$ \\
\hline 22 & Kunzler, L.S. & $\begin{array}{l}\text { Pense saudável: contribuições da Terapia Cognitiva para } \\
\text { promoção de saúde e incremento da qualidade de vida }\end{array}$ & 2011 & Araujo, T.C.C.F. & $\mathrm{M}$ \\
\hline 23 & Lima, H.S. & $\begin{array}{l}\text { Consultório na Rua em Goiânia: atenção a pessoas em } \\
\text { situação de rua e em uso de substâncias psicoativas }\end{array}$ & 2013 & Seidl, E.M.F. & $\mathrm{M}$ \\
\hline 24 & Lira, N.P.M. & $\begin{array}{l}\text { Mulheres em braquiterapia para câncer de colo do útero: } \\
\text { uma proposta de intervenção psicoeducativa }\end{array}$ & 2013 & Queiroz, E. & $\mathrm{M}$ \\
\hline 25 & Maia, T.M.S. & $\begin{array}{l}\text { Castração Química como pena, tratamento médico ou } \\
\text { experimento científico em casos de pedofilia: } \\
\text { considerações bioéticas }\end{array}$ & 2014 & Seidl, E.M.F. & $\mathrm{M}$ \\
\hline 26 & Mensório, M.S. & $\begin{array}{l}\text { Análise de estratégias de enfrentamento, ansiedade e } \\
\text { hábitos em pacientes elegíveis à cirurgia bariátrica }\end{array}$ & 2013 & Costa Junior, A.L. & $\mathrm{M}$ \\
\hline 27 & Naves, J.F. & $\begin{array}{l}\text { Avaliação de Qualidade de vida e bem-estar subjetivo em } \\
\text { Oncologia: uma investigação com sobreviventes de câncer } \\
\text { ósseo }\end{array}$ & 2013 & Araujo, T.C.C.F. & $\mathrm{M}$ \\
\hline 28 & Nogueira, G.S. & $\begin{array}{l}\text { Adaptação e validação do Brief Illness Perception } \\
\text { Questionnaire para a cultura brasileira }\end{array}$ & 2012 & Seidl, E.M.F. & $\mathrm{M}$ \\
\hline 29 & Rodrigues, M.P.C. & $\begin{array}{l}\text { Reabilitação de pessoas com lesão medular: relevância, } \\
\text { aplicações e desafios relacionados ao uso da internet }\end{array}$ & 2011 & Araujo. T.C.C.F. & $\mathrm{M}$ \\
\hline 30 & Salles, C.M.B. & $\begin{array}{l}\text { Efeitos de intervenção psicológica sobre a adesão ao } \\
\text { tratamento antirretroviral em adolescentes com HIV/Aids }\end{array}$ & 2011 & Seidl, E.M.F. & $\mathrm{D}$ \\
\hline 31 & Sanches, K.M.S. & Ortotanásia: uma decisão frente à terminalidade & 2012 & Seidl, E.M.F. & $\mathrm{M}$ \\
\hline 32 & Santos, F.B. & $\begin{array}{l}\text { Abandono do tratamento antirretroviral e busca consentida } \\
\text { de casos de pessoas vivendo com HIV/Aids }\end{array}$ & 2011 & Seidl, E.M.F. & $\mathrm{M}$ \\
\hline 33 & Sousa, V.F.S. & $\begin{array}{l}\text { Risco e Proteção na atuação em saúde: um estudo sobre } \\
\text { estresse e resiliência entre profissionais }\end{array}$ & 2014 & Araujo, T.C.C.F. & M \\
\hline 34 & Souza, J.R. & $\begin{array}{l}\text { Indicador de Risco Psicológico em Oncologia (IRPO): } \\
\text { construção e validação de um instrumento de triagem para } \\
\text { pacientes com câncer }\end{array}$ & 2014 & Seidl, E.M.F. & $\mathrm{D}$ \\
\hline 35 & Spehar, M.C. & $\begin{array}{l}\text { Mães de bebês prematuros no Método Canguru: aspectos } \\
\text { psicossociais, enfrentamento e autoeficácia }\end{array}$ & 2013 & Seidl, E.M.F. & $\mathrm{M}$ \\
\hline 36 & Staliano, $\mathrm{P}$. & $\begin{array}{l}\text { Promoção e comunicação em saúde: um estudo sobre a } \\
\text { atuação dos agentes comunitários }\end{array}$ & 2012 & Araujo, T.C.C.F. & $\mathrm{D}$ \\
\hline 37 & Tostes, N.A. & $\begin{array}{l}\text { Percepção de gestantes acerca da assistência pré-natal, seus } \\
\text { sentimentos e expectativas quanto ao preparo para o parto }\end{array}$ & 2012 & Seidl, E.M.F. & $\mathrm{M}$ \\
\hline 38 & Turra, V. & $\begin{array}{l}\text { Protocolo de Atendimento Psicológico em saúde Orientado } \\
\text { para o Problema (PAPO): proposta para internação } \\
\text { cirúrgica }\end{array}$ & 2012 & Costa Junior, A.L. & $\mathrm{D}$ \\
\hline 39 & Vera, R.S. & $\begin{array}{l}\text { Resiliência, Enfrentamento e Qualidade de Vida em } \\
\text { indivíduos com lesão medular }\end{array}$ & 2012 & Araujo, T.C.C.F. & $\mathrm{D}$ \\
\hline & Xavier, G.M. & $\begin{array}{l}\text { A formação do cirurgião-dentista no contexto do SUS: uma } \\
\text { avaliaçâo do ensino de Odontologia }\end{array}$ & 2013 & Costa Junior, A.L. & $\mathrm{M}$ \\
\hline
\end{tabular}

\subsubsection{Procedimentos de coleta de dados}

Foi efetuado download, em formato PDF (Portable Document Format, em português, Formato Portátil de Documento), de cada um dos trabalhos, teses e dissertações, no microcomputador pessoal da pesquisadora e em dispositivo móvel do 
tipo $e$-reader, da marca Kindle (fabricante Amazon).

Todos os trabalhos foram lidos, na íntegra, e os dados relevantes para análise foram catalogados e classificados em fichas geradas pela pesquisadora (Anexo 1).

\subsubsection{Procedimento de análise dos dados}

Para adequação às categorias de análise, tais como os temas dos estudos, foram consideradas as palavras-chave/descritores, mencionados pelos próprios autores dos trabalhos, de maneira literal, como constavam redigidos na estrutura de resumos dos estudos. Nas demais categorias, tais como de métodos empregados e de participantes de pesquisa, foram considerados os objetivos referidos pelos pesquisadores na seção correspondente. 


\section{CAPÍTULO 5 \\ RESULTADOS}

Neste capítulo, são apresentados os resultados obtidos a partir da leitura e análise descritiva e crítica dos quarenta trabalhos, no formato de teses e dissertações, produzidos nos últimos cinco anos, pela área de Psicologia da Saúde do IP/UnB.

A leitura e análise dos trabalhos permitiu sintetizar os dados dos estudos em categorias e, assim, traçar um panorama de interesses, características e tipos de pesquisas desenvolvidas pela área de Psicologia da Saúde. Os trabalhos foram classificados, inicialmente, por período de publicação, por docente orientador e, em seguida, pelas categorias "temas abordados pelos trabalhos", "métodos de pesquisa empregados" e "participantes de pesquisa ou fonte de dados". Posteriormente, os objetivos gerais dos estudos e os principais resultados foram descritos e analisados de maneira crítica.

As classificações, por ano de publicação e por docente orientador, encontram-se descritas no item "Material”, da seção de Delineamento do estudo, no capítulo anterior. As demais classificações seguem detalhadas nesta Seção.

\subsection{Temas abordados pelos trabalhos}

Para definição da categoria "Temas" utilizou-se, como critério, as palavraschave referidas pelos próprios autores dos trabalhos. Os temas identificados foram descritos com as dezesseis seguintes subcategorias: Adesão ao Tratamento, Apoio Social, Bioética, Comunicação em Saúde, Condição de saúde ou patologia, Cuidados de atenção à saúde, Curso de Vida, Formação profissional em saúde, Gênero, Intervenção profissional em saúde, Qualidade de vida, Odontologia, Oncologia, Processos de Adaptação, Processos de morte e morrer e Recursos tecnológicos, que são discriminados a seguir. 
Palavras-chave semelhantes, e/ou relacionadas funcionalmente, foram agrupadas, como no caso do tema Comunicação em Saúde, por exemplo, que abarcou estudos cujos descritores mencionaram qualquer aspecto comunicativo envolvido, tais como os referidos pelas palavras-chave comunicação, avaliação da comunicação e relação profissional de saúde-paciente (Dias, 2011; Guimarães, 2012; Staliano, 2012; Assunção, 2013; Coutinho, 2013; Kohlsdorf, 2013; Cristo, 2014).

Alguns temas receberam nomes diferentes dos termos referidos originalmente, nas palavras-chave, por serem mais abrangentes e/ou por representarem, de maneira mais ampla, o escopo dos trabalhos. Foi o caso do tema Cuidados de atenção à saúde, por exemplo, que abrangeu descritores de promoção da saúde, prevenção de doenças, perfil do cuidador e outras palavras-chave que se referiam a indicadores de saúde coletiva, atenção primária em saúde e/ou que configurassem algum tipo de orientação e/ou conduta visando cuidado, proteção ou conforto para melhoria do bem-estar físico, psicológico e/ou social de indivíduos e/ou grupos (Kunzler, 2011; Nogueira, 2012; Tostes, 2012; Turra, 2012; Flesch, 2013; Andrade, 2014; Doca, 2014; Sousa, 2014).

No tema Condição de Saúde ou Patologia, optou-se por denominar de 'condição de saúde', toda e qualquer alteração de estado funcional típico do indivíduo e/ou que o colocasse em situação desfavorável/adversa, mas que não se caracterizasse, necessariamente, como uma doença. Alguns exemplos podem ser um quadro de dor sem etiologia definida ou mesmo situações que descrevessem pessoas que experimentam algum tipo de dificuldade relacionada à saúde, como sobrevivência, prematuridade, vulnerabilidade e pessoas em situação de rua. Nessa mesma categoria foram também arrolados os descritores que se referiam a patologias propriamente ditas, como HIV/Aids, câncer de colo do útero, pedofilia, lesão medular e acidente vascular cerebral (Rodrigues, 2011; Salles, 2011; Santos, 2011; Duarte, 2012; Vera, 2012; Lira, 2013; 
Mensorio, 2013; Naves, 2013; Santos, 2013; Spehar, 2013; Maia, 2014).

A Tabela 3 descreve os dezesseis temas derivados da análise dos quarenta trabalhos.

Tabela 3. Distribuição de trabalhos por temas, conforme a ocorrência de palavras-chave/descritores.

Temas abordados pelos trabalhos

Total de trabalhos

\begin{tabular}{llc}
\hline 1 & Adesão ao tratamento & 1 \\
\hline 2 & Apoio social & 1 \\
\hline 3 & Bioética & 5 \\
\hline 4 & Comunicação em saúde & 7 \\
\hline 5 & Condição de saúde ou patologia & 19 \\
\hline 6 & Cuidados de atenção à saúde & 11 \\
\hline 7 & Curso de vida & 7 \\
\hline 8 & Formação profissional em saúde & 3 \\
\hline 9 & Gênero & 2 \\
\hline 10 & Intervenção profissional em saúde & 18 \\
\hline 11 & Qualidade de vida & 5 \\
\hline 12 & Odontologia & 1 \\
\hline 13 & Oncologia & 9 \\
\hline 14 & Processos de adaptação & 8 \\
\hline 15 & Processos de morte e morrer & 2 \\
\hline 16 & Recursos tecnológicos aplicados à saúde & $\mathbf{1 0 2}$ \\
\hline & Total & \\
\hline
\end{tabular}

O número total de trabalhos (102) ultrapassa a quantidade de trabalhos analisados (40), uma vez que alguns trabalhos abordavam, concomitantemente, mais de um tema, ou um mesmo trabalho apresentava descritores que poderiam estar agrupados em mais de uma temática.

O tema Curso de Vida abrange todos os trabalhos que se relacionavam com as etapas do processo de desenvolvimento humano e que tivessem como destaque a atenção à saúde na infância, na adolescência ou na terceira idade, como no caso dos estudos cujos descritores referidos foram envelhecimento, saúde do idoso, pediatria, preparação para o parto, adolescentes, criança e psicologia pediátrica, por exemplo 
(Gonzalez, 2011; Salles, 2011; Flesch, 2013; Coelho, 2013; Birck, 2013; Cristo, 2014).

Por Processos de adaptação ficaram compreendidos os trabalhos que investigaram quais recursos, de cunho psicológico ou não, diferentes indivíduos e/ou grupos de indivíduos adotam como forma de se adaptarem a condições adversas, como aqueles que estudaram processos de resiliência, ajustamento emocional, estresse e enfrentamento, distress e/ou auto-eficácia (Vera, 2012; Gobatto, 2012; Bergerot, 2013; Spehar, 2013; Mensorio, 2013; Birck, 2013; Sousa, 2014; Souza, 2014).

O tema Intervenção Profissional em Saúde foi o que abrangeu o maior número de descritores/palavras-chave, referindo-se aos trabalhos que descreviam, analisavam ou propunham algum tipo de intervenção de cunho multidisciplinar, com diferentes enfoques profissionais, como os trabalhos que tiveram como descritores os termos: intervenção comportamental, assistência pré-natal, educação nutricional, consultório de rua, castração química, suspensão ou limitação do suporte vital ou cirurgia bariátrica, por exemplo (Gonzalez, 2011; Kunzler, 2011; Salles, 2011; Duarte, 2012; Kohlsdorf, 2012; Sanches, 2012; Tostes, 2012; Santos, 2013; Abreu-Rodrigues, 2014; Maia, 2014).

Alguns temas tiveram um único trabalho como representante, sendo nomeados de acordo com a própria palavra-chave, referida pelo(a) autor(a), como nos casos dos temas: (a) Adesão ao tratamento, cujo trabalho teve o objetivo de analisar os efeitos de uma intervenção psicológica sobre o comportamento de adesão ao tratamento antirretroviral de adolescentes soropositivos com dificuldades de adesão à terapia antirretroviral (TARV) (Salles, 2011) ; (b) Apoio Social, que contou com a produção de uma pesquisa que, notadamente, buscou identificar e compreender as características do suporte social de pacientes bariátricos (Abreu-Rodrigues, 2014) e; (c) Odontologia, cujo trabalho visou analisar as condições atuais de ensino da odontologia no contexto do Sistema Único de Saúde (Xavier, 2013). 
O tema Gênero agrupou trabalhos que se debruçaram sobre algum tipo de investigação a respeito de como homens e mulheres enfrentam doenças diferentemente, ou como estão expostos de maneira particular a fatores de risco e vulnerabilidade a doenças (Gonzalez, 2011; Estavela, 2014).

O tema Oncologia contemplou trabalhos que foram desenvolvidos nessa área de especialidade médica e cujos descritores estavam relacionados com a prática multiprofissional da clínica oncológica, tais como psico-oncologia, oncologia pediátrica, câncer infantil, câncer de colo do útero (Gobatto, 2012; Guimarães, 2012; Kohlsdorf, 2012; Naves, 2013; Birck, 2013; Bergerot, 2013; Coutinho, 2013; Souza, 2014).

Já o tema Formação profissional em saúde abarcou um conjunto de trabalhos que tiveram a preocupação com a formação acadêmica e preparação para atuação de profissionais na área da saúde, por meio da proposição de programas de treinamento e/ou intervenção de cunho pedagógico, voltados a estudantes (Dias, 2011; Assunção, 2013), ou estudo de caráter investigativo voltado a docentes (Xavier, 2013).

Os estudos que tratavam de processos relacionados aos cuidados de fim de vida, tais como aqueles que tiveram os descritores morte, ortotanásia, terminalidade e/ou cuidados paliativos, ficaram agrupados no tema Processos de Morte e Morrer (Sanches, 2012; Braga, 2013).

Já aqueles trabalhos que exploraram assuntos relacionados à ética em pesquisa, bioética, autonomia, avaliação ética, comitês de ética em pesquisa, critérios de avaliação ética, Resolução do Conselho Nacional de Saúde (CNS) Nº 196/96 e/ou legislação de transplante, foram agrupados na subcategoria Bioética (Bernardes, 2011; Sanches, 2012; Jácome, 2013; Maia, 2014; Franco, 2015).

A subcategoria Recursos tecnológicos aplicados à saúde abrangeu estudos que 
se enveredaram pelo universo da tecnologia da informação aplicada à saúde, internet, jogos eletrônicos, prontuários eletrônicos e/ou qualquer outro tipo de sistema tecnológico, que facilitasse e/ou viabilizasse a prestação de serviços e/ou sistemas de avaliação em saúde (Rodrigues, 2011, Santos, 2011; Andrade, 2014).

Por fim, o tema Qualidade de Vida, contemplou pesquisas cujo escopo dizia respeito a fatores que interferem sobre a percepção de qualidade de vida e/ou bem-estar subjetivo de pessoas e/ou grupos de pessoas (Kunzler, 2011; Vera, 2012; Bergerot, 2013; Lira, 2013; Naves, 2013).

\subsection{Métodos de pesquisa empregados}

Para definição da categoria "Métodos de pesquisa", considerar apenas as palavras-chave como critérios não seria suficiente, uma vez que muitos métodos não aparecem listados nos descritores. Dessa forma, também foram contemplados os objetivos gerais apontados pelos estudos, além da descrição da seção Método, relatada no capítulo correspondente de cada trabalho.

No tipo de método nomeado como Análise Documental, apenas um trabalho foi listado (Maia, 2014), designando um estudo cujo propósito foi discutir achados e reflexões extraídos de pesquisas, publicadas na literatura, sobre o tema da castração química como pena, tratamento médico ou experimento científico em pedófilos, analisada à luz da Bioética. Vale ressaltar que na amostra de trabalhos do presente estudo, outras pesquisas também se propuseram a fazer algum tipo de análise documental, seja ela uma revisão sistematizada da literatura, como no caso da dissertação de Tostes (2012), ou por meio de revisão de prontuários de pacientes, como nas dissertações de Santos (2011) e Andrade (2014). No entanto, esses mesmos trabalhos não tiveram a análise documental como objetivo primário, sendo, por isso, 
categorizados em outros tipos de metodologias.

As dissertações e teses categorizadas como Avaliação em Saúde, que corresponderam ao tipo de método com o maior número de trabalhos (23), contemplaram estudos sobre opiniões, relatos de experiências de vida, percepções, concepções, crenças ou quaisquer outros tipos de processos psicológicos ou processos socioculturais subjacentes a pessoas e/ou grupos em cuidados com a saúde. Essa subcategoria abrange, ainda, estudos de fenômenos comportamentais habituais em settings de saúde que se referem a práticas profissionais de trabalhadores da saúde, como descreveu a pesquisa de mestrado conduzida por Gobatto (2012), por exemplo, e a pesquisa de doutorado conduzida por Staliano (2012).

Os estudos que buscaram compreender, ou descrever, como são vivenciados problemas de profissionais de saúde, familiares ou pessoas relacionadas ao tratamento dos pacientes, pela exposição exaustiva e/ou prolongada a variáveis potencialmente estressantes, advindas do convívio com pessoas doentes e/ou incapacitadas, também foram agrupados nessa subcategoria.

A Tabela 4 ilustra a distribuição dos trabalhos por métodos de pesquisa empregados. 
Tabela 4. Distribuição dos trabalhos por métodos de pesquisa empregados.

\begin{tabular}{|c|c|c|}
\hline Métodos de pesquisa & Descrição & Total de trabalhos \\
\hline Análise documental & $\begin{array}{l}\text { Análise teórica e discussão de } \\
\text { artigos e textos sobre assunto } \\
\text { relacionado à saúde }\end{array}$ & 1 \\
\hline \multirow{8}{*}{ Avaliação em saúde } & $\begin{array}{c}\text { Investigação de crenças, } \\
\text { concepções e/ou modos de atuação } \\
\text { de profissionais }\end{array}$ & \multirow{8}{*}{23} \\
\hline & $\begin{array}{c}\text { Análise e/ou caracterização de } \\
\text { percepções de usuários de serviços } \\
\text { de saúde }\end{array}$ & \\
\hline & $\begin{array}{l}\text { Análise de práticas de profissionais } \\
\text { de saúde }\end{array}$ & \\
\hline & $\begin{array}{c}\text { Busca de opiniões de docentes da } \\
\text { área de saúde }\end{array}$ & \\
\hline & $\begin{array}{l}\text { Compreensão de processos } \\
\text { psicológicos }\end{array}$ & \\
\hline & $\begin{array}{l}\text { Comparação de expectativas e } \\
\text { necessidades de uma população }\end{array}$ & \\
\hline & $\begin{array}{l}\text { Descrição de estratégias adotadas } \\
\text { por pacientes }\end{array}$ & \\
\hline & $\begin{array}{l}\text { Descrição de processos ou } \\
\text { procedimentos relacionados à } \\
\text { saúde }\end{array}$ & \\
\hline \multirow{7}{*}{ Intervenção profissional } & $\begin{array}{c}\text { Aplicação de programa } \\
\text { psicopedagógico para estudantes de } \\
\text { cursos da área da saúde }\end{array}$ & \multirow{7}{*}{14} \\
\hline & $\begin{array}{l}\text { Adoção de protocolo de } \\
\text { atendimento }\end{array}$ & \\
\hline & $\begin{array}{c}\text { Proposição de programa educativo } \\
\text { nutricional }\end{array}$ & \\
\hline & $\begin{array}{c}\text { Proposta ou implementação de } \\
\text { intervenção psicológica ou } \\
\text { psicoeducativa em pacientes e/ou } \\
\text { cuidadores }\end{array}$ & \\
\hline & $\begin{array}{c}\text { Proposição de um tipo de } \\
\text { assistência psicosocioeducacional }\end{array}$ & \\
\hline & $\begin{array}{l}\text { Análise de protocolo de } \\
\text { atendimento }\end{array}$ & \\
\hline & $\begin{array}{l}\text { Proposta de sistema de análise } \\
\text { interacional }\end{array}$ & \\
\hline Validação de instrumento & $\begin{array}{l}\text { Adaptação e validação de } \\
\text { instrumentos de pesquisa }\end{array}$ & 2 \\
\hline
\end{tabular}

Já as pesquisas cujo escopo envolveram a proposição, implementação ou 
aplicação de alguma forma de intervenção, atendimento (individual e/ou em grupo), assistência, orientação, oficina ou adoção de protocolo de atendimento, foram abarcadas na subcategoria Intervenção profissional, tal como o trabalho desenvolvido por Turra (2013), que propôs um Protocolo de Atendimento Psicológico em Saúde Orientado para o Problema (PAPO), como uma estrutura prática de assistência psicossocial e educacional voltada para o paciente cirúrgico internado, ou, ainda, como no caso da ferramenta proposta no trabalho de Guimarães (2012), no qual foi elaborada uma intervenção psicoeducativa através de um site na internet contendo um jogo eletrônico para uso de crianças que fossem familiares de pacientes pediátricos oncológicos.

Por fim, no tipo de método Validação de instrumento ficaram agrupados dois trabalhos que tiveram por objetivo a manipulação de instrumentos de pesquisa, tal como fizeram Souza (2014), ao construir e validar o Indicador de Risco Psicológico em Oncologia (IRPO) e, também, Nogueira (2012), que adaptou e validou, para a cultura brasileira, o Brief Illness Perception Questionnaire (Brief-IPQ).

\subsection{Participantes de pesquisa ou Base de dados}

A fim de identificar quais os principais interesses dos trabalhos desenvolvidos pela área de Psicologia da Saúde do IP/UnB foram categorizados, ainda, os tipos de participantes contemplados pelas pesquisas, que estão apresentados na Tabela 5, tendo a quantidade de trabalhos sido superior à quantidade de trabalhos analisados, em virtude de muitas pesquisas contemplarem mais de uma população estudada. 
Tabela 5. Modalidades de participantes, ou base de dados de pesquisa, nos trabalhos selecionados, conforme listados nas palavras-chave.

\begin{tabular}{lc}
\hline Tipos de participantes ou Base de dados & $\begin{array}{c}\text { Total de } \\
\text { trabalhos }\end{array}$ \\
\hline Adultos doentes & 15 \\
\hline Crianças e/ou adolescentes & 6 \\
\hline Cuidadores/familiares/acompanhantes & 6 \\
\hline Docentes na área de saúde & 1 \\
\hline Estudantes de cursos da área de saúde & 2 \\
\hline Gestantes & 1 \\
\hline Idosos & 2 \\
\hline Literatura em saúde (bases de dados) & 1 \\
\hline Mães de bebês prematuros & 1 \\
\hline Membros de Comitês de Ética em Pesquisa & 1 \\
\hline Outros profissionais (juristas, agentes & 3 \\
administrativos, servidores da BCE, gestores & \\
públicos) & 1 \\
\hline Pesquisadores e auxiliares de pesquisa & 12 \\
\hline Profissionais de saúde & 2 \\
\hline Prontuários médicos & 1 \\
\hline Usuários de SPA & $\mathbf{5 5}$ \\
\hline Total &
\end{tabular}

A subcategoria com o maior número de trabalhos foi a de Adultos doentes, que abarcou 15 estudos cujos respondentes corresponderam aos mais variados tipos de pacientes, maiores de 18 anos, de ambos os sexos, com diferentes tipos de diagnósticos ou condições de saúde. Foi o caso do estudo de Duarte (2012), por exemplo, com mulheres obesas participantes de um grupo de educação nutricional e do trabalho de Andrade (2014) cujos participantes foram pacientes com lesão vascular cerebral.

Os trabalhos realizados com Profissionais de Saúde também foram abundantes (12), como no exemplo da dissertação conduzida por Sousa (2014), que visou compreender o processo de resiliência entre profissionais de diferentes categorias atuantes em saúde e a tese de doutoramento de Estavela (2014), com profissionais de saúde sobre a percepção destes acerca da vulnerabilidade de homens e mulheres à 
infecção pelo vírus $H I V$ e questões de gênero na sociedade de Maputo, na República de Moçambique.

Os trabalhos que tiveram a preocupação de compreender, descrever, analisar e/ou caracterizar crenças, relações, interações, percepções ou opiniões de pessoas que acompanham e prestam cuidados a pacientes em tratamentos de saúde, sejam elas familiares ou não, ficaram designados na subcategoria Cuidadores/familiares/acompanhantes, e contou com a produção de seis trabalhos. Exemplos dessa subcategoria são as pesquisas realizadas por Doca (2014), que caracterizou e comparou a percepção de dor de pacientes crianças e adolescentes com as de familiares/acompanhantes e profissionais de saúde médicos e enfermeiros, e também a dissertação de mestrado de Coelho (2013), que analisou a relação entre crianças queimadas e seus cuidadores e como essa relação influencia a experiência de lidar com queimaduras no período de hospitalização e pós-alta.

Os trabalhos que se dedicaram a investir em estudantes de cursos na área da saúde, compreendendo que muitas das práticas profissionais são reflexo da (in)adequada formação acadêmica, ficaram agrupados na subcategoria Estudantes de cursos na área de saúde, tais como as pesquisas de Assunção (2013), que ofereceu uma oficina psicoeducativa a estudantes de graduação em Farmácia, Enfermagem, Odontologia, Medicina, Psicologia e Nutrição da UnB e a de Dias (2011), que mapeou como o tema da comunicação em saúde vem sendo abordado nos cursos do campus da Ceilândia-DF. Trabalhos cujos participantes eram crianças e/ou adolescentes, ficaram listados na subcategoria de mesmo nome (Crianças elou Adolescentes), como no caso de Guimarães (2012), que elaborou um jogo eletrônico para tratar do enfrentamento do câncer de um ente familiar próximo, ou da pesquisa de Birck (2013), que descreveu e analisou a adoção de estratégias de enfrentamento por crianças e adolescentes 
sobreviventes de câncer, bem como seus principais estressores.

Houve a ocorrência de dois trabalhos realizados com Idosos, que exploraram o universo do envelhecimento e da saúde do idoso, que foram os trabalhos de Gonzalez (2011) e de Flesch (2013).

Todas as demais subcategorias, tiveram apenas um único trabalho listado. São elas: Gestantes, Mães de bebês prematuros, Membros de Comitês de Ética em Pesquisa, Literatura em Saúde (Base de Dados), Docentes na área da saúde, Outros Profissionais (juristas, agentes administrativos, servidores da BCE e gestores públicos), Prontuários Médicos, Usuários de Substâncias Psicoativas, Pesquisadores e Auxiliares de Pesquisa.

\subsection{Principais resultados apontados pelos trabalhos analisados}

Neste tópico, os principais resultados de cada pesquisa são destacados, ordenados por consonância temática, população estudada e/ou metodologia adotada.

Dias (2011), buscando caracterizar a percepção do que seria comunicação em saúde para estudantes de cursos de saúde da UnB, da Faculdade Ceilândia, encontrou uma visão conceitual abrangente por parte dos alunos, corroborando a relevância do tema como componente curricular nos cursos de formação na área da saúde. Para os alunos, a definição de comunicação como transmissão e recepção de informações, sentimentos e ideias entre emissor e receptor, se mostrou consonante com a literatura acerca do tema, além de referência a uma forte valorização da comunicação não-verbal. Esses resultados evidenciaram a necessidade de treinamento de demandas específicas dos futuros profissionais de saúde e alguns preditivos de que eles já poderiam ter uma atuação mais norteada pelo modelo biopsicossocial, em relação a seus antecessores.

Resultados semelhantes foram apontados por Assunção (2013), quando investigou a percepção de alunos de cursos de saúde sobre alguma defasagem em sua 
formação, no que diz respeito ao desenvolvimento de habilidades interpessoais e identificação de aspectos psicossociais que envolvem comunicação em saúde. Observou-se pouca ênfase ao cuidado ampliado, sendo privilegiado um enfoque primariamente técnico, embora os estudantes tenham apontado alguma preocupação com aspectos relacionais, com destaque para temas como saber dosar envolvimento e afastamento na relação com o paciente. O trabalho propôs uma oficina psicoeducativa, que se mostrou bastante efetiva para a ampliação e desenvolvimento destes conceitos, com baixo custo financeiro e operacional.

A crítica à formação básica do profissional de saúde, também foi referida por Xavier (2013) quando analisou a opinião de docentes do DF, da área de Odontologia, sobre o ensino odontológico e, como uma formação eminentemente voltada à atuação em clínica particular, se mostra desarticulada com o SUS. Os professores apontaram uma deficiência em sua própria formação no que concerne à preparação para atuação no SUS, e, especialmente, em relação aos princípios de universalidade e integralidade na saúde. O autor fez críticas à fragmentação dos currículos, com pouca integração entre disciplinas que privilegiam técnicas odontológicas e precisão, sendo necessária uma reestruturação a fim de reforçar a integralização de conteúdos técnicos, demandas psicossociais e variáveis socioculturais. Muitos dos professores, participantes da pesquisa, referiram que os problemas não estão apenas na sua formação, mas no próprio modo de funcionamento do SUS.

Ainda complementando a discussão sobre a formação do profissional de saúde, foram identificados trabalhos que se debruçaram sobre a temática da saúde ocupacional desses trabalhadores. O estudo de Sousa (2014), por exemplo, indagou quais fontes de estresse estariam mais comumente presentes no trabalho dos profissionais de saúde e o que contribui para o processo de resiliência nessa área. Dados obtidos permitem 
concluir que o desenvolvimento de fatores de proteção, como suporte social vindo de colegas de trabalho, familiares e amigos, bem como o desenvolvimento de outros indicadores de resiliência, como satisfação no trabalho, competência emocional, tenacidade e inovação, auxiliam a diminuição do impacto gerado pela exposição aos riscos inerentes ao ambiente de trabalho, tais como altas demandas psicológicas, sobrecarga de trabalho, acúmulo de vínculos empregatícios e regime de plantões. Segundo os autores, a categoria mais atingida por desgaste emocional eram os técnicos de enfermagem, por não se beneficiarem suficientemente dos fatores de proteção.

Já Gobatto (2012) discutiu sobre um importante fator de proteção: o apoio da religiosidade e espiritualidade ao paciente em tratamento de neoplasia. A autora investigou as concepções de trabalhadores da saúde sobre a relação entre saúde, religiosidade e espiritualidade e sua abordagem com pacientes oncológicos, constatando que ainda é um desafio abordar essa temática no contexto da assistência em saúde, mesmo que $54,8 \%$ dos entrevistados já tivessem pacientes que requisitaram ajuda religiosa ou espiritual, ou mesmo tendo 59,7\% da amostra se declarado muito ou completamente espiritualizada. A autora destaca que a tendência é que ainda caiba ao psicólogo, ou ao nutricionista, a iniciativa de abordar o tema religiosidade/espiritualidade, quando comparados aos profissionais médicos.

A comunicação estabelecida entre agentes comunitários de saúde e pessoas da comunidade, foi descrita e analisada por Staliano (2012), numa pesquisa que buscou, além de caracterizar esses profissionais, também avaliar sua concepção sobre processos de saúde-doença, promoção da saúde e prevenção de doenças, tendo constatado que, apesar de grande parte dessa população ter uma visão integrada de saúde, reconhecendo aspectos social, físico e mental do paciente, há, ainda, bastante confusão de limites conceituais e práticos sobre a diferença entre os termos promoção e prevenção, além de 
relatos de insatisfação em relação à própria qualificação e formação continuada.

A exposição frequente e recorrente a riscos ocupacionais foi discutida por Braga (2013) num estudo que analisou práticas e percepções de profissionais de saúde sobre o trabalho realizado com neonatos fora de possibilidade de cura em unidade de terapia intensiva neonatal. Foram relatados sentimentos de impotência, fracasso, medo, culpa e dor pela perda do neonato, agravada pela ausência de sistematização de condutas e critérios terapêuticos sobre processos de tomada de decisão acerca da não-intervenção ou suspensão do tratamento aos pacientes mais graves. Neste trabalho, o médico foi o profissional considerado mais exposto a estressores advindos da responsabilidade pela tomada de decisão na conduta terapêutica e suas consequências.

A fim de minimizar os desafios cotidianos da prática profissional, estudos que buscaram sistematizar a comunicação entre profissionais e pacientes e/ou familiares também tiveram contribuições bastante expressivas, como foi o caso do estudo desenvolvido por Coutinho (2013), que analisou os efeitos de um protocolo de intervenção psicológica sobre os comportamentos de comunicação de médicos oncohematologistas pediatras com pacientes e familiares acompanhantes, atendidos em consultas regulares de acompanhamento e tratamento. A pesquisa avaliou a qualidade da comunicação em função de registros de frequência e sequências de ocorrência de perdas de oportunidade de interação, aproveitamento espontâneo de informação, aproveitamento pós-intervenção do psicólogo, ausência de resposta pós-intervenção do psicólogo e tentativa bem sucedida de interação por parte do médico. Os resultados obtidos, além de apontarem a consulta médica como uma estratégia de intervenção ao treinamento de comportamentos de comunicação do médico, contribuíram para a compreensão de aspectos funcionais envolvidos no processo de estabelecimento e manutenção da comunicação entre o médico e o paciente, como: (a) identificação de 
eventos e contingências que atuam como barreiras ao processo de comunicação, em contexto real de atendimento; (b) influência do estilo de comportamento de cada médico, tanto na comunicação com o paciente, quanto no aprendizado de alternativas mais eficazes de se comunicar; e (c) necessidade de individualização e adaptação das estratégias de treinamento às características de cada profissional e de cada contexto de atendimento. Ao mesmo tempo, tais resultados indicaram respostas para outras questões relacionadas ao treinamento médico em comunicação, tais como: (a) possibilidade e importância do desenvolvimento de treinamento de médicos já formados, paralelamente à prática clínica; (b) validade do uso de técnicas instrucionais individualizadas no processo de aprendizagem dos médicos; (c) possibilidade de manutenção dos comportamentos treinados de acordo com a estratégia de intervenção utilizada; e (d) função do trabalho interdisciplinar no processo de comunicação.

Também o trabalho de Kohlsdorf (2012) se propôs a criar um modelo de préconsulta comportamental a fim de otimizar o processo comunicativo nas tríades criançacuidador-médico, partindo do pressuposto de que uma pré-consulta pode sinalizar assuntos a serem abordados na consulta médica, para aprimorar a comunicação triádica personalizada e sob medida. $\mathrm{O}$ estudo revelou que a pouca participação da criança na interação é comum e, quando ocorrem interações comunicativas, elas costumam se dar na forma de orientações direcionadas aos cuidadores. Muitas das dúvidas nesse contexto, referem-se a aspectos biofisiológicos, em detrimento de aspectos psicossociais. Quando adotado um roteiro em pré-consulta, é possível enfatizar outras orientações, como de atividades escolares, recomendações de cuidados com higiene, alimentação, informações sobre como lidar com o tratamento, práticas educativas parentais, além de subsidiar noções sobre a neoplasia, sequelas e recaídas. O resultado mais expressivo foi o aumento do número de orientações promovidas pelos médicos e a 
ampliação dos assuntos verbalizados, além da focalização de temas que raramente eram abordados e incluídos nos atendimentos que aconteciam somente a partir de solicitações diretas dos cuidadores, sem a participação das crianças.

Cristo (2014) também explorou a temática da análise interacional entre tríades compostas por médico, criança e acompanhante, através da adaptação de um modelo teórico de comunicação já existente, o SAIT (Sistema de Análise Interacional para Tríades, de Northouse \& Northouse, 1992), voltado a consultas com o paciente adulto. A partir do estudo empírico de elaboração e avaliação desse sistema, foi possível compreender melhor o processo de comunicação no contexto pediátrico e ter seu uso aplicado em diferentes campos, como pesquisas e intervenções, checklist de atendimento e/ou instrumento de auto-avaliação profissional.

Outra ferramenta para diagnóstico e avaliação, útil para suporte em pesquisa e autocrítica da atuação profissional foi proposta por Turra (2012) num trabalho que visou a construção de uma estrutura prática interdisciplinar de assistência psicossocial e educacional, chamada PAPO - Protocolo de Atendimento em Saúde Orientado para o Problema, centrada no paciente cirúrgico, com enfoque na atenção à rede de apoio do paciente e à equipe. $\mathrm{O}$ estudo apontou que a ferramenta era extremamente útil para a prática profissional, podendo ser utilizada para treinar profissionais de saúde a identificar a condição clínica ampla do paciente, suas demandas qualificadas, rede de apoio social e vulnerabilidades a serem priorizadas.

Investimentos em instrumentos de avaliação também foram feitos por Nogueira (2012), que adaptou e validou, para a língua portuguesa do Brasil, a versão breve do Questionário de Percepção de Doenças, e Sousa (2014), que elaborou e validou um instrumento de avaliação/triagem que possibilita a identificação de distress e outras características psicológicas preditoras de dificuldades frente ao tratamento por pacientes 
oncológicos. No primeiro estudo, embora tivessem sido apontadas dificuldades de compreensão de algumas palavras, por parte dos respondentes, e alguns acréscimos tenham sido necessários para melhor definição de determinadas palavras, o questionário foi avaliado por profissionais como um instrumento útil, objetivo e rápido. Já no segundo estudo, embora a autora tenha reconhecido que o desenvolvimento de um instrumento de triagem psicológica não tenha a pretensão de responder a todos os problemas relacionados à adesão dos pacientes oncológicos aos serviços de psicologia, concluiu que o contato com um instrumento dessa natureza, geralmente, é a porta de entrada para um contato com essa especialidade e, portanto, uma potencial oportunidade para sensibilizá-los para as possíveis contribuições do atendimento psicológico disponível.

O tema do distress em pacientes oncológicos, e sua implicação na qualidade de vida e enfrentamento desses indivíduos, também foi foco de estudo por Bergerot (2013), que avaliou pacientes em tratamento oncológico quimioterápico e encontraram que a maior taxa de incidência de distress aparece no início do tratamento, sendo que pacientes com câncer de pulmão, em estadiamento inicial e avançado, são os que possuem média superior de distress, quando comparados a pacientes com outros diagnósticos. Esses pacientes tendem a optar por estratégias de enfrentamento de confronto, fuga/esquiva, autocontrole e busca por suporte social.

Mensorio (2013), buscando avaliar os efeitos de um programa de intervenção psicológica a pacientes elegíveis à cirurgia bariátrica, realizou levantamento das principais estratégias de enfrentamento adotados por esses indivíduos e quais as manifestações mais frequentes de ansiedade. Esta autora concluiu que pacientes que se submetem a intervenções sistemáticas, em grupo, tendem a desenvolver habilidades de enfrentamento mais adaptativas em relação a comportamentos alimentares, por 
adotarem estratégias focalizadas no problema e na busca por suporte social. Ao mesmo tempo, tendem a diminuir o enfrentamento focalizado na emoção e na busca de práticas religiosas/pensamento fantasioso.

Dentro desse universo do paciente bariátrico, Abreu-Rodrigues (2014) também implementou um procedimento de intervenção e buscaram investigar seus efeitos para o desenvolvimento do apoio social dos cuidadores de indivíduos que se submeteram à cirurgia bariátrica, mas que tiveram reganho de peso. A autora visou a adequação do apoio social às necessidades de cada paciente e avaliaram a satisfação com o suporte recebido por eles, a fim de viabilizar sua adesão aos cuidados pós-intervenção. Os resultados mais relevantes apontaram que o manejo e controle das contingências responsáveis por comportamentos estressantes são fundamentais quando se pretende fornecer apoio qualificado a esses pacientes. Abreu-Rodrigues (2014) verificou que a técnica de solução de problemas, visando a emissão de respostas adaptativas, foi fundamental para o manejo de comportamentos estressantes. Esses resultados são importantes para profissionais que acompanham pacientes bariátricos, mostrando a necessidade de maior atenção aos cuidadores, em todas as etapas de tratamento desses pacientes. O estudo se destacou por seu pioneirismo, uma vez que não foram identificadas, na literatura nacional ou internacional, publicações sobre intervenções específicas, em suporte social, a pacientes submetidos à cirurgia bariátrica com reganho de peso.

Ainda elencando os estudos que se debruçaram sobre a temática do enfrentamento e da qualidade de vida, Vera (2012) investigou as principais estratégias de enfrentamento adotadas por outra população de indivíduos: a de pessoas que sofreram lesão medular. A autora encontrou que a modalidade de enfrentamento mais adotada, pelos participantes de pesquisa, foi de focalização no problema, seguida por 
busca de práticas religiosas/ pensamento fantasioso e busca por suporte social, ao passo que a focalização na emoção foi a estratégia menos adotada. Observou-se que quanto maior o tempo de lesão medular, maiores eram as oportunidades para a desconstrução de crenças disfuncionais, o que permite melhor manejo de respostas emocionais negativas. Em relação à qualidade de vida, o estudo destacou que a vigência de problemas fisiológicos, como mal funcionamento da bexiga e do intestino, foram considerados aspectos difíceis de lidar; quanto mais comprometido for o funcionamento da bexiga neurogênica, por exemplo, mais adversa era a percepção da qualidade de vida.

O estudo de Vera (2012) teve pontos em comum com outros dois estudos: o de Rodrigues (2011), que também estudou a população de pacientes adultos com diagnóstico de lesão medular, e o de Kunzler (2011), que explorou o tema da qualidade de vida na população geral. Rodrigues (2011) investigou as características de uso da internet por pessoas que tiveram lesão medular e suas percepções sobre o impacto desse uso em suas vidas, uma vez que essas informações podem fundamentar novas formas de atuação em reabilitação. Ela concluiu que o emprego da internet pode favorecer bastante a reabilitação, permitindo acesso à informação e à comunicação, princípios compatíveis com os preconizados pela OMS. No entanto, ela não deve ser vista como uma forma de substituição às abordagens tradicionais em reabilitação, mas sim como uma alternativa de complementação. O trabalho chama a atenção para que profissionais e instituições de saúde estejam preparados para atuarem em consonância com as mudanças tecnológicas impregnadas no mundo atual, não deixando de contextualizar as repercussões provocadas por essa ferramenta nos programas de reabilitação de pessoas com LM.

Já Kunzler (2011), investigando a eficácia das técnicas cognitivas de "tomada de decisão e qualidade de vida" para promoção da saúde com servidoras públicas de uma biblioteca universitária, encontrou que a qualidade de vida aumentou quando as 
participantes tomaram a decisão pela redução de comportamentos não saudáveis e pela construção e manutenção de comportamentos saudáveis. A autora concluiu que os indivíduos acreditam que cognições, emoções, comportamentos e reações físicas são somente compatíveis com situações favoráveis.

O interesse pela temática da qualidade de vida se mantém quando o assunto passa a ser a sobrevivência a alguma condição adversa, ou mesmo a um tratamento considerado exaustivo e invasivo como o do câncer. Nesta esfera, foram identificadas pesquisas como as conduzidas por Naves (2013) e por Birck (2013). No primeiro estudo, a autora avaliou qualidade de vida e bem-estar subjetivo de sobreviventes de câncer ósseo, encontrando resultados de que o suporte familiar e o apoio espiritual ou religioso são os principais fatores que contribuem para o sucesso potencial tratamento, apesar da manifestação de indicadores de ansiedade, medo de um novo diagnóstico e medo de recidiva. Já no segundo estudo mencionado, a autora apontou que estratégias de enfrentamento como positividade, espiritualidade, suporte familiar e distração, por meio de rotinas do dia-a-dia, são as mais utilizadas por sobreviventes crianças e adolescentes. Por outro lado, seus cuidadores tendem a preocupar-se com efeitos tardios do tratamento, especialmente relacionados a sintomas endócrinos e metabólicos, como baixa imunidade, baixa estatura e problemas hormonais.

Ao adentrar no tema do cuidado continuado, após um período de internação e/ou intervenção em saúde, um estudo se destacou por sua preocupação em compreender como idosos e seus cuidadores percebem a alta hospitalar e como conduzem, em âmbito domiciliar, os cuidados orientados pela equipe de saúde. Nesse sentido, Flesch (2013) acompanhou 30 idosos ao longo de seu período de internação e, novamente, após um mês de alta do hospital. A autora identificou altos índices em aspectos como confiança nos profissionais de saúde, satisfação com o apoio emocional prestado pelos 
profissionais e satisfação com as informações obtidas. Todos os participantes afirmaram se sentir preparados no momento da alta. Quanto aos cuidadores, o estudo reportou alta sobrecarga, uma vez que, na maioria das famílias, apenas um familiar costumava se responsabilizar pelos cuidados ao idoso. Após o retorno ao domicílio, as dificuldades mais comumente identificadas foram as dificuldades de locomoção, carência financeira e problemas com administração de medicamentos.

Coelho (2013) também acompanhou pacientes após a alta hospitalar. Por meio de um trabalho que analisou a relação entre crianças queimadas e seus cuidadores e as influências dessa relação na experiência de cuidar da queimadura, no período de hospitalização e após alta, a autora identificou que um terço dos pacientes e de cuidadores preencheram critérios diagnósticos para Transtorno de Estresse PósTraumático (TEPT). Além disso, verificaram que ocorre uma intensificação da relação afetiva entre a criança e seu cuidador após o acidente da queimadura. Contudo, há relatos de certo sentimento de rejeição por parte de irmãos e familiares, relatado pelos participantes.

A preocupação com familiares de pacientes foi estudada por Guimarães (2012) ao buscar compreender a percepção de crianças, parentes de pacientes oncológicos, a respeito da doença e seus tratamentos, propondo uma intervenção psicoeducativa por meio de jogo eletrônico em site da internet. Os dados obtidos apontaram que a plataforma virtual favoreceu a compreensão das crianças sobre a temática do câncer, permitindo sua expressão emocional. A autora destacou que o jogo eletrônico permitiu que as crianças atingissem um estado de flow - conceito da Psicologia Positiva, criado na década de 1970, por Mihaly Csikszentmihalyi, para designar um estado mental onde corpo e mente fluem em perfeita harmonia, movido por alta carga motivacional, alta concentração, alta energia e alto desempenho - tendo os participantes ficado totalmente 
imersos na atividade. Através de recursos lúdicos, as crianças mencionaram percepções negativas sobre a doença e expressaram falsos conceitos e crenças equivocadas sobre fatores de risco e proteção. Alguns participantes, por exemplo, confundiram sintomas da doença com efeitos colaterais do tratamento, levando a percepções errôneas sobre o quadro clínico. Outros pacientes referiram o câncer como sendo uma doença infectocontagiosa.

Os cuidados em âmbito domiciliar também foram objeto de estudo da dissertação de mestrado de Andrade (2014), que buscou caracterizar o Programa de Internação Domiciliar (PID) para pacientes com acidente vascular cerebral (AVC), do Núcleo Regional de Atenção Domiciliar (NRAD) da Ceilândia. O estudo verificou que, nessa amostra de pacientes, a necessidade de cuidados e, portanto, de vínculo com a equipe era maior, em virtude do uso de dispositivos importantes para a atenção domiciliar, como traqueostomia, hemodiálise, sonda vesical de alívio e sonda vesical de demora, por exemplo. Com o levantamento de perfil dos participantes, a expectativa era de que o NRAD Ceilândia conseguisse rever seu processo de trabalho de forma a aprimorar o PID e, para tanto, foram referidas sugestões de ação em quatro eixos: (a) ampliação do olhar profissional para além do modelo biomédico; (b) ênfase na melhora da capacidade funcional dos pacientes e, também, na prevenção dos agravos inerentes à essa condição de limitação; (c) cuidados específicos aos cuidadores e; (d) maior inserção das atividades no sistema de saúde. O estudo teve caráter exploratório e foi conduzido por meio de pesquisa documental, através da análise de prontuários médicos.

Outro estudo que teve a análise documental como método de investigação foi o de Maia (2014) que examinou o tema da castração química como mecanismo de controle da pedofilia e discutiu sua natureza como pena, como tratamento médico e como experimento científico. Uma das reflexões que merecem destaque nesta pesquisa 
é a discussão sobre o quão a castração química é eticamente aceitável, ou não, para ser aplicada como pena. A autora destaca a necessidade de se considerar o aspecto da compulsoriedade ou voluntariedade do procedimento, levando em conta o entendimento do pedófilo como um indivíduo portador de uma doença, além de se discutir se seria usada como medida de segurança ou como diminuição de pena. A análise dos projetos de lei brasileiros indicou a castração química como uma legítima demanda legislativa.

Outros assuntos debatidos à luz da bioética foram tratados por Franco (2015), por Jácome (2013), por Sanches (2012) e por Bernardes (2011). No primeiro estudo, as autoras se dispuseram a analisar o processo de autorização de doação intervivos não relacionados, discutindo os critérios adotados pelas Comissões de Ética dos Estabelecimentos de Saúde Transplantadores (CEESTs). A amostra analisada referiu-se a pacientes renais, em tratamentos de diálise e hemodiálise, e com insuficiência hepática ou com tumor de fígado. Nessa população, é comum a presença de alterações biopsicossociais importantes que interferem diretamente sobre a qualidade de vida, ocasionando fragilidades pessoais, familiares e sociais. Segundo as autoras, os pacientes que necessitam de transplante hepático, são pessoas que convivem com preconceitos, discriminação e solidão, até perderem a autonomia e ficarem susceptíveis à diminuição da qualidade de vida e mesmo à morte. Uma preocupação ética da doação intervivos, apontada pelo estudo, é o risco para o doador, por ter que se submeter a um procedimento cirúrgico invasivo, sem que tenha qualquer benefício a sua saúde, o que moralmente seria contestável. Nesse sentido, o trabalho sugere que o sistema considere, como prioridade, a saúde do doador. Além da avaliação física, indica-se a necessidade de avaliação psicossocial a fim de detectar distúrbios emocionais, psiquiátricos e investigar o nível de compreensão cognitiva das informações que possam afetar a tomada de decisão e minimizar as complicações no período pós-transplante. 
No segundo estudo mencionado, as autoras analisaram a organização e o funcionamento dos Comitês de Ética em Pesquisa (CEPs) a partir da percepção de seus coordenadores e membros, revelando que a principal área de formação de seus integrantes eram as ciências biológicas e de saúde, com formações predominantemente em nível de doutorado. Não houve achados que apontassem qualquer despreparo para a avaliação ética, e os resultados se mostraram em consonância com a finalidade dos comitês e com os parâmetros da legislação vigente. Os resultados indicaram, ainda, que os comitês de ética estão consolidados no Brasil. No entanto, apesar dessa consolidação, o trabalho discutiu a falta de apoio adequado que garanta, aos membros, reconhecimento de horas de trabalho institucional para as atividades do comitê, como também para atividades de educação continuada.

O terceiro trabalho com temática relacionada à bioética, discutiu práticas de limitação ou suspensão de suporte vital em situações de terminalidade, a partir de relatos de médicos oncologistas. Nesse trabalho, mais do que debater sobre os critérios adotados na prática clínica do campo estudado, buscou-se conhecer as concepções dos profissionais médicos sobre conceitos de ortotanásia, eutanásia, distanásia e noções afins, além de avaliar o (des)conhecimento sobre a Resolução 1.805 de 2006 do Conselho Federal de Medicina (CFM). Dois terços dos participantes afirmaram que conheciam a Resolução do CFM e que ela respaldava legalmente a aplicabilidade da ortotanásia. Por outro lado, outros ressaltaram a fragilidade da resolução em termos de suporte jurídico, defendendo a necessidade de uma lei federal. O estudo verificou uma defasagem na formação dos profissionais no que diz respeito à suspensão ou limitação do suporte vital, sendo que, para a maior parte dos participantes, o conhecimento obtido sobre esta temática foi adquirida no dia-a-dia, a partir das experiências práticas.

Por fim, o quarto trabalho relacionado à bioética, discutiu o tema em interface 
com o tema da deficiência, se propondo a pesquisar a percepção de gestores públicos e conselheiros de direitos de pessoas com deficiência, discutindo que a vivência da deficiência ou a convivência com pessoas deficientes, é fator decisivo para uma adequada fundamentação para elaboração de políticas públicas para essa população.

$\mathrm{Na}$ amostra de trabalhos estudada, dois trabalhos discutiram questões de gênero mais diretamente, que foi o caso da tese de Estavela (2014), a partir da análise da percepção de pessoas vivendo com HIV/Aids e de profissionais de saúde sobre vulnerabilidade de gênero, pobreza e práticas culturais e o de Gonzalez (2011), que verificou os efeitos de uma intervenção psicoeducativa que foi planejada e implementada com a finalidade de fortalecer o autocuidado entre idosos do sexo masculino, tendo-se concluído que a intervenção foi vantajosa não somente para maximizar comportamentos de autocuidado, como também para aumentar as formas de interação social desses idosos.

Outros dois estudos se destacaram pela exclusividade de mulheres na amostra: (a) Duarte (2012), que propôs um programa de educação nutricional baseado no modelo cognitivo como estratégia para adoção de hábitos alimentares saudáveis e consequente redução do peso e do risco cardiovascular em mulheres com sobrepeso e obesidade e; (b) Lira (2013), que avaliou os efeitos de uma intervenção psicoeducativa de preparação psicológica para braquiterapia de alta taxa de dose, em formato individual e em grupo, sobre níveis de distress e domínios da qualidade de vida de pacientes com câncer de colo do útero. No primeiro estudo, os resultados apontaram que a abordagem em grupo favoreceu a adesão das mulheres, que eram sedentárias antes do estudo, à prática regular de atividade física, acompanhada de mudança nas práticas alimentares e na conscientização de aspectos relacionados à saúde. Já no segundo estudo, os resultados sugeriram que a intervenção individual possibilitou maior efeito de 
diminuição do distress antes da realização do procedimento de braquiterapia, quando comparado à intervenção aplicada em grupo.

Outro trabalho, cuja amostra foi exclusivamente feminina, foi a dissertação de mestrado produzida por Spehar (2013), que avaliou aspectos psicossociais, estratégias de enfrentamento e percepção de autoeficácia em relação aos cuidados do bebê, ao longo de três etapas constituintes do Método Canguru, composto por mães de recémnascidos prematuros de baixo peso. O estudo encontrou que entre essas mães há relatos de ambivalência de emoções positivas, como alegria, amor, tranquilidade e desejo de cuidar, e emoções negativas, como ansiedade, desespero, medo de piora do estado de saúde do bebê e medo de perda, além de crenças negativas sobre a UTI.

Nesse universo de ambivalência emocional, que caracteriza a maternidade, Tostes (2012) também se enveredou, ao investigar a percepção de mulheres primigestas acerca da assistência pré-natal de serviços da rede pública de Brasília e suas expectativas em relação ao parto. A autora identificou que o fato da concepção ser planejada ou não, influencia de forma importante as primeiras vivências da gestação, e que independente de possuírem ou não condições favoráveis, as gestantes enfrentam dificuldades e crises, caracterizadas por mudanças emocionais, mudanças estéticas, sintomas físicos e mudanças no funcionamento do corpo, sendo que muitas relataram não se sentirem preparadas para o momento do parto, a despeito do acompanhamento pré-natal recebido.

A fim de caracterizar e comparar a percepção de dor de pacientes crianças e adolescentes, seus familiares/ acompanhantes e profissionais de saúde e avaliar o manejo da dor em hospitais públicos do DF, Doca (2014) realizou um estudo no qual foi constatada incompatibilidade entre a percepção de dor dos pacientes e de seus cuidadores, o que aumenta a possibilidade de que essa seja subtratada, isto é, que os 
pacientes não recebam tratamento adequado para alívio da dor. A autora destacou dados que, embora apontem que a dor não tratada pode provocar transtornos físicos e psicológicos, muitos cuidadores ainda apresentam crenças disfuncionais sobre o uso de analgésicos em crianças.

A adolescência foi a etapa do curso de vida também estudada por Salles (2011), que sistematizou um procedimento de intervenção psicológica direcionada a adolescentes soropositivas para atender às suas necessidades relacionadas a dificuldades de adesão ao tratamento antirretroviral. A intervenção se mostrou eficaz, fortalecendo a adesão dos pacientes, no entanto, necessitando de monitoramento constante e contundente, uma vez que conviver com HIV/Aids na adolescência, tem nuances próprias e muito particulares, o que traz uma série de desafios aos profissionais de saúde. O trabalho dá destaque às particularidades de jovens que foram infectados por transmissão vertical e que convivem em contextos familiares soropositivos, onde os genitores desempenham um papel de modelo para as condutas de adesão, em contraponto com os jovens cuja infecção não se deu desta maneira.

O universo da adesão ao tratamento antirretroviral também foi explorado por Santos (2011), que discutiu a gravidade que significa o abandono do tratamento e o quanto a chamada "busca consentida" proposta pelo Ministério da Saúde, se mostra importante para resgatar o paciente que decide se afastar do serviço de saúde, auxiliar para o fortalecimento do vínculo com a equipe e elaborar conjuntamente respostas que atendam às dificuldades de adesão de cada pessoa. No entanto, faz-se necessário um adequado preparo dos profissionais de saúde que lidam com essa população, de forma a garantir que não sejam feridos os preceitos éticos e os direitos das pessoas vivendo com HIV/Aids.

Por último, ao falar do adequado preparo profissional no lidar com especifidades 
de cada doença ou condição adversa, podemos citar o trabalho de Santos (2013), que investigou modos de atuação e características do trabalho de intervenção com jovens adultos em situação de rua e usuários de substâncias psicoativas segundo percepções de profissionais do Consultório de Rua do município de Goiânia. Essa autora identificou fatores facilitadores e dificultadores para o exercício dessa função, destacando o vínculo entre os profissionais da equipe e os usuários como alicerce central para funcionamento dessa forma de atendimento. 


\section{CAPÍTULO 6}

\section{DISCUSSÃO}

Tomando por base os resultados expostos no capítulo anterior, a presente seção discute as principais contribuições das pesquisas analisadas, realizadas pelo IP/UnB, na área de Psicologia da Saúde, e quanto estão, ou não, em congruência com as diretrizes da Divisão 38 da APA.

Para fins de organização, os resultados são discutidos à luz dos mesmos tópicos definidos na Conferência de Pittsburgh, nos EUA, no ano 2.000, quando os pesquisadores da APA criaram grupos de trabalho que discutiriam os rumos da Psicologia da Saúde e que, quatro anos depois, gerou a publicação do Volume Especial do JHP. Os tópicos referem-se a: (a) a evolução do modelo biopsicossocial de saúde; (b) os avanços tecnológicos na área da saúde; (c) as mudanças em indicadores demográficos das populações (com indicação da necessidade de adoção de instrumentos sensíveis à essa diversidade); (d) os fatores econômicos na saúde e as perspectivas de mercado para o psicólogo (com desenvolvimento de competências profissionais e refinamento da formação curricular); (e) as prioridades de políticas de prevenção em saúde; e (f) as intervenções clínicas em psicologia da saúde (com ênfase em estudos controlados).

\subsection{Evolução do modelo biopsicossocial de saúde}

Uma vez que o completo potencial da perspectiva filosófica biopsicossocial e, em particular, a capacidade de avançar conhecimentos em modelos teóricos e serviços profissionais coerentes com a atenção integral à saúde, ainda parecia pouco explorado no início do século XXI (Suls \& Rothman, 2004), estudos que discutissem como 
transformar as implicações dessa perspectiva filosófica em programas de intervenção de qualidade, atualizados aos perfis e estilos de saúde de indivíduos e grupos, poderiam garantir o sucesso contínuo da psicologia da saúde.

A maior parte dos trabalhos realizados pelo IP/UnB no período escolhido, incluíram, de alguma maneira, debater a evolução do modelo biopsicossocial entre as populações e/ou instituições estudadas, sobretudo entre outros profissionais de saúde, compreendendo que essa evolução é consonante com o próprio avanço contínuo da psicologia da saúde, tornando-se, de certa maneira, indissociável a discussão das implicações desse modelo, com os objetivos de cada estudo.

$\mathrm{Na}$ amostra selecionada, verificou-se que os trabalhos que se dispuseram a identificar e/ou caracterizar percepções, condutas e/ou práticas profissionais que evidenciassem a aplicação dessa perspectiva em seus campos, foram mais representativos desses esforços alcançados ao longo do tempo. Nesse quesito, se enquadram pesquisas que questionaram percepções e/ou crenças de profissionais ou estudantes das áreas de medicina, enfermagem, farmácia, terapia ocupacional, odontologia e saúde coletiva, acerca de fatores de risco e proteção psicossociais, tanto para si próprios quanto para seus pacientes (Sanches, 2012; Braga, 2013; Gobatto, 2012; Sousa, 2014) e aquelas que debateram aspectos constituintes da formação profissional, tendo o modelo biopsicossocial como eixo norteador (Dias, 2011; Staliano, 2012; Xavier, 2013; Assunção, 2013).

Os estudos contribuíram tanto provocando reflexões sobre a estruturação curricular de cursos de formação em saúde como, também, propondo modelos de treinamento a estudantes, com vistas à ampliação de competências e habilidades requeridas à atuação profissional, em sistema público de saúde, com ênfase na colaboração interdisciplinar, sem perder de vista a qualidade de vida do próprio 
profissional, já formado ou em formação. Assim, as contribuições destes trabalhos têm o potencial de fornecer subsídios para o desenvolvimento de políticas curriculares e de financiamento para a próxima geração de pesquisadores e profissionais que reconheçam a complexidade desses objetivos.

\subsection{Avanços tecnológicos na área de saúde}

A discussão levantada pelo JHP sobre os avanços tecnológicos na área da saúde, explorou mais detalhadamente a profusão de interfaces de multimídia e TI voltada para a saúde nos primeiros anos do século XXI.

Nesse campo, o advento de sistemas de informação em contextos de saúde, nos últimos anos, vem viabilizando desde o cadastro de pacientes até o registro de informações médicas e de outros profissionais em prontuários eletrônicos, priorizando a integração de informações clínicas e administrativas como elementos-chave para um adequado acompanhamento de tratamentos e procedimentos em saúde, nos mais variados tipos de unidades de saúde (hospitalares, ambulatoriais, cirúrgicas, intensivas). No entanto, o avanço da tecnologia da informação no setor da saúde em geral, e hospitalar em particular, exige uma educação paralela dos profissionais de saúde e um estudo destinado a melhorar as práticas de registro, indispensáveis à melhoria da qualidade do tratamento médico (Rodrigues Filho, Xavier \& Adriano, 2001).

Como demonstrado por dois dos estudos da amostra (Santos, 2011; Andrade, 2014), a despeito das contribuições que essas plataformas forneçam, sobretudo na caracterização mais ampliada de perfis demográficos de determinadas populações de pacientes, as limitações provocadas pela perda acentuada de informações, próprias de fontes secundárias de dados, pode ter impacto significativo na relevância do trabalho, comprometendo, inclusive, seu potencial de replicabilidade e, portanto, diminuindo seus 
índices de validade e fidedignidade. É sempre necessário destacar que um sistema de informação jamais deve ser considerado artefato puramente técnico, devendo ser visto como um sistema social, em que as pessoas são mais importantes do que a tecnologia (Saab \& cols., 2004, Rodrigues Filho \& cols, 2001).

Em que pesem os avanços na elaboração e disseminação de atendimentos em saúde oferecidos remotamente, por meio de recursos de telecomunicação e multimídia, amplamente ilustrados pelo JHP e discutidos em capítulo anterior, apenas dois trabalhos utilizaram recursos de tecnologia da informação aplicados à saúde. Um deles (Guimarães, 2012) usou recursos de multimídia como ferramenta potencial para uma intervenção psicoeducativa, no caso, direcionada a crianças que tinham algum familiar em tratamento oncológico. $\mathrm{O}$ trabalho investigou o quanto o formato de um jogo eletrônico computadorizado poderia subsidiar a proposta de intervenção, tendo deixado grande contribuição como instrumento clínico a psicólogos e outros profissionais de saúde que lidam com essa população.

O outro (Rodrigues, 2011) analisou as percepções de pessoas com lesão medular sobre o impacto que o acesso à internet provoca em suas vidas, relacionando-as aos princípios da reabilitação. Esse trabalho permitiu trazer ao debate, nas esferas governamental e internacional, aspectos importantes relacionados à inclusão digital, sugerindo a promoção de políticas públicas que garantam acesso à internet, não somente às pessoas em reabilitação, mas a todos os cidadãos.

Em relação ao tema do transplante de órgãos e tecidos, um dos trabalhos da amostra (Franco, 2015), discutiu não só a conhecida escassez de órgãos de doadores falecidos, como trouxe luz ao debate da doação intervivos, que carrega características diferenciadas. A autora analisou o processo de obtenção de autorização da doação de órgãos e/ou tecidos entre pessoas geneticamente não relacionadas, ressaltando desde 
aspectos legais, que regulamentam a submissão do procedimento à autorização judicial, passando pela aprovação tanto de comissões e comitês da esfera institucional, estadual e federal, em quatro diferentes Estados brasileiros.

O estudo reconheceu que a legislação brasileira não propõe critérios de avaliação próprios às diferentes instâncias autorizadoras e criticou a inexistência de registros de dados que forneçam informações fidedignas que favoreçam o controle social. O trabalho evidenciou, ainda, que essas instâncias cumprem as formalidades legais, mas não utilizam ações interventivas que favoreçam a diminuição da vulnerabilidade dos envolvidos, tornando-os mais fragilizados e aumentando os conflitos éticos. Para tanto, a pesquisadora chamou atenção à responsabilidade do Estado na proteção dos doadores e receptores, vulneráveis tanto pela necessidade de um órgão para a melhoria da qualidade de vida como, também, em relação aos motivos, altruístas ou não, que levam uma pessoa a dispor de parte do seu corpo em benefício de outra. Essa lacuna na legislação, apontada pelo estudo, dificulta, inclusive, a coibição do comércio ilegal de órgãos. O trabalho mereceu destaque por sua relevância acadêmica, política e social.

Sobre estudos em genética, mencionados por alguns estudiosos no JHP de 2004, não houve registro de trabalho, na amostra selecionada, que contemplasse diretamente este tema.

\subsection{Mudanças nos indicadores demográficos das populações (e a adoção de instrumentos sensíveis à essa diversidade)}

Quando alguns artigos do JHP sugeriram que o foco de trabalho dos psicólogos da saúde vinha se modificando ao longo do tempo, de maneira a atender às mudanças demográficas das populações e às alterações em seus padrões de saúde 
(Smith \& Suls, 2004; Yali \& Revenson, 2004), o periódico se referia à consideração de variáveis como ampliação de faixa etária (fruto do envelhecimento populacional, por exemplo), diversidade étnica, orientação sexual, novas configurações familiares e arranjos parentais, além de variáveis disposicionais para ansiedade e depressão, por exemplo. Para tanto, a sugestão foi a necessidade do refinamento de modelos teóricos e metodológicos que abarcassem essas variações e explicassem as mudanças de comportamentos decorrentes destes (novos) contextos.

Nessa perspectiva, trabalhos que investigaram algum tipo de vulnerabilidade tanto por variáveis de gênero (Estavela, 2014) quanto de risco social, como, por exemplo, pela exposição à situação de rua e ao uso de substâncias psicoativas (Santos, 2013) ou pela identificação de necessidades de idosos (Gonzalez, 2011) em relação ao próprio autocuidado ou, mais especificamente, após alta hospitalar (Flesch, 2013), foram ao encontro desses objetivos.

No que se refere à preocupação, já apontada pela literatura, pela adequação de instrumentos de medida capazes de abranger um maior número de fatores psicossociais (Yali \& Revenson, 2004), com destaque especial à normatização brasileira (Gorayeb, 2010), dois trabalhos deixaram significativas contribuições (Nogueira, 2012; Sousa, 2014), por legarem instrumentos empiricamente validados para uso na prática e pesquisa clínica e hospitalar.

\subsection{Fatores econômicos na saúde e perspectivas de mercado para o Psicólogo da}

\section{Saúde}

A fim de consolidar a figura do psicólogo da saúde como profissional apto a conceber e implantar intervenções psicológicas direcionadas à melhoria da prestação de serviço das equipes profissionais, que favoreçam processos de comunicação em saúde, 
atendimentos de preparo para procedimentos médicos, dentre outras intervenções de cunho psicológico ou psicossocial, inclusive ampliando suas perspectivas de inserção no mercado de trabalho, na área da saúde, cabe mencionar os estudos que propuseram protocolos de atendimento a pacientes cirúrgicos internados (Turra, 2012) e os que mediaram a comunicação triádica entre pacientes, seus cuidadores e profissionais de saúde (Kohlsdorf, 2012; Cristo, 2014; Coutinho, 2014).

Nessa mesma linha, Lira (2013) propôs um estudo com o intuito de desenvolver uma proposta de intervenção compatível com as demandas relacionadas a distress e qualidade de vida de pacientes com diagnóstico de câncer de colo do útero, em tratamento de braquiterapia de alta taxa de dose. O trabalho, além de deixar importante contribuição com a provisão de informações úteis às equipes multidisciplinares que trabalham com essa população, incluindo planejamento específico às necessidades de cada paciente, ainda destacou a forte necessidade de um psicólogo da saúde exclusivo para setores de radioterapia, o que ainda não é uma realidade na maior parte dos hospitais brasileiros.

Estes estudos contribuem, também, para consagrar o psicólogo da saúde como um cuidador primário, conforme sugerido por Tovian (2004), que serve como primeiro canal de acolhimento, em qualquer sistema de saúde, para posterior referenciamento, a fim de direcionar o fornecimento efetivo dos serviços de saúde, evitando eventuais custos financeiros e operacionais desnecessários e respondendo às demandas de prestação responsável de contas, além, é claro, de empoderar o indíviduo em relação aos cuidados com sua própria saúde.

Ainda dentro do campo de análise das condições necessárias para o desenvolvimento da psicologia da saúde, tendo a pesquisa, as políticas públicas e o seio acadêmico-profissional como principais palcos, o papel das sociedades científicas como 
propulsoras das diretrizes de crescimento mereceu destaque através do trabalho que analisou a organização e o funcionamento dos comitês de ética em pesquisa no Brasil (Jácome, 2013). Muito embora o objetivo do trabalho não tenha contemplado a análise de pesquisas específicas da área de psicologia da saúde, contribuiu para subsidiar uma revisão da capacitação técnica dos avaliadores, além de propor a incorporação de novos referenciais bioéticos às atividades dos Comitês de Ética em Pesquisa no Brasil.

\subsection{Políticas de prevenção}

A literatura referida no JHP chama a atenção para a necessidade de maior inserção do psicólogo da saúde em ações de atenção básica, construindo, em última instância, uma barreira para impedir que impactos excessivamente dispendiosos viessem a ocorrer pelo investimento tão somente em níveis secundário e terciário de atenção à saúde (Smith, Orleans \& Jenkins, 2004). Como exemplo de estudo que discutiu aspectos de prevenção e promoção da saúde comportamental, pode ser citado o trabalho que investigou expectativas de mulheres primigestas em fase pré-natal de cuidados com a saúde (Tostes, 2012), contribuindo para incentivar uma maior oferta de informações, práticas e apoio psicoeducacional para preparar gestantes e seus acompanhantes para o momento do parto, reduzindo indicadores de ansiedade a aproveitado melhor as informações disponíveis.

A preocupação com a inserção do psicólogo, como profissional que reúne habilidades e competências que o capacitam a conduzir adequadamente atendimentos em grandes grupos nas unidades de saúde, em substituição às abordagens clínicas individuais tradicionais, de natureza puramente psicoterápica, ou mista, também apontada pela literatura (Smith, Orleans \& Jenkins, 2004), foi alcançada pela pesquisa que propôs um programa de educação nutricional em grupo para mulheres com excesso 
de peso (Duarte, 2012) em seu local de trabalho, comprovando os efeitos do formato grupal para favorecimento da adesão às orientações de dieta saudável e prática regular de exercícios físicos, com vistas à redução de peso e o de risco cardiovascular.

Como o debate em torno das polticas de prevenção, sugere que cabe ao psicólogo da saúde o desafio de dialogar com outras esferas e desenvolver parcerias com outras profissões na área da saúde, esse mesmo estudo ilustrou bem essa interface com a área de nutrição e como um modelo teórico da psicologia da saúde, como no caso do modelo cognitivo proposto por Judith Beck (2009), pode contribuir para mudanças comportamentais e de crenças individuais no combate à obesidade.

\subsection{Aumento das Intervenções Clínicas em Psicologia da Saúde (com ênfase em} estudos controlados)

A preocupação de se levar em consideração métodos de pesquisa mais sofisticados e confiáveis, que reconheçam toda a complexidade dos (novos) contextos do mundo real, e suas relações com comportamentos de saúde, foi debatida por Nicassio e cols. (2004), que destacaram a necessidade de mais intervenções em níveis secundário e terciário, especificamente para situações como: (a) manejo de doenças crônicas e sequelas provocadas por doenças e/ou tratamentos de saúde; (b) desordens psicofisiológicas; (c) tratamento adjuvante para sintomas refratários; e (d) preparo précirúrgico e para procedimentos médicos invasivos.

Consonante com essa necessidade, Spehar (2013) propôs um estudo longitudinal, de curto prazo, adotando metodologia combinada para análise dos dados, a fim de avaliar os aspectos psicossociais que permeavam a realidade de mães de bebês considerados prematuros e que recebiam orientações do chamado Método Canguru. 
Trata-se de uma estratégia de assistência ao bebê de baixo peso ao nascer, que consiste em colocar o bebê entre os seios maternos, em contato pele a pele, de forma que o ventre do bebê fique em contato com o corpo da mãe. Essa estratégia ajuda a manter o bebê aquecido com o corpo da mãe, possibilitando que ele saia mais cedo da incubadora e, por consequência, tenha alta hospitalar precoce, diminuindo a exposição a infecções e outros aspectos adversos do ambiente hospitalar.

O trabalho teve como principal contribuição, a constatação da importância do Método Canguru não somente para a formação da competência materna - na medida em que auxiliou as mães na identificação de quando há ou não necessidade de buscar suporte social ou técnico - mas, também, para a formação de competências da criança, em virtude da proximidade de contato e interação entre ambos.

No tocante ao manejo de doenças crônicas, vários trabalhos da presente amostra foram realizados com esse objetivo, deixando contribuições valiosas como o estabelecimento de diretrizes para práticas em saúde, em âmbitos da reabilitação de pessoas com lesão medular (Rodrigues, 2011; Vera, 2013), crianças que sofreram queimaduras graves (Coelho, 2013), pessoas vivendo com HIV/Aids (Salles, 2011; Santos, 2011) ou da sobrevivência ao câncer (Naves, 2013; Birck, 2013). Com exceção do trabalho de Bergerot (2013), que se tratou de um estudo empírico longitudinal, todos os demais adotaram cortes transversais, com caráter descritivo, usando métodos quantiqualitativos para a análise dos dados.

Em relação ao aumento de pesquisas relacionadas a desordens psicofisiológicas, como hipertensão, síndrome do intestino irritável, cefaléia tensional e insônia, como sugerido por Nicassio e cols. (2004), não houve, na amostra estudada, trabalhos que contemplassem essas temáticas. 
Já no que concerne ao tratamento adjuvante para sintomas refratários, como a dor, por exemplo, destaca-se o trabalho de Doca (2014), que - através de estudo de corte transversal, com análise quantitativa descritiva e correlacional - caracterizou a epidemiologia da dor pediátrica de pacientes internados, contribuindo com um amplo retrato da realidade em torno da histórica negligência ao tema, além de deixar como legado um abrangente mapeamento dessa problemática e adotar metodologia de pesquisa consagrada em uma instituição de saúde do Canadá e adaptada para o Brasil por uma equipe da Faculdade de Medicina de Ribeirão Preto, da Universidade de São Paulo. A perspectiva de que dados de pesquisa sejam utilizados em análises multicêntricas é bem referida nos principais periódicos internacionais de Psicologia da Saúde.

Por fim, o compromisso em desenvolver trabalhos que oferecessem respostas e instrumentos para preparo de pacientes para tratamentos cirúrgicos e outros procedimentos invasivos, ficou a cargo de pesquisadores que propuseram programas de intervenção psicológica, objetivando mudança de hábitos em pacientes elegíveis à cirurgia bariátrica (Mensório, 2013) ou para pessoas integrantes da rede de apoio dessa mesma população, com o objetivo de treiná-los a oferecer suporte adequado, por meio de técnicas comportamentais de automonitoramento, resolução de problemas e reforçamento diferencial, e assim, evitar ou diminuir a probabilidade de reganho de peso (Abreu-Rodrigues, 2014).

Ambos os estudos, contribuíram para comprovar a necessidade de acompanhamento contínuo para pacientes obesos, inclusive chamando a atenção para a importância do investimento em treinamento de equipes multidisciplinares e, sobretudo, no treinamento dos acompanhantes/cuidadores/familiares, ou seja, das pessoas provedoras de apoio social, entendendo que essa horizontalização do cuidado pode 
ajudar os pacientes bariátricos a manterem níveis satisfatórios de adesão às recomendações médicas e, consequentemente, à melhora da saúde e qualidade de vida dessa população. O sucesso destes indicadores ainda reduz potencialmente os gastos futuros com a saúde, elemento apontado pelo JHP, em 2004, como essencial ao sustento e consolidação da área.

\subsection{Outras contribuições apontadas pelos estudos}

Embora não se relacione diretamente com os eixos de diretrizes para contribuições apontados pelos estudiosos da APA, o estudo documental e de revisão literária, proposto por Maia (2014), para analisar o tema da castração química para pedófilos, à luz da bioética, se mostrou relevante diante da escassez de trabalhos acadêmicos de referência sobre esse assunto, além de contribuir com importante levantamento bibliográfico sobre um tema bastante polêmico e atual, apontando evidências de que o Brasil vem se preparando para progredir no que diz respeito à forma de lidar com a pedofilia enquanto crime e doença. Deve-se destacar, ainda, que o tema aumenta a chance de interface da psicologia da saúde com outras áreas de conhecimento, incluindo o Direito, as Ciências Sociais e a Medicina.

\subsection{Limitações apontadas pelos estudos da amostra}

A maior parte dos estudos que fizeram parte da amostra analisada esbarrou em limitações comuns a pesquisas nas ciências humanas, sociais e da saúde. No que diz respeito aos participantes, essas limitações se referiram a eventuais efeitos de desejabilidade social (especialmente quando o pesquisador era funcionário da própria instituição estudada), amostras reduzidas (tornando difícil uma eventual generalização dos resultados), seleção de participantes por conveniência (gerando perfil homogêneo, 
em alguns casos, e impedindo comparações sociodemográficas) e perda de respondentes por não comparecimento ou recusa (seja por questões de saúde, questões socioeconômicas ou de dependência de terceiros).

Em alguns casos, o curto tempo para execução da pesquisa foi responsável por limitar alguns estudos. Em outros casos, as limitações se referiram aos instrumentos utilizados. Em algumas situações foram criticadas a não-especificidade dos instrumentos às populações estudadas ou o tamanho extenso de um roteiro de entrevista, por exemplo, num contexto onde há urgência para andamento dos processos e atendimentos.

\subsection{Sugestões de novos estudos em Psicologia da Saúde no Brasil}

Face ao exposto nessa revisão cronológica, que permitiu visualizar o crescimento da Psicologia da Saúde no mundo e, paralelamente, na Universidade de Brasília, considerando avanços positivos e limitações ainda existentes, alguns objetos de estudo podem ser sugeridos como temas para pesquisas futuras, alinhados com as diretrizes da APA:

(1) Estudos que explorem, de maneira detalhada, o impacto provocado, em diferentes níveis, pelo uso de recursos de tecnologia da informação e/ou de multimídia por indivíduos que utilizam internet e/ou mídias sociais em computadores ou dispositivos móveis, como ferramentas para obtenção de informações sobre doenças, tratamentos e assuntos correlacionados, bem como pesquisas que investiguem mais sistematicamente, variáveis psicossociais relacionadas ao advento de aplicativos para redes móveis relacionados com cuidados em saúde.

(2) Estudos que continuem a explorar e se aprofundem nas questões atreladas à obtenção de autorização para transplante de órgãos e tecidos, em doadores vivos, e 
que investiguem fatores psicossociais relacionados a cada etapa desse processo e para todos os atores envolvidos.

(3) Estudos que se aprofundem no universo, ainda pouquíssimo explorado por psicólogos brasileiros, da genética do comportamento, uma vez que - como já discutido - os genes definem tendências, mas são as experiências individuais que, quase sempre, as modulam. Mais especificamente, o psicólogo da saúde seria responsável pelo desenvolvimento de pesquisas que analisassem o impacto cognitivo, emocional e comportamental dos resultados de testes genéticos dos e nos indivíduos que optem por fazê-los;

(4) Estudos que busquem compreender e avaliar, mais amplamente, variáveis de gênero em processos saúde-doença, buscando respostas a perguntas sobre, por exemplo, padrões diferenciados de adesão ao tratamento entre homens e mulheres.

(5) Estudos que descrevam e proponham novas frentes de atuação ao psicólogo da saúde, principalmente em nível primário de atenção à saúde, ou seja, na atenção básica, nicho ainda pouco ocupado e valorizado por sistemas de saúde baseados em ações curativas.

(6) Nas pesquisas que visem debater e avaliar a aplicação do modelo biopsicossocial de saúde, que possam haver esforços por parte dos estudiosos na resolução de questões metodológicas como tamanho da amostra, otimização do tempo de condução da pesquisa, além da atenção - na medida do possível - ao uso de instrumentos adequados à população estudada;

(7) Investimento na padronização, adaptação e validação de instrumentos de pesquisa para a cultura brasileira, que sejam de rápida e fácil aplicação em contextos de saúde. 


\subsection{Contribuições e limitações desta análise descritivo-crítica}

O presente trabalho cumpriu seus objetivos, na medida em que traçou um perfil da produção bibliográfica em nível de pós-graduação strictu sensu desenvolvida pela área de Psicologia da Saúde do IP/UnB, permitindo realizar um balanço do quanto essa

produção está alinhada com diretrizes da American Psychological Association e sintonizada com publicações do Journal of Health Psychology, dentre outros importantes periódicos da área. A análise também subsidiou sugestões para novos temas de estudo a serem investigados pela área na UnB e por outras universidades brasileiras que desenvolvem pesquisas em Psicologia da Saúde.

Algumas limitações importantes na elaboração e execução deste trabalho devem ser mencionadas:

(1) Não ter contemplado análise da produção bibliográfica de outras universidades e instituições brasileiras, nos últimos doze anos, de modo a situar os avanços e lacunas de pesquisa num cenário mais ampliado;

(2) Ausência de recursos de estatística descritiva na metodologia que poderiam enriquecer eventuais correlações entre variáveis;

(3) Os critérios de escolha para a consideração de resultados mais relevantes em cada trabalho são passíveis de crítica, de maneira que outros pesquisadores, ao conduzirem estudos semelhantes, podem vir a adotar critérios distintos. 


\section{CONSIDERAÇÕES FINAIS}

A série de artigos publicados pelo JHP, em comemoração ao aniversário de 25 anos da fundação da Divisão 38 da APA, destacou importantes direções futuras, as quais os psicólogos de saúde deveriam seguir para manter o crescimento e o reconhecimento que a área vinha apresentando desde seu surgimento. Ao reverem as realizações de pesquisa em psicologia da saúde ao redor do mundo, os estudiosos se orgulharam dos rumos que a área havia tomado e apontaram que as projeções de futuro, embora desafiadoras, mostravam-se promissoras.

Nesse compasso, a presente análise descritivo-crítica, verificou o quanto o Instituto de Psicologia da UnB se mostra alinhado com as principais e mais atualizadas instituições que lideram estudos pioneiros e pesquisas inovadoras na área de psicologia da saúde, mostrando-se em sintonia com as tendências globais de pesquisa sobre fenômenos psicossociais ligados a processos saúde-doença, mudanças comportamentais de pessoas e grupos, consonante com os avanços tecnológicos e científicos mais recentes na área da saúde.

Ao destacarem as mudanças radicais necessárias em nível educacional, prático e de pesquisa por parte dos psicólogos da saúde, os estudiosos da APA que debatiam o futuro da área naquela época, preocupavam-se em encontrar respostas para temas que também inquietaram os pesquisadores vinculados à UnB no período analisado, demostrando o comprometimento dessa universidade com a realização e avaliação de intervenções psicossociais, conduzidas por meio de estudos sistematizados e que perseguem, na medida do possível, parâmetros de rigor metodológico.

No entanto, outras lacunas de conhecimento ainda precisam ser preenchidas. Da mesma forma que, no início do século, os artigos comemorativos do JHP chamaram a atenção para a premente necessidade de que os psicólogos da saúde se envolvessem 
mais na área da genética comportamental, observou-se, na análise atual, que pouco ou nenhum progresso foi obtido nesse quesito. É cada vez mais claro que fatores genéticos podem afetar diferencialmente resultados clínicos individuais. Nesse sentido, o investimento em intervenções de adaptação comportamental a variáveis genéticas, se mantém como forte tendência de pesquisa e atuação profissional, para esse e outros institutos de ensino e pesquisa.

Foi dado destaque ao fato de que, muito embora grande parte das intervenções em psicologia da saúde tenha sido desenvolvida para melhorar a compreensão, o enfrentamento e a qualidade de vida de pessoas em tratamentos de saúde, continuava a haver uma escassez de dados que mostrassem, de maneira cada vez mais controlada e sistematizada, o quanto as intervenções comportamentais e psicológicas podem influenciar a evolução do tratamento e da prevenção de doenças. Nesse campo, a amostra de trabalhos selecionados foi representativa do quanto o IP/UnB entrega, periodicamente à comunidade científica, trabalhos relevantes e com grande potencial de aplicabilidade em contextos prático-clínicos e profissionais.

Outrossim, a preocupação em desenvolver mais trabalhos envolvendo variáveis de gênero, permanece carente, uma vez que, possivelmente, as intervenções empiricamente validadas pelas pesquisas da amostra, têm efeitos distintos em diferentes subgrupos de pacientes, por exemplo. Quando da publicação dos referidos artigos do JHP, já havia evidências em grupos de mulheres, por exemplo, demonstrando que elas respondem de forma diferente a intervenções que provaram ser eficazes em homens brancos.

Outro alerta, diz respeito ao fato de que, com o advento e o crescimento da perspectiva biopsicossocial entre as equipes de saúde, cada vez mais profissionais de saúde não psicólogos, se mostram interessados em pesquisas na área de psicologia da 
saúde e de medicina comportamental, o que gera o potencial de diminuir o número de psicólogos envolvidos em atividades de investigação nesse campo.

Um outro ponto-chave, referido pelos estudiosos, consistiu na necessidade de levar-se em consideração, preocupações éticas e legais na implementação de intervenções em telesaúde. Nessa perspectiva, a contribuição do IP/UnB ainda se mostra tímida, deixando enorme potencial para objetos de estudo que envolvam a adaptação de protocolos sensíveis à realidade da assistência psicológica remota por meio de recursos de telecomunicação e multimídia, debatendo, inclusive problemas tais como confidencialidade e segurança das informações veiculadas.

Particularmente oportuna foi a sugestão dos estudiosos do JHP para que os psicólogos de saúde investigassem os efeitos da doação de órgãos e tecidos no bemestar físico e emocional de doadores vivos. Embora em muitas instituições, um papel de destaque já venha sendo dado a psicólogos, na avaliação de potenciais receptores de órgãos para transplantes, ainda existem poucos dados de pesquisa sobre os fatores psicossociais associados a resultados bem sucedidos. Nesse sentido, o IP/UnB mais uma vez merece reconhecimento por contribuir num campo onde os avanços, especialmente no Brasil, ainda são discretos.

Como vimos, problemas como seleção e retenção de participantes de pesquisa são significativos, gerando uma série de limitações aos estudos. Entretanto, esses desafios não são exclusivos dos pesquisadores do IP/UnB. Os artigos do JHP sugeriram que são justamente as habilidades e competências próprias dos psicólogos da saúde, que podem ter um papel chave na solução desses entreveros, na medida em que podem ajudar os indivíduos candidatos à pesquisa a identificarem possíveis obstáculos à participação, melhorar métodos de seleção de amostra, de obtenção de consentimento e estratégias de retenção dos participantes. 
$\mathrm{O}$ que mais mereceu destaque ao IP/UnB foi a produção de um número significativo de pesquisas que contribuíram para a consolidação do modelo biopsicossocial, legitimando o estudo dos fatores psicossociais no desenvolvimento e curso de doenças e, com isso, fornecendo uma importante base conceitual no entendimento de que as intervenções psicossociais podem ser importantes na gestão do tratamento de pessoas doentes ou que enfrentam algum tipo de condição adversa.

Conclui-se, portanto, que a psicologia da saúde desenvolveu-se rapidamente nos seus primeiros 25 anos, de modo a se tornar um campo de estudo e trabalho bem estabelecido. Desde a publicação do JHP, em 2004, até os dias atuais, viu-se que o crescente e rápido desenvolvimento da área se mantém, lançando os psicólogos da saúde ao posto de vanguardistas de muitas novas pesquisas e fronteiras clínicas.

Como resultado, alguns desafios permanecem em aberto e novos desafios são lançados, na direção de fazer com que nós, psicológos da saúde, nos mantenhamos bem preparados para lidar com uma realidade em constante transformação e, assim, fazer importantes e constantes contribuições futuras. 


\section{REFERÊNCIAS BIBLIOGRÁFICAS}

Ajzen, I., \& Fishbein, M. (1977). Attitude-behaviour relations: A theoretical analysis and review of empirical research. Psychology Bulletin, 84, 888-918.

Almeida, F. F. (2011). Análise de variáveis psicossociais relacionadas à experiência dolorosa entre pacientes cirúrgicos. Dissertação de mestrado, Universidade de Brasília, DF.

Aquino, E. M. L. (2006). Gênero e saúde: perfil e tendências da produção científica no Brasil. Revista de Saúde Pública, 40 (N Esp), 121-132.

Beck, J. (2009) Pense Magro: a dieta definitiva de Beck. Porto Alegre: ArtMed.

Bennett, P., \& Murphy, S. (1997). Psychology and Health Promotion. Buckingham: Open University Press.

Carvalho, D. B. (2013). Psicologia da Saúde Crítica no contexto hospitalar. Psicologia: Ciência e Profissão, 33(2), 350-365.

Castro, E. K., \& Bornholdt, E. (2004). Psicologia da Saúde X Psicologia Hospitalar: definições e possibilidades de inserção profissional. Psicologia: Ciência e Profissão, $24,48-57$.

Cavalcanti, A. P. R., Dias, M. D., Rodrigues, C. F. F., Gouveia, C. N. N. A., Ramos, D. D., \& Serrano, F. J. O. (2007). Crenças e influências sobre dietas de emagrecimento entre obesos de baixa renda. Ciência \& Saúde Coletiva, 12(6), 1567-1574.

Cerqueira-Silva, S., Dessen, M. A., \& Costa Junior, A. L. (2011). As contribuições da Ciência do Desenvolvimento para a Psicologia da Saúde. Ciência e Saúde Coletiva, 16(1), 1599-1609.

Creswell, J. W. (2010). Projeto de pesquisa: métodos qualitativo, quantitativo e misto. ArtMed: Porto Alegre.

Cunha, J.A. (2001). Manual da versão em português das Escalas Beck. São Paulo: Casa 
do Psicólogo.

Dela Coleta, M. F. (1999). O modelo de crenças em saúde (HBM): uma análise de sua contribuição à psicologia da saúde. Temas em Psicologia, 7(2), 175-182.

Dias, M. R., Duque, A. F., Silva, M. G., \& Durá, E. (2004). Promoção da saúde: o renascimento de uma ideologia? Análise Psicológica, 3(22), 463-473.

Engel, G. (1977). The need for a new medical model: A challenge for biomedicine. Science, 196, 129-136.

Faustino, Q. M. (2006). Intervenção cognitivo-comportamental e comportamento de adesão ao tratamento de pessoas vivendo com HIV/AIDS. Dissertação de mestrado. Universidade de Brasília, DF.

Fleury, M. S. (2006) Comportamentos de autocuidado em diabetes tipo 1: estratégias para a promoção da adesão. Dissertação de mestrado, Universidade de Brasília, DF.

Freire, F. M. S., \& Pichelli, A. A. W. S. (2013). O psicólogo apoiador matricial: percepções e práticas na atenção básica. Psicologia: Ciência e Profissão, 33(1), 162173.

Gimenes, M.G.G., \& Queiroz, B. (1997). As diferentes fases de enfrentamento durante primeiro ano após a mastectomia. Em M.G.G. Gimenes \& M.H. Fávero (Orgs)., A mulher e o câncer (pp. 171-195). Campinas: Editorial Psy.

Giorgi, A. (1970) Psychology as Human Science. New York: Harper \& Row.

Giorgi, A. (1978). Problems encoutered in developing a phenomenological approach to research. In F. Fransella (Org.), Personal construct psychology, 1977 (pp. 07-23). New York: Academic Press.

Gonçalves, S. M. C. M., \& Dias, M. R. (1999). A prática do auto-exame da mama em mulheres de baixa renda: um estudo de crenças. Estudos de Psicologia, 4(1),141-159.

Gorayeb, R. (2010). Psicologia da Saúde no Brasil. Psicologia: Teoria e Pesquisa, 26, 115- 
122.

Horiuchi, S., Tsuda, A., Watanabe, Y., Fukamachi, S., \& Samejima, S. (2013). Validity of the six stages of change for exercise. Journal of Health Psychology, 18(4), 518-527.

Isaac, K., Hay, J., \& Lubetkin, E. (2016). Incorporating Spirituality in Primary Care. Journal of Religion and Health, 55(3), 1065-1077.

Instituto Nacional do Câncer [INCA] (2007), Norma técnica: cuidados ao fim da vida. Rio de Janeiro, INCA.

Keefe, F., \& Blumenthal, J. A. (2004). Health Psychology: What will the Future Bring? Health Psychology, 23(2),156-157.

Kerbauy, R. R. (2002). Behavior and Health: Disease and Challenges. Psicologia USP, 13 (1), 11-28.

Kirk, A., MacMillan, F., \& Webster, N. (2010). Application of the Transtheoretical Model to physical activity in older adults with Type 2 Diabetes and/or cardiovascular disease. Psychology of Sport and Exercise, 11(4), 320-324.

Martins, K. C. (2009) “Eu queria, mas não conseguia...”: aspectos relacionados a mudanças do comportamento de fumar em participantes de grupo de tabagismo. Dissertação de mestrado, Universidade de Brasília, DF.

Matarazzo, J. D. (1980). Behavioral Health and Behavioral Medicine: Frontiers for a new Health Psychology. American Psychologist, 35(9), 807-817.

Matarazzo, J. D. (1982). Behavioral Health's Challenge to Academic, Scientific and Professional Psychology, Health Psychology, 37(1), 1-14.

Moutinho, K., \& Roazzi, A. (2010). As teorias da Ação Racional e da Ação Planejada: relações entre intenções e comportamentos. Avaliação Psicológica, 9(2), 279-287.

Naar-King, S., Wright, K., Parsons, J.T., Frey, M., Templin, T., Ondersma, S., \& Kaplan, R. M. (2006). Transtheoretical model and condom use in HIV-positive youths. Health 
Psychology, 25(5), 648-652.

Nicassio, P.M., Kerns, R.D., \& Meyerowitz, B. E. (2004). The Future of Health Psychology Interventions, Health Psychology, 23(2),132-137.

Ogden, J. (1999). Health Psychology: A Textbook. Buckingham: Open University Press.

Organização Mundial de Saúde [OMS] (2000)., Relatório Mundial de Saúde 2000 Sistemas de Saúde: Aprimorando a performance. Genebra: Nações Unidas.

Pedroso, M.C. \& Malik, A.M. (2015). As quatro dimensões competitivas em saúde in Harvard Bussiness Review Brazil.

Prochaska, J. O., Velicer, W. F., Rossi, J. S., Goldstein, M. G., Marcus, B. H., Rakowski, W., Fiore, C., Harlow, L. L., Redding, C. A., Rosenbloom, D., \& Rossi, S. R. (1994). Stages of change and decisional balance for 12 problem behaviour. Health Psychology, 13(1), 39-46.

Reis, J. C. (1998), O Sorriso de Hipócrates: a integração biopsicossocial dos processos de saúde e doença. Lisboa: Vega.

Rodrigues Filho, J.; Xavier, J.C.B., \& Adriano, A.L. (2001) A Tecnologia da Informação na área hospitalar: um caso de implementação de um sistema de registro de pacientes. Revista de Administração Contemporânea, 5(1), 105-120.

Rosentock, I. M. (1974) Historical origins of the health belief model. Health Education Monographs 2, 328-335.

Saab, P. G., McCalla, J. R., Coons, H. L., Christensen, A. J., Kaplan, R., Johnson, S. B., Ackerman, M. D., Stepanski, E., Krantz, D. S., \& Melamed, B. (2004). Technological and Medical Advances: Implications for Health Psychology. Health Psychology, 23(2), 142-146.

Salvetti, M. G., \& Pimenta, C. A. M. (2005). Validação da Chronic Pain Self-Efficacy Scale para a Língua Portuguesa. Revista de Psiquiatria Clínica, 32(4), 202-210. 
Santiago-Delfosse, M., \& Chamberlain, K. (2008). Évolution des idées em psychologie de la santé dans le monde anglo-saxon: de la psychologie de la santé à la psychologie critique de la santé. Psychologie Française, 53, 195-210.

Schneider, K. (1998). Toward a Science of the Heart. American Psychologist, 53(3), $277-$ 289.

Schneider, K. (1999). The revival of the romantic means a revival of psychology. Journal of Humanistic Psychology, 39(3), 13-39.

Smith, T. W., Jenkins, C. D., \& Orleans, C. T. (2004). Prevention and Health Promotion: Decades of Progress, New Challenges and an Emerging Agenda. Health Psychology, 23(2), 126-131.

Smith, T.W., \& Suls, J. (2004). Introduction to the Special Section on the Future of Health Psychology. Health Psychology, 23(2), 115-118.

Staliano, P. (2012). Promoção e comunicação em saúde: um estudo sobre a atuação de agentes comunitários; Tese de Doutorado, Universidade de Brasília, Brasília, DF.

Straub, R. O. (2014). Psicologia da Saúde, Porto Alegre: ArtMed.

Suls, J., \& Rothman, A. (2004). Evolution of the Biopsychosocial Model: Prospects and Challenges for Health Psychology. Health Psychology, 23(2),119-125.

Tovian, S. M. (2004). Health Services and Health Care Economics: The Health Psychology Marketplace. Health Psychology, 23(2), 138-141.

Travassos, C., \& Martins, M. (2004). Uma revisão sobre os conceitos de acesso e utilização de serviços de saúde. Cadernos de Saúde Pública, 20 (Sup.2), 190-198.

United States Census Bureau (2012) extraído do site http://www.census.gov/popest

Wilson, M. (1993). DSM-III and the transformation of American psychiatry: A history. American Journal of Psychiatry, 150(3), 399-410.

Yali, A. M., \& Revenson, T. A. (2004). How Changes in Population Demographics Will 
Impact Health Psychology: Incorporating a Broader Notion of Cultural Competence Into the Field. Health Psychology, 23(2),147-155.

Yamamoto, O., Trindade, L., \& Oliveira, I. (2002). O psicólogo em hospitais no Rio Grande do Norte. Psicologia USP, 13(1), 217-246. 
ANEXOS 


\section{ANEXO 1}

MODELO DE FICHA CATALOGRÁFICA PARA

ANÁLISE DE CADA TRABALHO

\begin{tabular}{|c|c|}
\hline Modalidade & \\
\hline TÍTULO & \\
\hline $\begin{array}{l}\text { Orientador } \\
\text { (a) }\end{array}$ & \\
\hline Ano defesa & \\
\hline $\begin{array}{l}\text { Palavras- } \\
\text { chave }\end{array}$ & \\
\hline $\begin{array}{l}\text { Questões de } \\
\text { pesquisa }\end{array}$ & \\
\hline $\begin{array}{l}\text { Delineamento } \\
\text { do estudo }\end{array}$ & \\
\hline OBJETIVOS & Específicos \\
\hline & Participantes: \\
\hline Metedolooia & Instrumentos: \\
\hline & Procedimentos de coleta de dados: \\
\hline & Procedimentos de análise de dados: \\
\hline $\begin{array}{l}\text { Principais } \\
\text { Resultados }\end{array}$ & \\
\hline $\begin{array}{l}\text { Conteúdos } \\
\text { discutidos }\end{array}$ & \\
\hline $\begin{array}{l}\text { Limitações do } \\
\text { estudo }\end{array}$ & \\
\hline $\begin{array}{l}\text { Contribuições } \\
\text { do estudo }\end{array}$ & \\
\hline
\end{tabular}

